
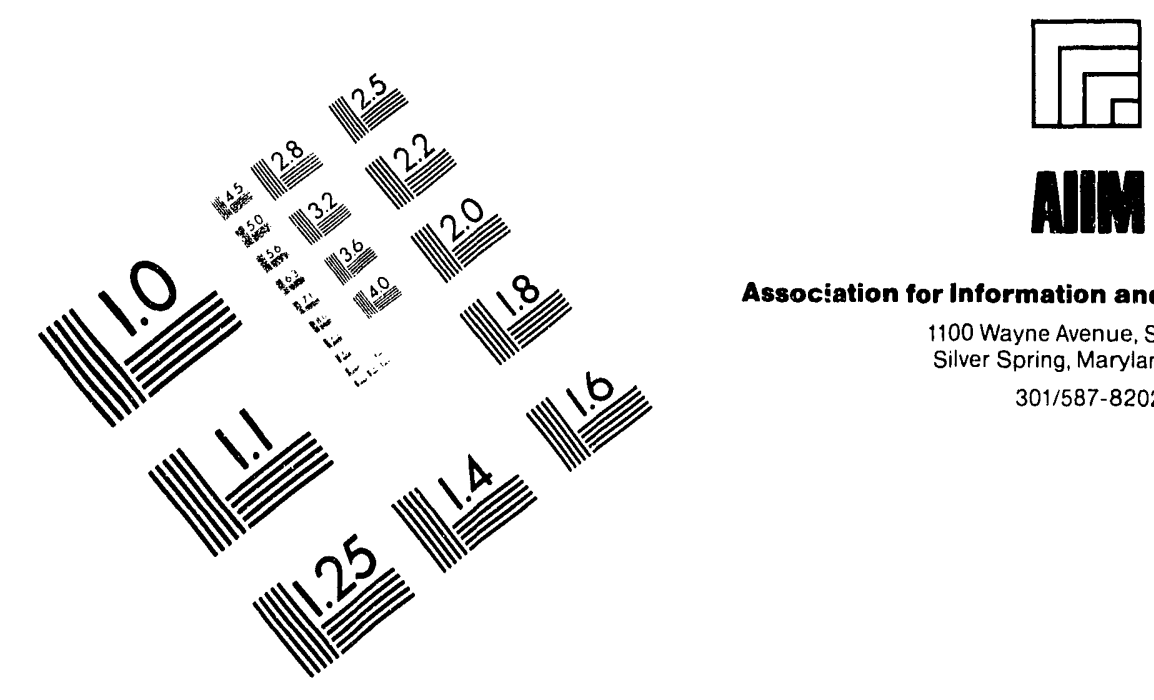

Association for Information and Image Management

1100 Wayne Avenue, Suite 1100

Silver Spring, Maryland 20910

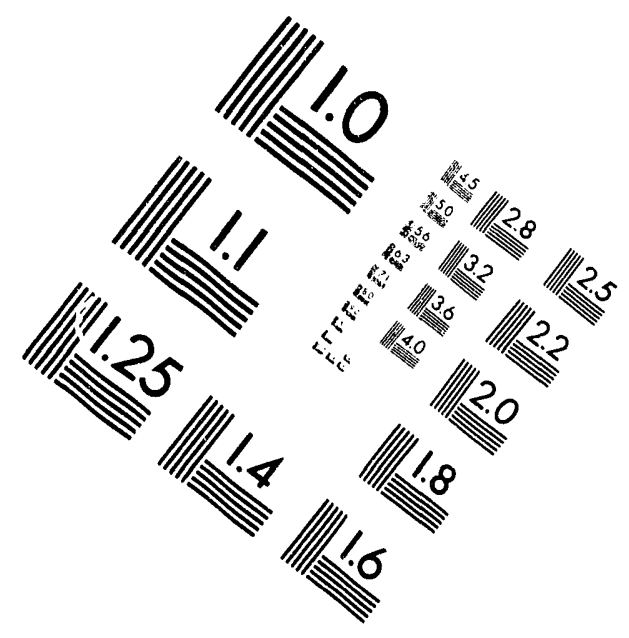

\title{
Centimeter
}

$\begin{array}{llllllllllllllll}1 & 2 & 3 & 4 & 5 & 6 & 7 & 8 & 9 & 10 & 11 & 12 & 13 & 14 & 15 & \mathrm{~mm}\end{array}$

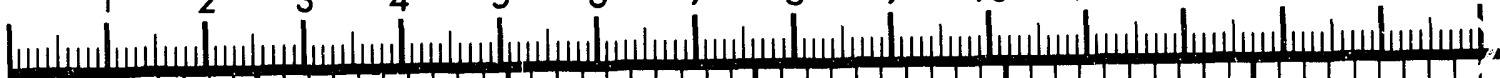

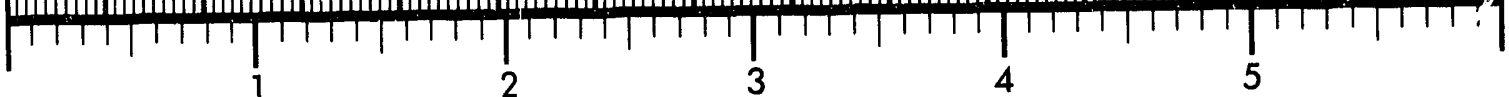
Inches
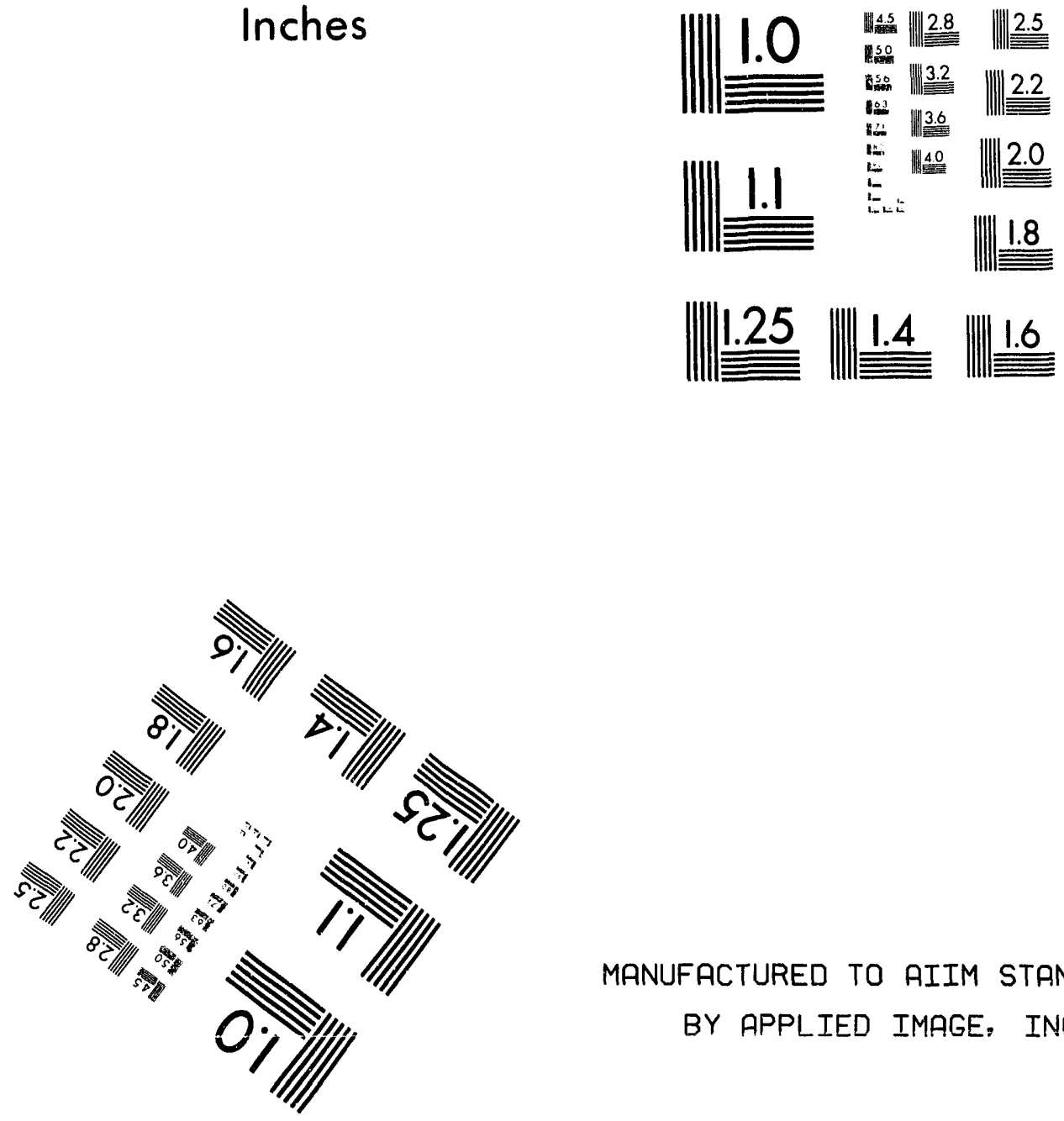

MANUFACTURED TO AIIM STANDARDS

BY APPLIED IMAGE, INC.

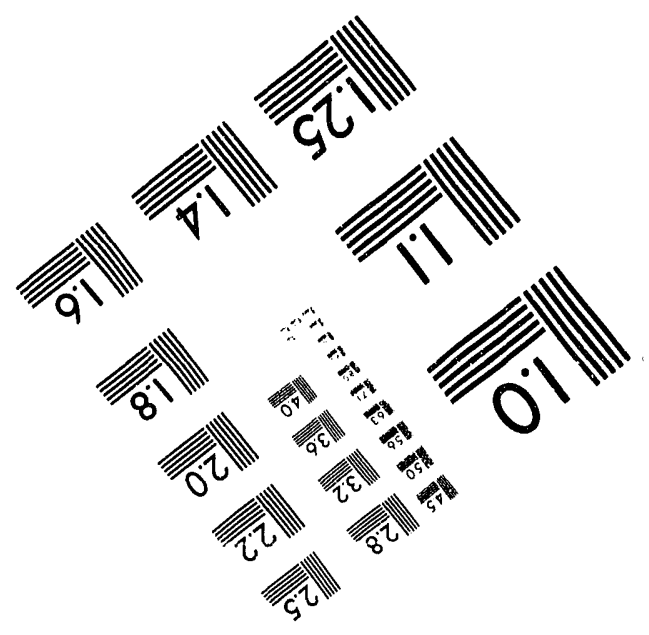



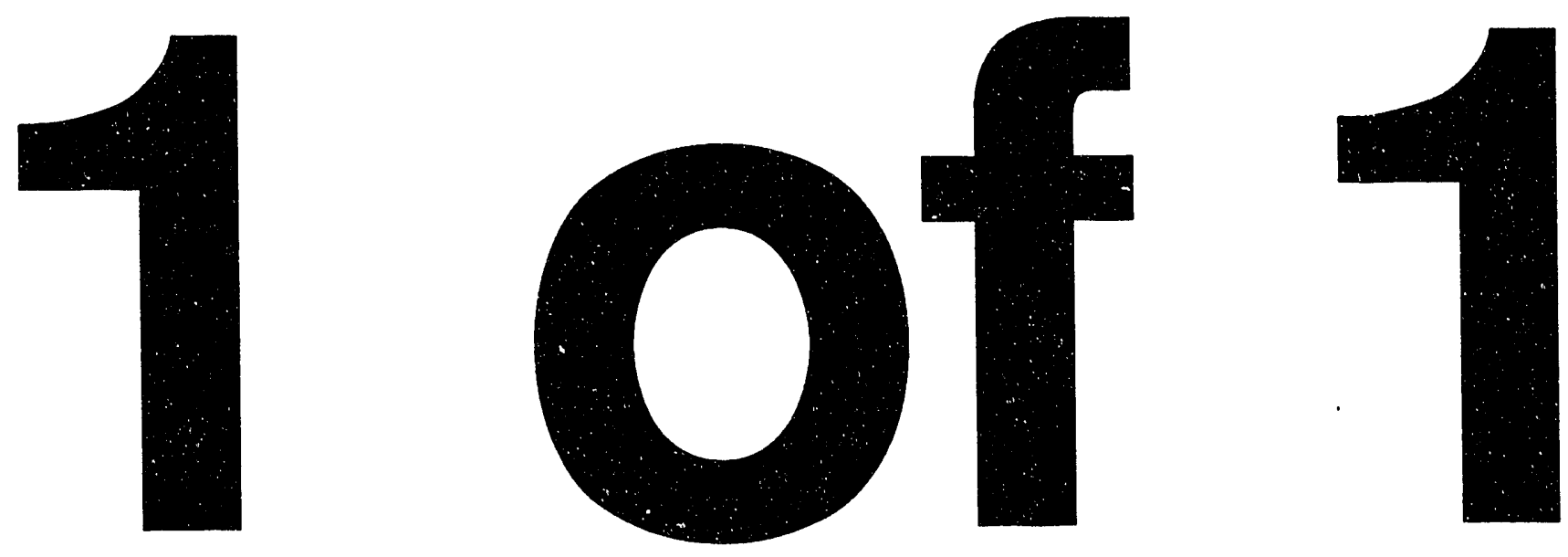


\section{Tank 101-SY Window E Core Sample: Interpretation of Results}

Date Published

February 1993

Prepared for the U.S. Department of Energy Office of Environmental Restoration and Waste Management

\footnotetext{
(28) Westinghouse

P.O. Box 1970

Hanford Company Richland, Washington 99352

Hanford Operations and Engineering Contractor for the

U.S. Department of Energy under Contract DE-AC06-87RL10930
}

Approved for Public Release 


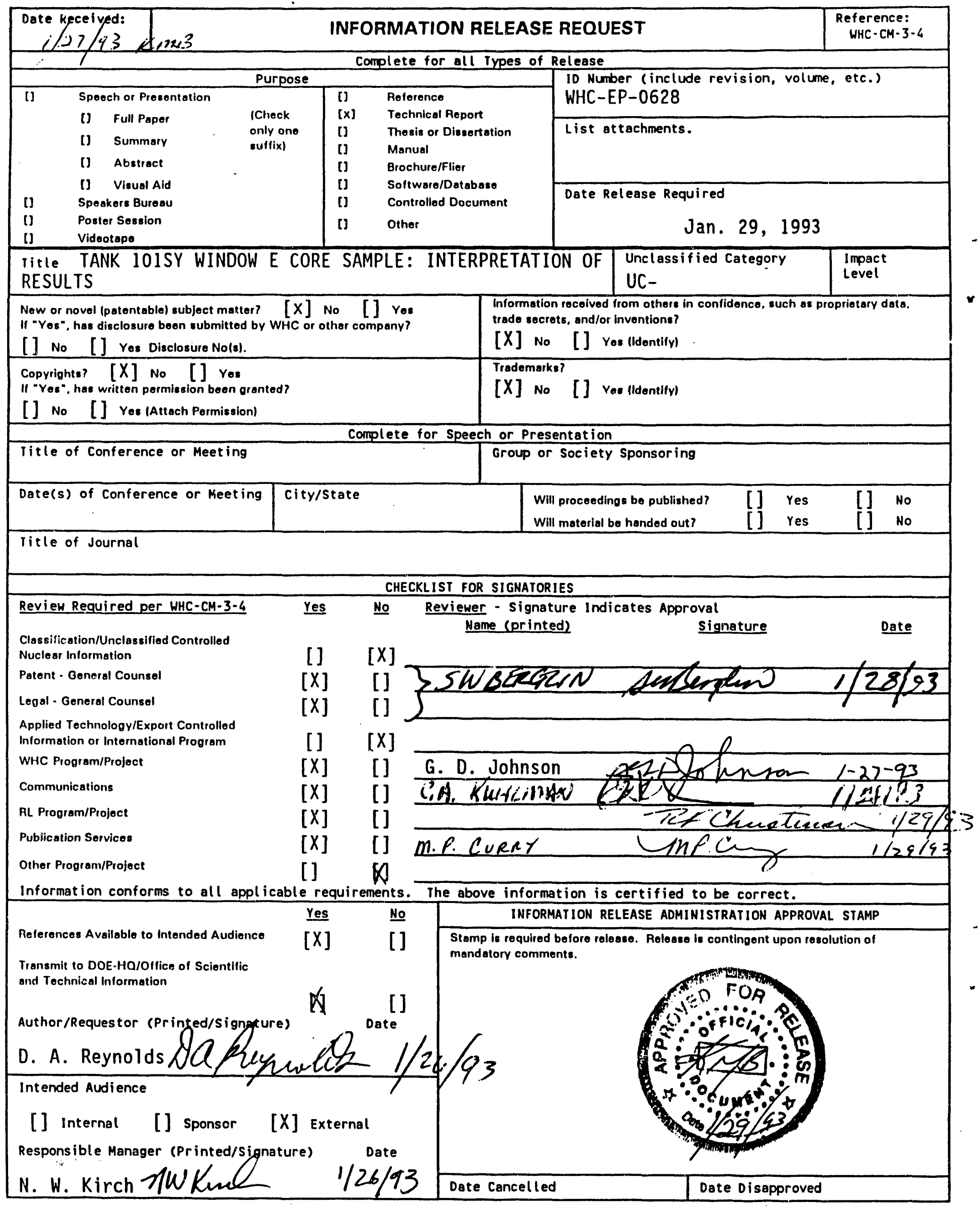


WHC-EP-0628

APPROVAL PAGE

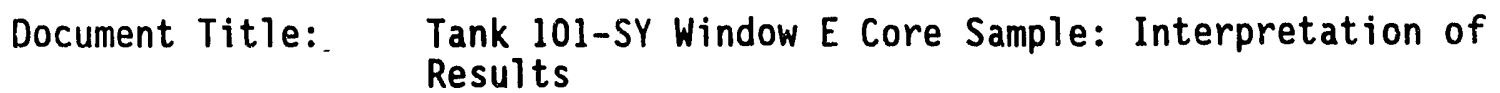

Prepared by:

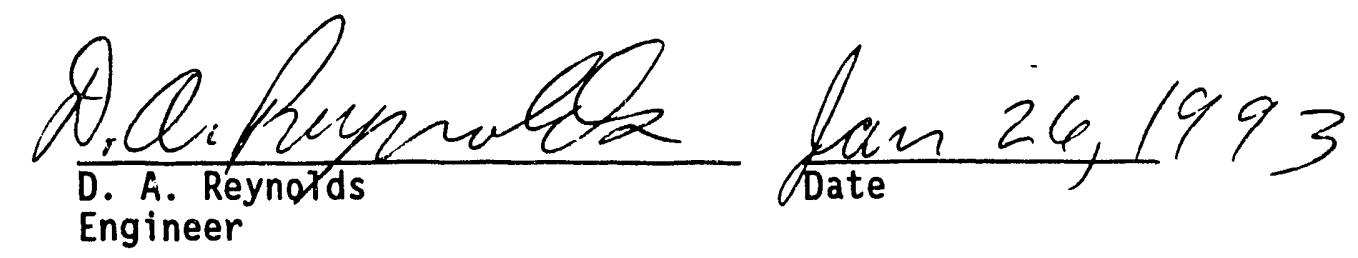

Approved by:

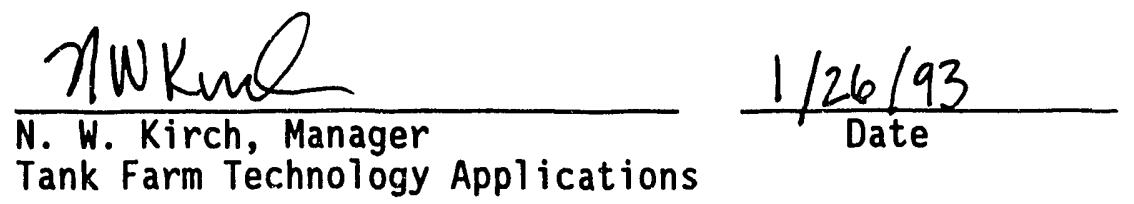




\section{TANK 101-SY WINDOW E CORE SAMPLE:}

INTERPRETATION OF RESULTS

D. A. Reynoids

\section{ABSTRACT}

A full depth core sample was taken for tank 241-sy-101 in December 1991 during a time period called "Window E." This was the second full depth core sample from this tank during the year. The core had two major portions that are know as the convective zone and the nonconvective zone. A crust was on the top of tank but was poorly sampled. The analysis of the Window $E$ core sample stressed segment composite chemical analysis instead of segment by segment as in Window C. Adiabatic calorimetry on samples from both cores showed a slow self heating reaction above $150{ }^{\circ} \mathrm{C}$ on dried samples. The exothermic events were milder than similar synthetic samples. The chemical and physical properties complemented the information from Window $C$. The Window $E$ material from the convective zone was more viscous than the Window $C$ convective zone material. The nonconvective zone viscosities were similar for both cores. Heating and dilution tests were made to test mitigation concepts. 


\section{CONTENTS}

1.0 INTRODUCTION . . . . . . . . . . . . . . . . . . . . 1-1

2.0 TANK CONDITIONS DURING SAMPLING . . . . . . . . . . . . . 2-1

3.0 EXTRUSION AND VISUAL OBSERVATIONS . . . . . . . . . . . . . 3-1

4.0 PHYSICAL PROPERTIES OF CORE ................... . . 4-1

4.1 DENSITY . . . . . . . . . . . . . . . . . . . 4-1

4.2 RHEOLOGY ........................ . . . 4-3

4.2.1 Viscosity . . . . . . . . . . . . . . . . . $4-3$

4.3 PARTICLE SIZE DISTRIBUTION ANALYSIS . . . . . . . . . . 4-6

4.4 POLARIZED LIGHT MICROSCOPY ................... . . . . 4-7

5.0 CHEMICAL CONSTITUENTS . . . . . . . . . . . . . . . . . 5-1

5.1 OVERALL COMPOSITION .................... $5-1$

5.2 TRENDS ........................ . . $5-1$

5.3 REGULATORY ANALYSES . . . . . . . . . . . . . . . 5-6

5.4 SEMIVOLATILE ORGANIC ANALYSIS . . . . . . . . . . . . 5-6

5.5 CHELATOR FRAGMENTS . . . . . . . . . . . . . . . . 5-8

5.6 CALORIMETRY . . . . . . . . . . . . . . . . . 5-8

6.0 RADIOACTIVITY . . . . . . . . . . . . . . . . . 6-1

6.1 RADIONUCLIDE ANALYSES .................. . . . 6-1

6.1.1 Comparisons Between Window $C$ and Window $E$. . . . . . 6-1

6.1.2 Gamma Scanning .. . . . . . . . . . . . . . 6-3

6.2 RADIOLYTIC HEATING OF THE TANK ............. . . 6-4

6.2.1 Heat Rate Equation .. . . . . . . . . . . . . 6-4

6.2.2 Depth of Layers ................. . 6-6

6.2.3 Specific Gravity . . . . . . . . . . . . . . . . . . 6-6

6.2.4 Calculation of the Heat Content of Tank 101-SY. . . . . 6-7

6.3 PLUTONIUM INVENTORY ESTIMATE ................ . . . 6-7

6.4 AMERICIUM INVENTORY ANALYSIS ............... . 6-10

7.0 HEATING AND DILUTION TESTS . . . . . . . . . . . . . . . . 7-1

7.1 RESULTS OF DILUTION STUDIES . . . . . . . . . . . . . 7-1

7.2 HEATING ONLY . . . . . . . . . . . . . . . . . . . . . . . 7-7

7.2.1 Physical Properties .................. . . 7-7

7.2.2 Chemical Changes ................ . 7-10

7.3 HEATING AND DILUTION .................... . . . . . . . .

7.3.1 Regression ................... 7-16

8.0 SUMMARY AND RECOMMENDATIONS . . . . . . . . . . . . 8-1

9.0 REFERENCES .......................... . . . . . .

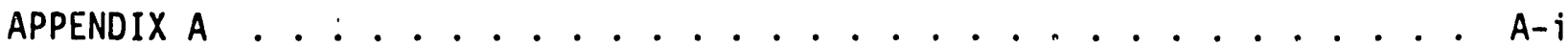


WHC-EP-0628

\section{LIST OF FIGURES}

2-1 Tank 241-SY-101 Riser Locations . . . . . . . . . . . 2-2

2-2 Temperature Profile During Sampling. . . . . . . . . . 2-3

4-1 Tank 101-SY Bulk Densities . . . . . . . . . . . . . 4-2

4-2 Viscosity of Segment 8 from Window $E$ as a Function of Shear Rate ............. . 4-4

4-3 Viscosity of the Segment 15 Sample from Window $E$ as a Function of Shear Rate ............... 4-5

6-1 Scatter Plot of ${ }^{137}$ Cs Data .............. 6-5

6-2 Plutonium Concentrations ............... 6-8

6-3 Americium Concentrations ................. 6-11

7-1 Density Change With Dilution at $50{ }^{\circ} \mathrm{C} . . . . . . . . .7-3$

7-2 Core "E," $50{ }^{\circ} \mathrm{C}$ Dilution Data on Density . . . . . . . . . 7-4

7-3 Core "E," $50{ }^{\circ} \mathrm{C}$ Dilution Data on Weight \% Solids . . . . . . 7-6

7-4 Temperature Effects Oniy on Tank 101-SY Density . . . . . . . 7-8

7-5 Temperature Effect Only on Tank 101-SY Samples . . . . . . 7-9

7-6 Tank 101-SY Yield Strength . . . . . . . . . . . . . 7-11

7-7 Tank 101-SY Nonconvective Layer Yield Stress . . . . . . . . . 7-12

7-8 Temperature Effect on Water in Solid Phase . . . . . . . 7-13

7-9 Temperature Effect on Tank 101-SY Solid Composition . . . . . . 7-14

7-10 Temperature Effect on Composition of Solid Waste . . . . . 7-15

7-11 Solid Phase Density. . . . . . . . . . . . . . . 7-17

7-12 Weight $\%$ of Solid Phase . . . . . . . . . . . . 7-18 


\section{LIST OF TABLES}

4-1 Recommended Densities for 101-SY .............. 4-1

5-1 Chemical Analysis Results for Composites 1 and 2

(all values in weight percent) . . . . . . . . . . . . . 5-2

5-2 Chemical Analysis Results for Composites 3 and 4

(all values in weight percent) ................ 5-3

5-3 Chemical Analysis Results for Segments 19 and 22R

(all values in weight percent) ................ 5-4

5-4 Overall Average Bulk Composition of Core Sample

(all values in weight percent) .............. . 5-5

5-5 Summary of Chemical Analyses of Minor Constituents (ppm) . . . . . . 5-7

6-1 Results of Radionuclide Analyses of Solid Phase Samples

(all results in $\mu \mathrm{Ci} / \mathrm{g}$ except Uranium, which is $\mu \mathrm{g} / \mathrm{g}$ ) . . . . . . 6-2

6-2 Results of Radionuclide Analyses of Liquid Phase Samples

(all results in $\mu \mathrm{Ci} / \mathrm{g}$ except Uranium, which is $\mu \mathrm{g} / \mathrm{g}$ ) . . . . . . . . 6-3

6-3 Calculation of Heat Generation in Tank 101-SY . . . . . . . . 6-7

6-4 Average Plutonium Concentrations in Tank 101-SY . . . . . . . . 6-9

6-5 Average Concentrations of Americium . . . . . . . . . . . 6-12

7-1 Regression Coefficients for Curves in Figure 2........ . T-5

7-2 Void Fraction in Solid Phase Needed to Reach Neutral Buoyancy . . . 7-5

7-3 Estimated Volumes of a 100-g Sample (Diluted) . . . . . . . . 7-5

7-4 Heating/Dilution Effects Assuming 100-g Sample......... . . 7-19 
WHC-EP-0628

\section{LIST OF TERMS}

$C A$

ED3A

EDTA

HEDTA

NIDA

NPH

NTA

PNL

rps

TIC

TOC

TRU citrate

ethylenediametriacetate

ethylenediaminetetraacetate

$\mathrm{N}$-(2-hydroxyethy $\mathrm{l})$ ethylened $\mathrm{i}$ aminetriacetate

nitrosoiminodiacetate

normal paraffin hydrocarbons

nitrilotriacetate

Pacific Northwest Laboratory

revolutions per second

total inorganic carbon

total organic carbon

transuranic 
WHC-EP-0628

This page intentionally left blank. 
TANK 101-SY WINDCW E CORE SAMPLE:

INTERPRETATION OF RESULTS

\subsection{INTRODUCTION}

Tank 241-SY-101 is a double-shell, high-level waste storage tank located in the 200 West Area of the U.S. Department of Energy Hanford Site, in southcentral Washington State. This tank contains about 1 Mgal of concentrated nuclear waste, and periodically vents a mixture of hydrogen, nitrous oxide, and nitrogen gas. Venting causes the tank surface level to drop by as much as 10 inches.

In December 1991, Tank 241-SY-101 was sampled to assist an understanding of processes that produce the gas mixture. The sampling al so was used to measure physical properties and enhance models of the gas release phenomena. A full-depth core sample was taken in 22 segments as part of the sampling effort. Duplicate segments were taken at three depths. Tank 241-SY-101 had been core sampled in May 1991, and the December 1991 sample was taken in a different location in the tank.

The details of the sample analyses for the December 1991 samples were reported in WHC-SD-WM-DTR-026 (Herting et al. 1992a). This report provides additional explanation and evaluation of these sample analyses. 
WHC-EP-0628

This page intentionally left blank. 


\subsection{TANK CONDITIONS DURING SAMPLING}

A full-depth core sample was taken of Tank 241-SY-101 (101-SY) during "Window E" in December 1991. This sample was taken from riser 11B, which is on the opposite side of the tank from the sample taken in May 199: ("Window C") core. Figure 2-" shows the location of the riser relative to other points on the tank.

The full core sample was planned to consist of 21 full segments, each $48 \mathrm{~cm}$ ( $19 \mathrm{in.}$ ) long, and one partial segment, $5 \mathrm{~cm}$ long at the top of the crust. The segments are $2.54 \mathrm{~cm}$ ( 1 in.) in diameter. Duplicate samples of Segments 21 and 22 were planned and taken on the same day as the original Segment 21 and 22 samples. In addition, a duplicate sample (14R) of segment 14 was planned and taken 4 days after the original sample to evaluate the movement of the convective/nonconvective layer interface over the 4-day period. However, the interface actually appeared somewhat lower (Segment 15) in the Window $E$ core sample than the observed interface in the Window $C$ core sample.

Figure 2-2 shows the temperature profile during the time that the tank was sampled. The temperature profile was essentialiy flat (isothermal), which is an indication that (1) the tank was well mixed and (2) stratification into different layers had not occurred. 
Figure 2-1. Tank 241-SY-101 Riser Locations.

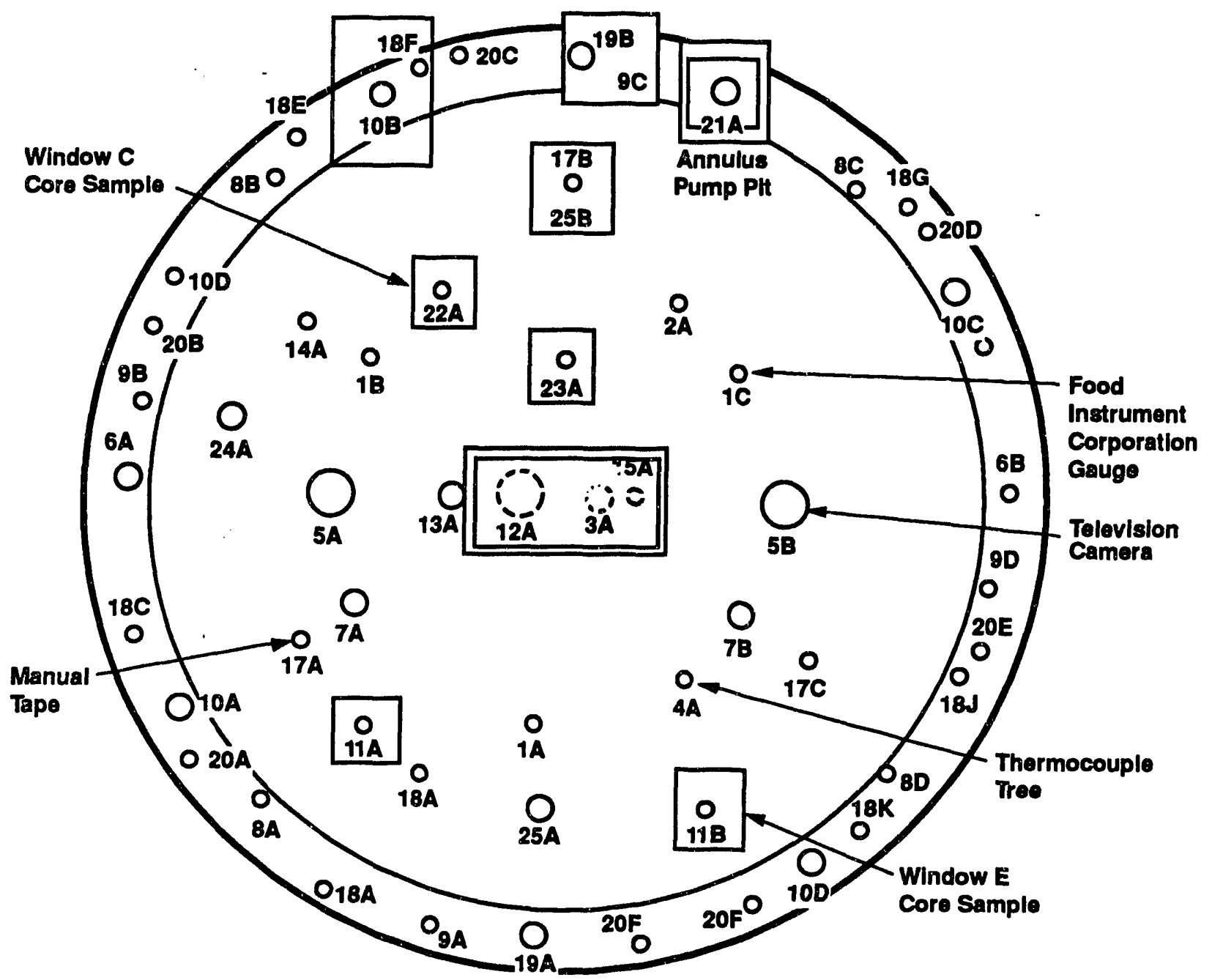


Figure 2-2. Temperature Profile During Sampling.

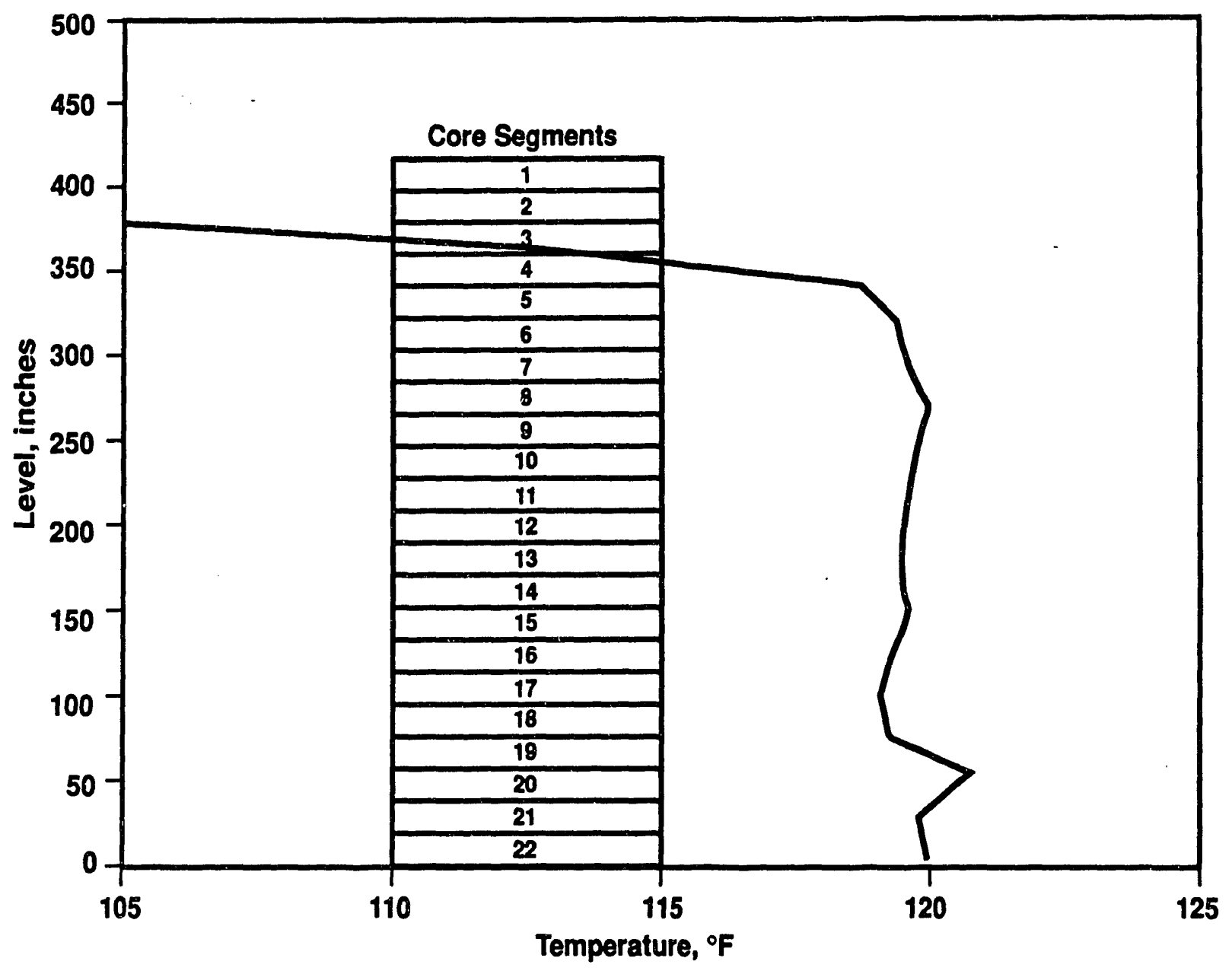

29301014.16 


\section{WHC-EP-0628}

This page intentionally left blank. 
WHC-EP-0628

\subsection{EXTRUSION AND VISUAL OBSERVATIONS}

All the segments produced valid tank waste samples, with the exceptions of Segments 1, 2, 20, 21, 21R, and 22. Segment 1 was empty, as it was in the Window $C$ core sample. Segment 2 appeared to have been diluted with water (used as a hydraulic head fluid), again as in Window $C$. The core sampler appears to have encountered some difficulty near the bottom of the tank, with only partial sample recovery and/or water dilution problems encountered in the last three segments. The samples from Segments 20 and 21 are probably valid samples in terms of composition, but the samplers were partially empty. The samples in Segments $21 R$ and 22 were compromised by dilution with water (presumably from the hydrostatic fluid in the drill string), and were not analyzed at all.

Segments 3 through 14 were all virtually identical in appearance, and represent the convective layer of waste in tank 101-SY. All were more cohesive and contained much less drainable liquid than the corresponding segments from Window $C$ samples. Segments 15 through $22 R$ all appeared identical to each other and to the corresponding Window $C$ segments. These were quite cohesive, and represented the nonconvective layer. It is important to emphasize that observations are made at an ambient hot-cell temperature $\left(32^{\circ} \mathrm{C}\right)$, not at the tank temperature $\left(48{ }^{\circ} \mathrm{C}\right)$, and that rheological properties vary greatly with temperature.

There are several reasons for the differences in physical appearance between the Window $C$ and Window $E$ convective-layer segments. First, and probably most significant, the gas release event preceding Window $E$ was much more vigorous than the event preceding Window $C$. Therefore, it would be expected that the Window $E$ core sample would contain more suspended solids in the convective layer. Another factor to consider is the length of time elapsed between the gas release event and the sampling activity. For Window $C$, the elapsed time was 6 days compared to 10 days for Window $E$. With more time elapsed in Window $E$ between the gas release event and sampling, additional solids settling would be expected. Because the opposite was observed, this factor does not appear to be significant. Finally, the Window $C$ core sample was taken in late spring when the ambient air temperature in the tank farm where the samples were stored awaiting shipping was quite warm. The Window $E$ samples, in contrast, were stored outdoors in mid-December nearfreezing temperatures for several days before being shipped to the laboratory. However, because both Window $C$ and Window $E$ samples were stored in the laboratory for several days before extrusion, both sets of samples had sufficient time to reach equilibrium at room temperature. 
WHC-EP-0628

This page intentionally left blank. 


\subsection{PHYSICAL PROPERTIES OF CORE.}

Certain physical property measurements were made of selected segments of the core. The physical measurements were made by Pacific Northwest Laboratory (PNL) at various temperatures.

\subsection{DENSITY}

The combined density measurements for both cores totaled 126 determinations at temperatures ranging from $32^{\circ} \mathrm{C}$ to $80^{\circ} \mathrm{C}$. These are broken down into several categories and the average density for selected sample types is reported in Table 4-1. A table of all the density measurements is included in Appendix $A$.

Table 4-1. Recommended Densities for 101-SY.

\begin{tabular}{|l|c|c|c|c|}
\hline \multicolumn{1}{|c|}{ Type waste } & $\begin{array}{c}\text { Average } \\
\text { density } \\
\mathrm{g} / \mathrm{mL}\end{array}$ & $\begin{array}{c}\text { Standard } \\
\text { deviation }\end{array}$ & $\begin{array}{c}\text { Maximum } \\
\mathrm{g} / \mathrm{mL}\end{array}$ & $\begin{array}{c}\text { Minimum } \\
\mathrm{g} / \mathrm{mL}\end{array}$ \\
\hline Bulk, convecting & 1.57 & 0.036 & 1.62 & 1.48 \\
\hline Bulk, nonconvecting & 1.70 & 0.043 & 1.75 & 1.61 \\
\hline Centrifuged supernate* & 1.50 & 0.033 & 1.57 & 1.43 \\
\hline Centrifuged solids & 1.79 & 0.100 & 2.16 & 1.66 \\
\hline
\end{tabular}

*Without Window $E$ composite samples, which were processed using a different method.

Table 4-1 shows that the nonconvective layer is definitely more dense than the convective layer. Therefore, the convective layer would float on top of the nonconvective layer. The convective layer density approaches the centrifuged supernate density and the nonconvective layer density approaches the centrifuged solids density. The density of the centrifuged solids had the largest standard deviation and range.

The density of the waste did not appear to be dependent on temperature. At least the scatter in the data was greater than the temperature effect. This can best be seen in Figure 4-1, which shows the bulk density measurements. There is no clear temperature dependency.

It should also be noted that the differences between samples taken in Window $C$ and Window $E$ are not significant. Therefore, the data for both cores are combined for calculating the average density presented in Table 4-1.

The density measurements were made in a tared graduated centrifuge cone. The sample was weighed and total volume noted. These measurements are used for the bulk density. The cone is centrifuged at temperature. The liquid is 
WHC-EP-0628

Figure 4-1. Tank 101-SY Bulk Densities.

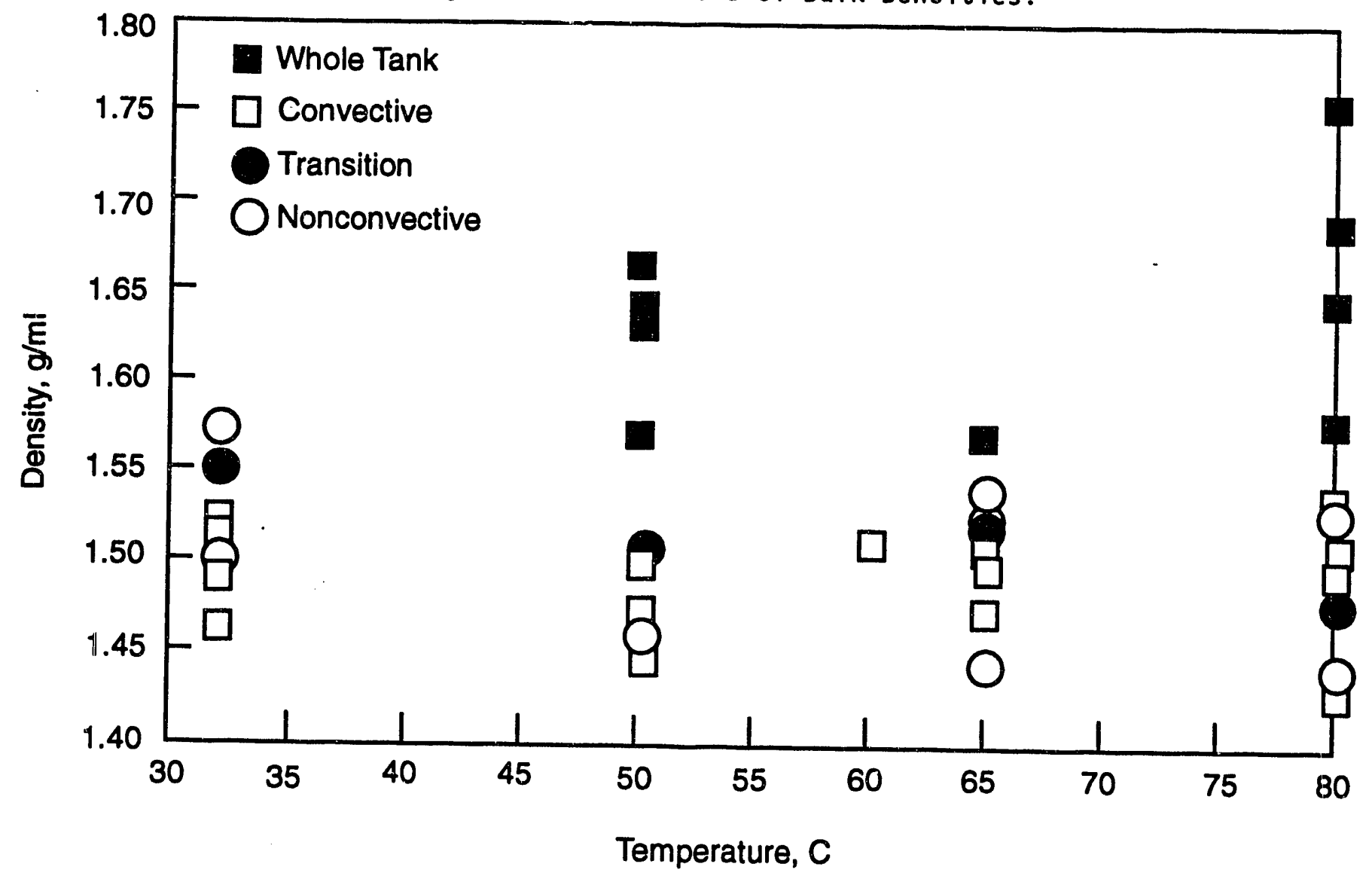

29301014.15 
poured off. The solid phase volume and weight are noted. The liquid phase is determined by taking the difference between the bulk and solid phases. For hot cell operations, the weights are more accurate than the volumes.

\subsection{RHEOLOGY}

Window $E$ convective zone segments did not show significant drainable liquid at the extrusion temperature. The rheology of these segments show nonNewtonian characteristics. In contrast, Window $C$ convective zone segments had a portion of drainable liquid and were Newtonian.

\subsubsection{Viscosity}

Viscosities were measured in the PNL hot cell using a cone and plate-type viscometer. The rheograms provided information on the yield stress and the viscosity at various shear rates and temperatures between $30^{\circ} \mathrm{C}$ and $80^{\circ} \mathrm{C}$. The yield stress is the stress at which the sample changes from a gel or solid-like material to a fluid material. All samples from Window E also were thixotropic (that is, the viscosity is dependent on the length of time under shear).

Segments 3,8 , and 13 were the convective layer segments used for viscosity measurements. These samples exhibited non-Newtonian behavior and showed a siight decrease in viscosity as the temperature of the samples was increased. The viscosity at high shear rates $(2,500$ revolutions per second [rps]) ranged from approximately 15 to $100 \mathrm{cp}$ over the temperature range of these measurements. The yield stress appeared to be essentially independent of temperature $(5100 \pm 1100 \mathrm{~Pa})$. At low shear rates, the viscosities were all greater than $10,000 \mathrm{cp}$.

Segments 15 and 19 of the nonconvective layer behaved similarly to the Window $C$ nonconvective layer samples. The yield stresses appeared to be independent of temperature, with an average value of $5000 \pm 2100 \mathrm{~Pa}$. The viscosity at high shear rates is dependent on temperature. Segment 15 showed a substantial decrease in viscosity from $50^{\circ} \mathrm{C}$ to $80^{\circ} \mathrm{C}$. Segment 19 had a decrease in viscosity in this temperature range, but not a substantial one. The low shear rate viscosity measurements were all greater than $10,000 \mathrm{cp}$.

The shear stress was meziured both with a uniformly increasing shear rate (the up-curve, solid line) ar $I$ with a uniformly decreasing shear rate (the down curve, broken line), as shown in Figures 4-2 and 4-3. For the nonconvective slurry, the shear stress of the down curve is significantly lower than the shear stress observed in the up curve. This indicates that these samples are shear thinning.

As can be seen in the viscosity data of the non-pourable samples, significant variability was observed in the data obtained with the cone and plate viscometer. This variability may be due to several factors, including (1) heterogeneity within the samples; (2) differences in the volume of sample used; (3) slight differences in the gap between the cone and plate; 
Figure 4-2. Viscosity of Segment 8 from Window $E$ as a Function of Shear Rate.

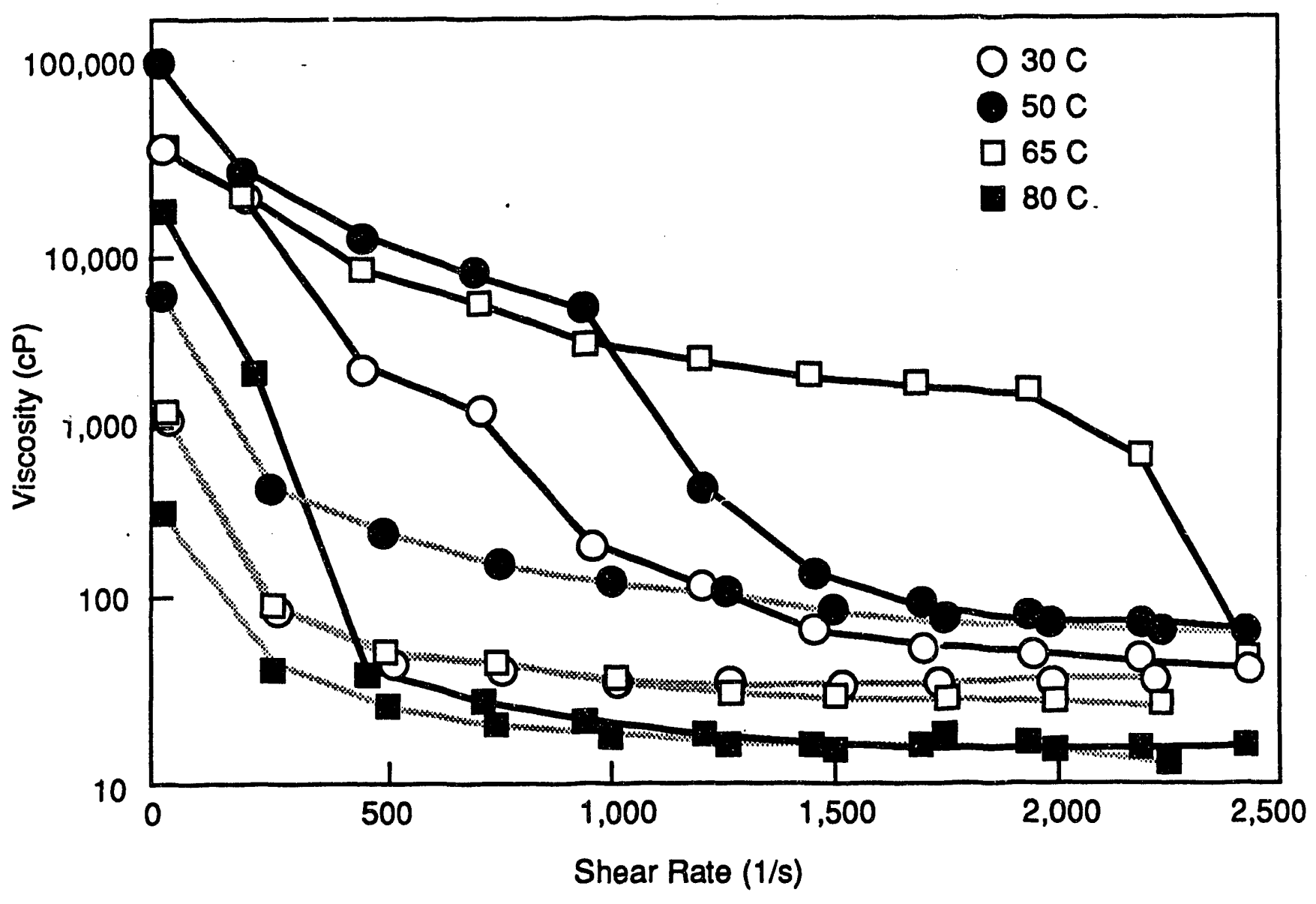

29301014.14 
Figure 4-3. Viscosity of the Segment 15 Sample from Window $E$ as a Function of Shear Rate.

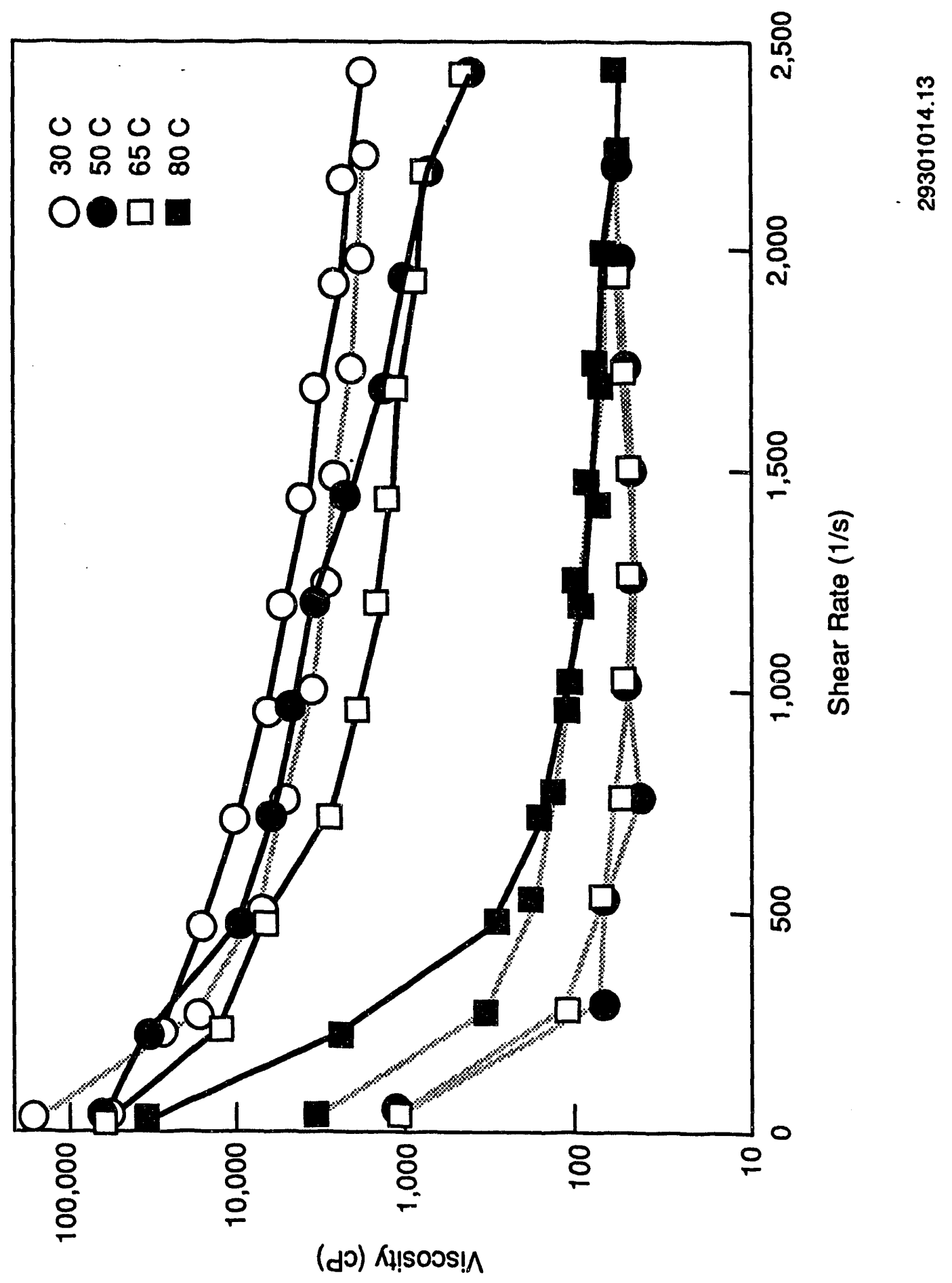


(4) slippage of the cone on the sampler surface. Some samples showed lower viscosities at lower temperatures than at higher temperatures due to this variability.

\subsection{PARTICLE SIZE DISTRIBUTION ANALYSIS}

The results of particle size analysis of Window $E$ materials differed in a major way from the results of Window $C$ cores. Window $E$ particles were apparently distributed over smaller particle sizes, and the distributions were more consistent between samples than were those from Window $C$ counts. As discussed below, Window $E$ samples were treated differently from Window $C$ samples before particle size analysis.

Six samples of Window E material were analyzed. All core segments were first individually homogenized until they appeared mixed. Then portions of each segment were heated to $60^{\circ} \mathrm{C}$ to liquefy them. The portions then were spun in a heated $60^{\circ} \mathrm{C}$ centrifuge to concentrate the solids. The concentrated solids were then sampled. The centrifuged liquid appeared clear, indicating that the particulates were in the concentrated solids.

The important differences from Window $C$ pretreatment were as follows:

A. Homogenization. Window $C$ samples were mixed but not homogenized at high speed with a low-clearance blade.

B. Temperature of the centrifuge. Window $C$ samples were merely heated, then centrifuged without heating the centrifuge. Window $C$ samples were centrifuged for 5 to 10 minutes while Window $E$ samples were centrifuged for 1 hour.

C. Attainment of clear centrifuged liquid. Window C liquid remained cloudy.

Data for each of the six Window $E$ samples were acquired over a range of 0.5 to $150 \mu \mathrm{m}$. There was no indication from these data that particles over that size existed, so no attempt to acquire data at larger particle diameters was made. This is in significant contrast to Window $C$ results, where many samples required the 2 to $300 \mu \mathrm{m}$ range to capture the complete distribution.

The Sauter means for the six Window $E$ samples average $2.5 \mu \mathrm{m}$. The means for Window $E$ sample are significantly lower than those from the Window $C$ analysis. This is perhaps a reflection of the superior centrifugation that Window $E$ cores received, or the different homogenization. However, microscopic analysis indicated that large, easily disrupted, agglomerates were present in the Window $E$ samples from which particle size analysis aliquots were drawn. The particle size data appear to be compromised by the sample handling and are provided here for information only. 


\subsection{POLARIZED LIGHT MICROSCOPY}

Polarized light microscopy identified three main crystalline salts: sodium nitrate, sodium nitrite, and sodium carbonate. The sizes of the carbonate crystals were generaliy much smaller than the sodium nitrate and sodium nitrite, and so appeared to be the minor constituent of the solid material. Sodium nitrate accounted for the largest crystals with particle sizes from 10 to $500 \mu \mathrm{m}$.

Core $C$ analyses also showed similar types of crystals. The "sponge" crystals reported from the Core $C$ samples are not reported for Window samples. The Window $E$ report does not discuss gas bubbles though one is present in the photographs of the crystals. 
WHC-EP-0628

This page intentionaliy left blank. 


\subsection{CHENICAL CONSTITUENTS}

Window $E$ chemical analyses were focused on composite samples, while Window $C$ chemical analyses examined segments. Window $E$ results agree quite well with the results from Window $C$. Window $E$ results for carbonate and hydroxide were more consistent, and provide a better knowledge of the chemical makeup of the waste. In addition, analyses were performed on several species that were not analyzed in Window $C$.

Tables 5-1, 5-2, and 5-3, which are reproducerj here from WHC-SD-WM-DTR-026 (Herting et a1. 1991a), show values that represent the average of four or more determinations. Herting presented details on how each table was developed, as well as extensive discussions on the accuracy of the results. These will not be presented here to prevent duplication. Also presented in WHC-SD-WM-DTR-026 are a number of plots comparing Window $E$ with Window $C$ results. Some of the trends that are apparent will be discussed.

The composites were created by combining proportional amounts (by weight) of several homogenized segment samples into a sample. All segment and composite samples were mixed by a homogenizer until the samples appeared to be well mixed (about $3 \mathrm{~min}$ ).

\subsection{OVERALL COMPOSITION}

There is some interest in knowing the overall composition of waste in tank 101-SY, especially for generating simulated waste mixtures. Table 5-4 shows the calculaced ovelall tank average composition for the combined convective and noriconvective iayers. The crust layer has not been included in the calculation because of the iack of compositional data and accurate information on the depth of the crust. As in Window $C$, it was no surprise that water, sodium, nitrate, nitrite, aluminum, and hydroxide make up the bulk of the waste. What is of interest are the trace materials and trends.

\subsection{TRENDS}

Chromium is almost all in the solid phase. It is also obvious that $\mathrm{Cr}$ (VI) represents a very small fraction of the total chromium in the tank, but virtually all of the chromium in the liquid phase is $\operatorname{Cr}(V I)$. Iron and nickel are found almost exclusively in the solid phase. Sulfate, fluoride, and ammonia are much higher in the solid phase than the liquid phase. Phosphate appears to be slightly higher in the solid phase. Chloride concentrations are somewhat higher in the liquid phase than the solid phase. All the chloride values are higher than expected, but agree well with the Window $C$ analyses.

Sodium is slightly higher in the solid phase than the liquid phase. Sodium would be present as sodium salts in the solid phase.

Nitrate, nitrite, and aluminum seem evenly distributed between solid and liquid phases. Total organic carbon (TOC) agrees well with Window $C$, and is higher in the solid phase. 
Table 5-1. Chemical Analysis Results for Composites 1 and 2 (all values in weight percent).

\begin{tabular}{|c|c|c|c|c|}
\hline \multirow{2}{*}{ Analysis. } & \multicolumn{2}{|c|}{ Solid phase } & \multicolumn{2}{|c|}{ Liquid phase } \\
\hline & Comp 1 & Comp 2 & Comp 1 & Comp 2 \\
\hline $\mathrm{Na}^{+}$ & 22.4 & 23.2 & 18 & 19.5 \\
\hline AT & 3.00 & 2.35 & 3.12 & 3.41 \\
\hline $\operatorname{cr}($ total $)$ & 0.70 & 0.86 & 0.01 & 0.01 \\
\hline $\operatorname{cr}(V I)$ & $<0.001$ & $<0.001$ & 0.007 & \\
\hline Ca (Acid Digest) & 0.033 & 0.069 & 0.011 & 0.006 \\
\hline Ca (Fusion) & 0.082 & 0.117 & -- & -- \\
\hline $\mathrm{Fe}$ & 0.046 & 0.058 & 0.003 & 0.002 \\
\hline $\mathrm{K}^{+}$ & 0.276 & 0.243 & 0.382 & 0.408 \\
\hline $\mathrm{Ni}$ & 0.023 & 0.028 & 0.003 & 0.003 \\
\hline $\mathrm{Zn}$ & 0.002 & 0.004 & 0.001 & 0.001 \\
\hline $\mathrm{NO}_{3}^{-}$ & 14.1 & 16.4 & 10.4 & 10.3 \\
\hline $\mathrm{NO}_{2}^{-}$(IC) & 10.8 & 10.9 & 10.8 & 11.9 \\
\hline $\mathrm{NO}_{2}^{-}$(spec) & -- & $-\therefore$ & 9.7 & 11 \\
\hline $\mathrm{OH}^{-}$ & 2.06 & 2.29 & 2.68 & 2.82 \\
\hline TOC & 1.77 & 1.72 & 0.97 & 1.01 \\
\hline TIC & 1.10 & 0.99 & 0.11 & 0.12 \\
\hline $\mathrm{PO}_{4}^{-3}$ & 0.59 & 0.57 & 0.35 & 0.50 \\
\hline $\mathrm{SO}_{4}{ }^{-\cdot}$ & 0.53 & 0.62 & 0.09 & 0.07 \\
\hline $\mathrm{Cl}^{\circ}$ & 0.69 & 0.64 & 0.92 & 0.90 \\
\hline$F^{-}$ & $<0.04$ & $<0.04$ & $<0.01$ & $<0.01$ \\
\hline $\mathrm{NH}_{3} / \mathrm{NH}_{4}^{+}$ & $<0.26$ & $<0.90$ & 0.02 & $<0.01$ \\
\hline WT\% H2O (grav) & 32.4 & 29.4 & 41.2 & 41.2 \\
\hline WT\% H2O (TGA) & 27.1 & 27.1 & 42 & 44.9 \\
\hline
\end{tabular}

TOC $=$ total organic carbon.

TIC $=$ total inorganic carbon. 
Table 5-2. Chemical Analysis Results for Composites 3 and 4 (all values in weight percent).

\begin{tabular}{|c|c|c|c|c|}
\hline \multirow{2}{*}{ Analysis. } & \multicolumn{2}{|c|}{ Bulk sample } & \multicolumn{2}{|c|}{ Liquid phase } \\
\hline & Comp 3 & Comp 4 & Comp 3 & Comp 4 \\
\hline $\mathrm{Na}^{+}$ & 22.0 & 21.6 & 20.0 & 20.8 \\
\hline Al & 3.39 & 3.40 & 3.56 & 3.52 \\
\hline $\operatorname{cr}($ total $)$ & 0.645 & 0.689 & 0.012 & 0.015 \\
\hline $\operatorname{cr}(V I)$ & $<0.001$ & $<0.001$ & 0.017 & 0.015 \\
\hline Ca (Acid Digest) & 0.027 & 0.027 & 0.026 & 0.018 \\
\hline Ca (Fusion) & 0.108 & 0.097 & -- & -- \\
\hline $\mathrm{Fe}$ & 0.040 & 0.046 & 0.002 & 0.002 \\
\hline$K^{+}$ & 0.289 & 0.275 & 0.401 & 0.376 \\
\hline $\mathrm{Ni}$ & 0.023 & 0.025 & 0.003 & 0.004 \\
\hline Zn & 0.003 & 0.002 & 0.001 & 0.001 \\
\hline $\mathrm{NO}_{3}^{-}$ & 11.6 & 11.8 & 11.8 & 14.7 \\
\hline $\mathrm{NO}_{2}^{-}$(IC) & 9.6 & 9.4 & 12.1 & 11.4 \\
\hline $\mathrm{NO}_{2}^{-}$(spec) & - & - & 12.6 & 10.8 \\
\hline $\mathrm{OH}^{-}$ & 2.50 & 2.09 & 3.06 & 2.61 \\
\hline TOC & 2.00 & 1.95 & 1.06 & \\
\hline TIC & 0.88 & 1.08 & 0.15 & 0.16 \\
\hline $\mathrm{PO}_{4}^{-3}$ & 0.83 & 0.91 & 0.56 & 0.76 \\
\hline $\mathrm{SO}_{4}^{-\cdots}$ & 0.64 & 0.66 & 0.06 & 0.07 \\
\hline $\mathrm{Cl}^{-}$ & 0.72 & 0.71 & 0.98 & 0.86 \\
\hline $\mathrm{F}^{-}$ & $<0.04$ & $<0.04$ & $<0.01$ & $<0.01$ \\
\hline $\mathrm{NH}_{3} / \mathrm{NH}_{4}^{+}$ & $<0.24$ & $<0.20$ & $<0.01$ & \\
\hline WT\% H2O (grav) & 31.5 & 31.9 & 38.5 & 37.5 \\
\hline WT\% H2O (TGA) & 31.0 & 29.6 & 31.2 & 29.5 \\
\hline
\end{tabular}

$T O C=$ total organic carbon.

TIC = total inorganic carbon. 
Table 5-3. Chemical Analysis Results for Segments 19 and 22R (all values in weight percent).

\begin{tabular}{|c|c|c|c|c|}
\hline \multirow{2}{*}{ Analysis. } & \multicolumn{2}{|c|}{ Solid phase } & \multicolumn{2}{|c|}{ Liquid phase } \\
\hline & Segment 19 & Segment $22 A$ & Segment 19 & Segment $22 \mathrm{~A}$ \\
\hline $\mathrm{Na}^{+}$ & 24.6 & 23.8 & 19.2 & 18.1 \\
\hline Al & 3.50 & 3.33 & 3.16 & 3.03 \\
\hline $\operatorname{cr}($ total $)$ & 1.17 & 1.07 & 0.01 & 0.01 \\
\hline \multicolumn{5}{|l|}{$\operatorname{Cr}(V I)$} \\
\hline Ca (Acid Digest) & 0.062 & 0.044 & 0.028 & 0.036 \\
\hline Ca (Fusion) & 0.000 & 0.000 & 0.000 & 0.000 \\
\hline $\mathrm{Fe}$ & 0.07240 & 0.081 & 0.001 & 0.002 \\
\hline $\overrightarrow{k^{+}}$ & 0.259 & 0.232 & 0.358 & 0.343 \\
\hline $\mathrm{Ni}$ & 0.040 & 0.036 & 0.003 & 0.004 \\
\hline $\mathrm{Zn}$ & 0.004 & 0.003 & 0.001 & 0.003 \\
\hline $\mathrm{NO}_{3}^{-}$ & 9.9 & 15.1 & 16.5 & 16.8 \\
\hline $\mathrm{NO}_{2}^{-}$(IC) & 8.5 & 7.1 & 11.1 & 14.9 \\
\hline $\mathrm{NO}_{2}^{-}$(spec) & 8.9 & 7.3 & 11.3 & 12.8 \\
\hline \multicolumn{5}{|l|}{$\mathrm{OH}^{-}$} \\
\hline TOC & 2.40 & 2.15 & 1.07 & 1.31 \\
\hline TIC & 1.48 & 1.38 & 0.15 & 0.18 \\
\hline $\mathrm{PO}_{4}^{-3}$ & 0.71 & 0.79 & 0.60 & 0.64 \\
\hline $\mathrm{SO}_{4}{ }^{-\cdots}$ & 0.93 & 0.96 & 0.09 & $<0.10$ \\
\hline $\mathrm{Cl}^{\circ}$ & 0.65 & 0.58 & 0.92 & 1.09 \\
\hline$F^{-}$ & $<0.04$ & $<0.04$ & $<0.02$ & $<0.02$ \\
\hline \multicolumn{5}{|l|}{$\mathrm{NH}_{3} / \mathrm{NH}_{4}^{+}$} \\
\hline WT\% H2O (grav) & 27.7 & 27.4 & 37.4 & 31.5 \\
\hline WT\% H2O (TGA) & 28.2 & 27.4 & 33.5 & \\
\hline
\end{tabular}

TOC = total organic carbon.

TIC = total inorganic carbon. 
Table 5-4. Overall Average Bulk Composition of Core Sample (all values in weight percent).

\begin{tabular}{|c|c|c|c|c|c|}
\hline \multirow[b]{2}{*}{ Analysis } & \multicolumn{5}{|c|}{ Bulk Sample } \\
\hline & Comp 1 & Comp 2 & Comp 3 & Comp 4 & $\begin{array}{c}\text { Tank } \\
\text { Average }\end{array}$ \\
\hline $\mathrm{Na}^{+}$ & 19.2 & 20.5 & 22.0 & 21.6 & 20.7 \\
\hline Al & 3.09 & 3.14 & 3.39 & 3.40 & 3.2 \\
\hline $\operatorname{cr}($ total $)$ & 0.20 & 0.23 & 0.645 & 0.689 & 0.41 \\
\hline $\operatorname{cr}(V I)$ & 0.005 & 0.000 & 0.001 & 0.001 & 0.002 \\
\hline Ca (Acid Digest) & 0.017 & 0.022 & 0.027 & 0.027 & 0.023 \\
\hline $\mathrm{Fe}$ & 0.014 & 0.017 & 0.040 & 0.046 & 0.028 \\
\hline $\mathrm{K}^{+}$ & 0.353 & 0.365 & 0.289 & 0.275 & 0.326 \\
\hline $\mathrm{Ni}$ & 0.008 & 0.009 & 0.023 & 0.025 & 0.015 \\
\hline $2 n$ & 0.001 & 0.002 & 0.003 & 0.002 & 0.002 \\
\hline $\mathrm{NO}_{3}^{-}$ & 11.4 & 11.9 & 11.6 & 11.8 & 11.7 \\
\hline $\mathrm{NO}_{2}^{-}$(IC) & 10.8 & 11.6 & 9.6 & 9.4 & 10.5 \\
\hline $\mathrm{OH}^{-}$ & 2.51 & 2.68 & 2.5 & 2.09 & 2.47 \\
\hline TOC & 1.19 & 1.19 & 2.00 & 1.95 & 1.53 \\
\hline TIC & 0.38 & 0.34 & 0.88 & 1.08 & 0.63 \\
\hline $\mathrm{PO}_{4}^{-3}$ & 0.41 & 0.51 & 0.83 & 0.91 & 0.64 \\
\hline $\mathrm{SO}_{4}{ }^{--}$ & 0.21 & 0.21 & 0.64 & 0.66 & 0.40 \\
\hline $\mathrm{Cl}^{-}$ & 0.85 & 0.83 & 0.72 & 0.71 & 0.79 \\
\hline $\mathrm{NH}_{3} / \mathrm{NH}_{4}^{+}$ & 0.09 & 0.24 & 0.24 & 0.20 & 0.19 \\
\hline WT\% H2O (grav) & 38.8 & 38.1 & 31.5 & 31.9 & 35.5 \\
\hline
\end{tabular}

TOC = total organic carbon.

$T I C=$ total inorganic carbon. 


\subsection{REGULATORY ANALYSES}

Severa? analyses were performed on samples to evaluate the hazardous or toxic characteristics of the waste. These include arsenic, selenium, mercury, cyanide, $\mathrm{Cr}(V I)$, noble metals, and semivolatile organics. The $\mathrm{Cr}(V I)$ results were presented in Section 5.1. Average results for As, Se, $\mathrm{Hg}$, and noble metals are shown in Table 5-5. Arsenic and selenium analyses were done on centrifuged solids from composites 1 and 2 , and on bulk sample from composites 3 and 4. Mercury anaiyses were done on buik samples from all four composites.

The noble metal analyses were performed at the Savannah River Laboratory. Bulk samples from segments 5 and 10 and centrifuged solids from composites 3 and 4 were analyzed. The samples had to be dried before analys is to meet shipping regulations. The samples were dried at $100{ }^{\circ} \mathrm{C}$ for two days before being packaged for shipping. The values shown in Table 5-5 have been corrected to account for the change in weight caused by drying. The wet and dry sample weights are included in the table for reference.

Noble metal analyses were performed using two types of sample preparation: (1) acid digestion in aqua regia; and (2) fusion in sodium peroxide. Results for both preparations are included in Table 5-5. For the most part, the acid digestion gave the higher results, though there were exceptions.

In addition to the noble metals ruthenium, rhodium, palladium, and silver (as shown in the table) analyses were also performed for gold and platinum, which were not detected at the part per million level.

Cyanide values were reported for Window $C$ core samples. However, the analytical procedure for cyanide has not been verified. Window $E$ material was not analyzed for cyanide.

\subsection{SEMIVOLATILE ORGANIC ANALYSIS}

One sample of each of the four main composites (1-4) was sent to PNL for semivolatile analysis. The only target compounds found were in one of the duplicate samples for composite No. 2. They were identified as:

- Di-n-butylphthalate - $330 \mu \mathrm{g} / \mathrm{Kg}$

- Benzo(a)pyrene - $660 \mu \mathrm{g} / \mathrm{Kg}$

- $\operatorname{Benzo}(\mathrm{g}, \mathrm{h}, \mathrm{i})$ perylene $-1500 \mu \mathrm{g} / \mathrm{Kg}$.

( $\mu \mathrm{g} / \mathrm{Kg}$ is part per million, ppm, by weight.) These compounds were considerably below the quantitation limits for the compounds.

A11 the samples were found to contain normal paraffin hydrocarbons (NPH) in the $C_{12}$ to $C_{15}$ range, in concentrations ranging from a few parts per million up to several hundred parts per million. These were the only "tentatively identified compounds."

It is not known whether the hydrocarbons were actually in the waste, or whether they were introduced during the core sampling operation. One possible external source is the head tank used to contain the hydrostatic fluid. 
Table 5-5. Summary of Chemical Analyses of Minor Constituents (ppm).

\begin{tabular}{|c|c|c|c|c|}
\hline Analysis & $\begin{array}{c}\text { Composite } 1 \\
\text { Centrifuged } \\
\text { Solids }\end{array}$ & $\begin{array}{c}\text { Composite } 2 \\
\text { Centrifuged } \\
\text { Solids }\end{array}$ & $\begin{array}{l}\text { Composite } 3 \\
\text { Bulk Sample }\end{array}$ & $\begin{array}{l}\text { Composite } 4 \\
\text { Bulk Sample }\end{array}$ \\
\hline As & $<0.52$ & $<0.61$ & $<0.57$ & $<0.76$ \\
\hline $\mathrm{Se}$ & 0.70 & $<0.65$ & 0.89 & 0.96 \\
\hline \multicolumn{5}{|r|}{ - } \\
\hline & $\begin{array}{l}\text { Composite } 1 \\
\text { Bulk Sample }\end{array}$ & $\begin{array}{l}\text { Composite } 2 \\
\text { Bulk Sample }\end{array}$ & $\begin{array}{l}\text { Composite } 3 \\
\text { Bulk Sample }\end{array}$ & $\begin{array}{l}\text { Composite } 4 \\
\text { Bulk Sample }\end{array}$ \\
\hline \multirow[t]{2}{*}{$\mathrm{Hg}$} & $<0.12$ & $<0.12$ & 0.18 & 0.23 \\
\hline & $\begin{array}{c}\text { Segment } 5 \\
\text { Bulk Sample }\end{array}$ & $\begin{array}{l}\text { Segment } 10 \\
\text { Bulk Sample }\end{array}$ & $\begin{array}{c}\text { Composite } 3 \\
\text { Centrifuged } \\
\text { Solids }\end{array}$ & $\begin{array}{c}\text { Composite } 4 \\
\text { Centrifuged } \\
\text { Solids }\end{array}$ \\
\hline Wet Weight (g) & 5.4567 & 6.5143 & 5.0484 & 8.2689 \\
\hline \multicolumn{5}{|c|}{ Acid Digestion, Aqua Regia } \\
\hline $\mathrm{Ru}$ & 19 & 19 & 14 & 15 \\
\hline $\mathrm{Rh}$ & 6.1 & 6.9 & 3.1 & 1.9 \\
\hline $\mathrm{Pd}$ & 4.0 & 4.8 & 26 & 29 \\
\hline $\mathrm{Ag}$ & 0 & 0.5 & 0.5 & 0.4 \\
\hline \multicolumn{5}{|c|}{ Fusion, Sodium Peroxide } \\
\hline Ru & 10.1 & 8.2 & 9.3 & 8.4 \\
\hline $\mathrm{Rh}$ & 2.7 & 2.7 & 4.7 & 3.1 \\
\hline $\mathrm{Pd}$ & 2.7 & 4. & 16.3 & 12.2 \\
\hline $\mathrm{Ag}$ & 0 & 0 & 0 & 0 \\
\hline
\end{tabular}


Though water was used as the hydrostatic fluid, the water was initially pumped from a head tank that had previously contained NPH. About halfway

through the core sample, the source of the water for the hydrostatic head was switched to drums that were free of contamination. This could explain why the amounts of NPH found in the samples were high in the upper part of the tank, and low in the bottom of the tank.

\subsection{CHELATOR FRAGMENTS}

Chelators and chelator fragments that were identified and quantified by PNL include the following:

- NIDA = nitrosoiminodiacetate

- NTA = nitrilotriacetate

- $C A=$ citrate

- $E D 3 A=$ ethylenediametriacetate

- EDTA = ethylenediaminetetraacetate

- HEDTA $=\mathrm{N}-(2$-hydroxyethyl $)$ ethyl enediaminetriacetate.

The sum of the concentrations of all the chelators and chelator fragments that were detected accounts for about $10-20 \%$ by weight of the total organic content of the samples. The remaining $80-90 \%$ of the organic compounds are still unidentified. Some of the major unidentified organics are believed to be small molecular weight degradation products, such as oxalate and acetate.

\subsection{CALORIMETRY}

Extensive adiabatic calorimetry was done on samples from 101-SY. This is reported in detail in Herting 1992a. This section will briefly summarize the findings.

The adiabatic calorimeter uses up to $10 \mathrm{~g}$ samples to measure rate of self-heating and gas production and to gauge the severity of a thermal runaway. It complements the differencial scanning calorimeter and the thermogravametric analysis.

The waste was dried prior to running the adiabatic calorimetry. Actual waste showed an onset of self-heating between $150{ }^{\circ} \mathrm{C}$ and $180^{\circ} \mathrm{C}$. At this temperature, the chemical reaction is going fast enough that the heat is not transferred from the sample. The rate of temperature rise in the synthetic samples of 101-SY crust was much more vigorous. The synthetic samples showed a self-heating temperature increase of 1,000 to $1,500^{\circ} \mathrm{C} / \mathrm{min}$. This compares with actual waste, which had 6 to $63^{\circ} \mathrm{C} / \mathrm{min}$.

The main conclusion is the actual waste does possess a mild self-heating reaction that should not support combustion of a damp material. 


\subsection{RADIOACTIVITY}

\subsection{RADIONUCLIDE ANALYSES}

The radionuclide analysis performed on Window $E$ core samples was more extensive than on Window $C$ samples. That is, more radioisotopes were determined. For those radionuclides that were determined for both core samples, the agreement between the cores is generally good. The Window $E$ results are shown in Table 6-1 for the solid phase composite samples and Table 6-2 shows the liquid phase composite samples.

\subsubsection{Comparisons Between Window $C$ and Window $E$}

All conclusions drawn in the Window $C$ report (Herting et al. 1992b; Section 8.1.2) are valid in light of the Window $E$ data. These conclusions are as follows:

- Most of the radionuclides are much more concentrated in the solid phase than the liquid phase. Cesium-137 is a notable exception.

- Plutonium-239/240 is consistently 10-12 times lower than ${ }^{241} \mathrm{Am}$.

- Americium-241 is about 100 times more concentrated in solid phase of the samples than in liquid samples.

- Cesium-137, being soluble, is typically a little higher in the liquid samples than in the bulk samples or centrifuged solids.

Some minor discrepancies between Window $C$ and Window $E$ can be pointed out. Total uranium results for the Window $E$ solid samples are substantially higher than the Window $C$ results (except for composite 1), while the liquid samples are in good agreement. The bulk samples in Window $E$ are about 3-10 times higher than Window $C$.

Americium-241 was determined by both WHC and PNL laboratories. However, a direct comparison between the results is not possible because the fusion digest analyses for composites 1 and 2 were performed on centrifuged solids samples, while the PNL analyses were performed on bulk samples. Agreement between the two methods is good for the bulk samples, where a direct comparison can be made. The fusion digest results are about four times higher than the Window $C$ results for the composite 1 and 2 centrifuged solids.

Strontium-90 and ${ }^{239 / 240} \mathrm{Pu}$ bulk sample results agree well with Window $\mathrm{C}$, while the centrifuged solids samples are about four times higher than the corresponding Window $C$ results, Because this same factor-of-four discrepancy occurs in the ${ }^{241} \mathrm{Am},{ }^{90} \mathrm{Sr}$, and ${ }^{239 / 240} \mathrm{Pu}$ analyses, it may indicate that the results are correct (i.e., the discrepancy is real). It may be caused by the much larger amount of solids in the Window $E$ convective layer that were suspended due to the more vigorous gas release event preceding the core sampling. 
Table 6-1. Results of Radionuclide Analyses of Solid Phase Samples

(a)l results in $\mu \mathrm{Ci} / \mathrm{g}$ except Uranium, which is $\mu \mathrm{g} / \mathrm{g}$ ).

\begin{tabular}{|c|c|c|c|c|}
\hline \multirow{2}{*}{ Analys is } & \multicolumn{2}{|c|}{ Centrifuged solids } & \multicolumn{2}{|c|}{ Bulk sample } \\
\hline & Composite 1 & Composite 2 & Composite 3 & Composite 4 \\
\hline FD Total Alpha & 0.14 & 0.22 & 0.22 & 0.20 \\
\hline FD ${ }^{241} \mathrm{Am}$ & 0.18 & 0.19 & 0.17 & 0.16 \\
\hline$P N L *{ }^{241} A m$ & 0.04 & 0.06 & 0.18 & 0.23 \\
\hline FD ${ }^{239 / 240} \mathrm{Pu}$ & 0.012 & 0.013 & 0.012 & 0.010 \\
\hline$P N L *{ }^{243 / 4} \mathrm{Cm}$ & 0.004 & 0.003 & 0.007 & 0.013 \\
\hline PNL * ${ }^{242} \mathrm{Cm}$ & $1.4 E-04$ & $4.7 E-05$ & $4.5 E-04$ & $6.8 E-04$ \\
\hline FD GEA ${ }^{137} \mathrm{Cs}$ & 334 & 263 & 347 & 314 \\
\hline WD GEA ${ }^{137} \mathrm{Cs}$ & 222 & 187 & 310 & 323 \\
\hline FD Total Beta & 560 & 441 & 556 & 521 \\
\hline${ }^{14} \mathrm{C}$ (bulk) & $5.3 E-04$ & $9.1 E-04$ & $1.3 E-03$ & $1.6 E-03$ \\
\hline $\mathrm{FO}{ }^{90} \mathrm{Sr}$ & 32 & 38 & 32 & 35 \\
\hline$F{ }^{99} \mathrm{Tc}$ & 0.30 & 0.26 & 0.30 & 0.29 \\
\hline FO ${ }^{129} I$ & $<0.022$ & $<0.016$ & $<0.018$ & $<0.008$ \\
\hline $\mathrm{FO}{ }^{237} \mathrm{~Np}$ & $<0.062$ & $<0.018$ & $<0.097$ & $<0.073$ \\
\hline$A D^{237} \mathrm{~Np}$ & $<0.0006$ & $<0.027$ & $<0.009$ & $<0.010$ \\
\hline $\mathrm{PNL} *{ }^{237} \mathrm{~Np}$ & $2.3 E-05$ & $2.9 E-05$ & $<3.6 E-05$ & $3.0 E-05$ \\
\hline FD U (Total) & 107 & 135 & 105 & 99 \\
\hline $\mathrm{PNL} *{ }^{79} \mathrm{Se}$ & $2.4 E-04$ & $2.5 E-04$ & $2.4 E-04$ & $1.9 E-04$ \\
\hline$P N L *{ }^{94} \mathrm{Nb}$ & $<6 E-05$ & $<7 E-05$ & $<1 E-04$ & $<5 E-05$ \\
\hline $\mathrm{PNL}$ * $93 \mathrm{~m} \mathrm{Nb}$ & $2 E-03$ & $3 E-03$ & $4 E-03$ & $9 E-03$ \\
\hline $\mathrm{PNL} *{ }^{59} \mathrm{Ni}$ & $1.6 E-04$ & $4 E-05$ & $7 E-05$ & $2.6 E-05$ \\
\hline $\mathrm{PNL} *{ }^{63} \mathrm{Ni}$ & $2.6 E-02$ & $6 E-03$ & $1.5 E-02$ & $4.8 E-02$ \\
\hline
\end{tabular}

$F D=$ Fusion Digestion

$A D=$ Acid Digestion

WD = Water Digestion

*A11 PNL samples were bulk (uncentrifuged) samples. 
Table 6-2. Results of Radionuclide Analyses of Liquid Phase Samples (a) 1 results in $\mu \mathrm{Ci} / \mathrm{g}$ except Uranium, which is $\mu \mathrm{g} / \mathrm{g}$ ).

\begin{tabular}{|l|r|r|r|r|}
\hline \multirow{2}{*}{ Analysis } & \multicolumn{2}{|c|}{ Centrifuged liquid } & \multicolumn{2}{c|}{ Centrifuged liquid } \\
\cline { 2 - 5 } & Composite 1 & Composite 2 & Composite 3 & Composite 4 \\
\hline FD Total Alpha & 0.48 & $<0.019$ & 0.035 & $<0.019$ \\
\hline FD ${ }^{241} \mathrm{Am}$ & $5.6 E-04$ & $5.4 E-04$ & $5.1 E-04$ & $4.4 E-04$ \\
\hline FD ${ }^{239 / 240} \mathrm{Pu}$ & $5.5 E-05$ & $7.0 E-05$ & $6.3 E-05$ & $1.9 E-04$ \\
\hline WD GEA ${ }^{137} \mathrm{Cs}$ & 435 & 338 & 461 & 288 \\
\hline FD Total Beta & 538 & 696 & 607 & 648 \\
\hline FD ${ }^{90} \mathrm{Sr}$ & 2.8 & 2.9 & 2.4 & 2.7 \\
\hline FD ${ }^{99} \mathrm{TC}$ & 0.13 & 0.062 & 0.12 & 0.076 \\
\hline FD ${ }^{129} \mathrm{I}$ & $<0.0006$ & $2.4 \mathrm{E}-04$ & $<0.00024$ & $<0.00012$ \\
\hline FD ${ }^{237} \mathrm{~Np}$ & $<7 E-05$ & $<4 E-05$ & $<5 E-05$ & $<1 \mathrm{E}-04$ \\
\hline FD U (Total) & 0.97 & 1.13 & 1.69 & 1.27 \\
\hline
\end{tabular}

FD $=$ Fusion Digestion

WD = Water Digestion

\subsubsection{Gamma Scanning}

In addition to the standard wet chemistry radionuclide analyses, a new technique, direct gamma scanning of the segment shipping casks, was used for the first time on the Window $E$ core samples. Each of the core segments was scanned with a collimated germanium gamma detector before the segments were removed from their shipping casks. The results provide information about the vertical distribution of ${ }^{137} \mathrm{Cs},{ }^{154} \mathrm{Eu}$, and ${ }^{60} \mathrm{Co}$ within each individual segment and within the core sample as a whole.

Scanning showed that the cesium is evenly distributed throughout the waste, though it may be just slightly higher in the convective region.

Europium is expected to behave very much like americium in the waste (i.e., it is insoluble). The scan clearly shows that the ${ }^{137} \mathrm{Eu}$ is three to four times more concentrated in the nonconvective layer than in the convective layer. Because virtually all of the ${ }^{249} \mathrm{Am}$ (and ${ }^{154} \mathrm{Eu}$ ) is in the solid phase, this finding indicates that the concentration of solid phase is 3-4 times higher in the nonconvective region. ("Solid phase" in this instance refers to actual solids, not including interstitial liquid.) The ${ }^{154}$ Eu profile also shows that the transition between waste layers begins in segment 14 and continues smoothly through segment 15 . This is the best indication of the interface between the layers that was derived from any of the analyses that were done in the entire core sample analysis. 
The ${ }^{60} \mathrm{Co}$ profile shows that cobalt, like cesium, is fairly evenly distributed among the waste layers. Therefore, cobalt is much more soluble in the waste than europium.

\subsection{RADIOLYTIC HEATING OF THE TANK}

Two cores samples were taken out of tank 101-SY. Various segments and composites of the core samples were analyzed for radionuclide content. The predominant radionuclide is ${ }^{137} \mathrm{Cs}$. The heat of ${ }^{90} \mathrm{Sr}$ is al so included, but the other radionuclides are much lower concentrations and are not incTuded. The heat generation rate is $38,300 \mathrm{BTU} / \mathrm{hr}$ with a standard deviation of 12,600 .

There were 225 different determinations for ${ }^{137} \mathrm{Cs}$ from both of the cores (see Herting et a1. 1992a and b). Five determinations were discarded as "fliers." One was because of a low value and four were because of high values. The low value was in a sample that showed other chemical constituents also low, which would indicate that the sample was diluted with water. The four high values do not have a similar explanation.

There did not seem to be a difference between cores. The values were sorted into three groups that relate to the three layers in the tank. Figure 6-1 shows a scatter plot of the data. The large overlapping indicates that most probably there is no difference between the three arbitrary groups, but they were kept separate for the following analysis.

\subsubsection{Heat Rate Equation}

$$
\begin{aligned}
\text { Heat Rate }= & (\text { Depth, inch })\left(2750 \frac{\mathrm{gal}}{\mathrm{inch}}\right)\left(8.3 \frac{\mathrm{lb}}{\mathrm{gal}}\right)(\mathrm{SPG}) \\
& (454 \mathrm{~g} / \mathrm{lb})\left({ }^{137} \mathrm{Cs} \frac{\mu \mathrm{Ci}}{\mathrm{g}}\right)\left(\frac{0.0161 \mathrm{BTU}}{[\mathrm{hr} \mathrm{Ci}]}\right)
\end{aligned}
$$

The constants can be gathered into one value:

$$
\mathrm{K}=0.1668 \text { (BTU g) /(inch hr } \mu \mathrm{Ci}) \text {. }
$$


WHC-EP-0628

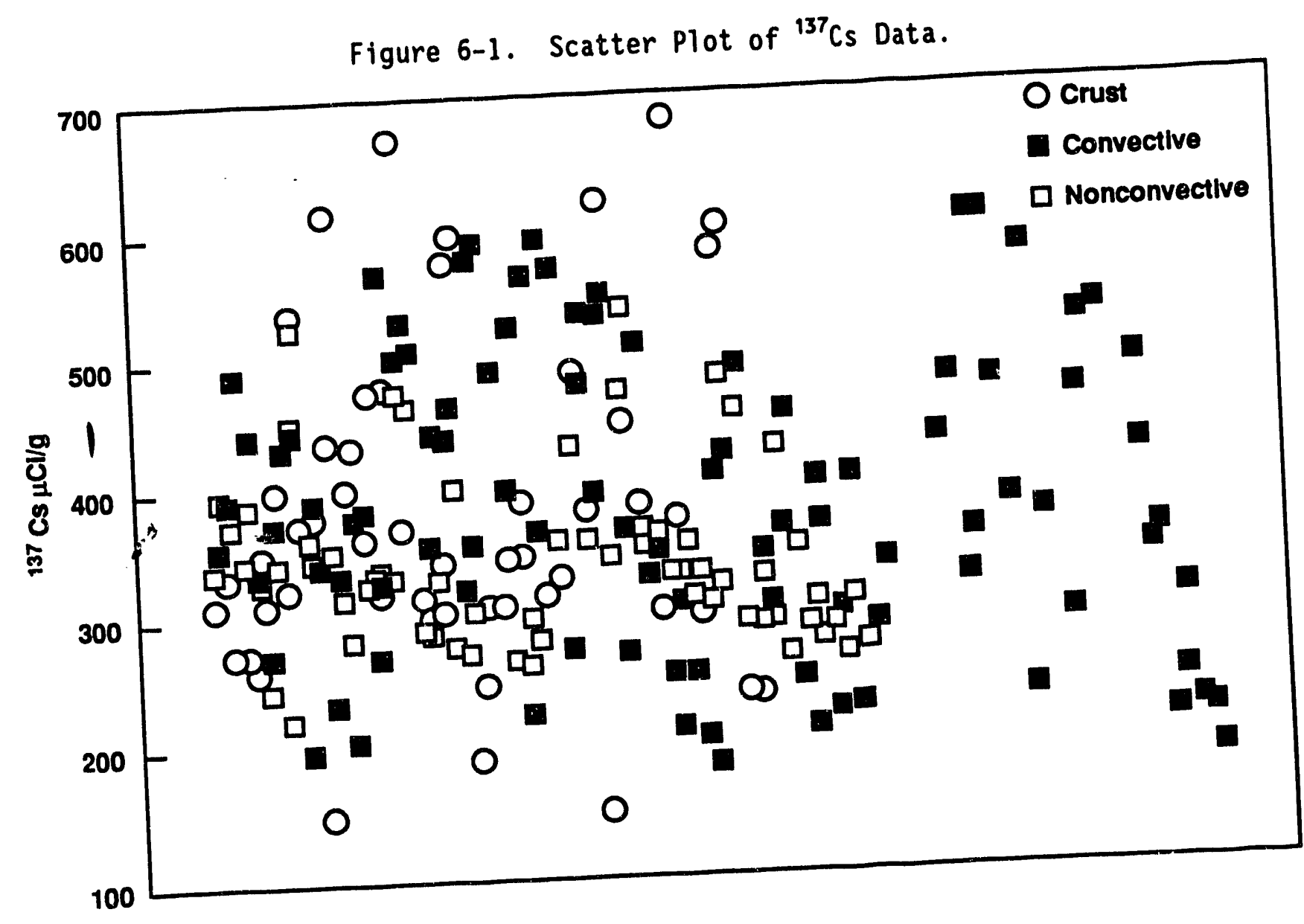

29301014.20 
All the constants can be brought into one constant as:

$$
\begin{gathered}
K=\left(2750 \frac{\mathrm{gal}}{i \mathrm{nch}}\right)\left(8.3 \frac{\mathrm{lb}}{\mathrm{gal}}\right)\left(454 \frac{\mathrm{g}}{\mathrm{lb}}\right) \\
(0.0161 \mathrm{BTU} / \mathrm{hr} / \mathrm{Ci})\left(1 \times 10^{-6} \frac{\mu \mathrm{Ci}}{\mathrm{Ci}}\right) .
\end{gathered}
$$

The remaining variables are depth of the layer, specific gravity of the layer, and ${ }^{137} \mathrm{Cs}$ content.

A similar constant can be made for ${ }^{90} \mathrm{Sr}$ :

$$
\mathrm{K}=0.2373 \text { (BTU g) /(inch hr } \mu \mathrm{Ci}) \text {. }
$$

\subsubsection{Depth of Layers}

There are three layers in the tank. The demarcation between the layers is not clear cut. The nonconvective layer included segments 15 to 22 . The transition segment was 14 in Core C and 15 in Core E. Segments 15 to 22 includ'e eight 19-inch segments for 152 inches. Two inches are added because the core did not go clear to the bottom of the tank, which gives 154 inches for the nonconvective layer.

The crust is estimated to be 40 inches thick, based on 48 -inch spacing of thermocouples and two 19-inch segments that were essentially empty on both cores.

Assuming 402 inches of total waste, 208 inches of convective layer are left after subtracting the depth of the crust and nonconvective layer.

\subsubsection{Specific Gravity}

The sample density was measured on various segments in the core. The difference between specific gravity and density is small and inconsequential for this analysis. Therefore, the densities are used as specific gravity.

The density of the crust is unknown. The crust floats, which means that it is less dense than the convective zone. The commonly used value is 1.35 . The probable range is 1.35 to 1.5 . 


\subsubsection{Calculation of the Heat Content of Tank 101-sY}

The calculation of the heat load is summarized in Table 6-3. This calculation uses the constant found in Section 6.2.1 and the values of the variables for each layer. The layers are summed.

Table 6-3. Calculation of Heat Generation in Tank 101-SY.

\begin{tabular}{|c|c|c|c|c|c|c|c|c|c|}
\hline \multirow{2}{*}{ Layer } & \multirow{2}{*}{ Depth } & \multicolumn{2}{|c|}{$\begin{array}{l}\text { Specific } \\
\text { gravity }\end{array}$} & \multicolumn{2}{|c|}{ 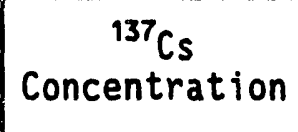 } & \multicolumn{2}{|c|}{${ }^{90} \mathrm{Sr}$} & \multicolumn{2}{|c|}{$\begin{array}{l}\text { Heat } \\
\text { generation } \\
\text { rate }\end{array}$} \\
\hline & & g.inL & $\begin{array}{l}\text { Std } \\
\text { Dev }\end{array}$ & $\mu \mathrm{Ci} / \mathrm{g}$ & $\begin{array}{l}\text { Std } \\
\text { Dev }\end{array}$ & $\mu \mathrm{Ci} / \mathrm{g}$ & $\begin{array}{l}\text { Std } \\
\text { Dev }\end{array}$ & BTU/hr & $\begin{array}{l}\text { Std } \\
\text { Dev }\end{array}$ \\
\hline Crust & 40 & 1.35 & & 371 & 131 & 69.1 & 95.0 & 4,220 & 6,000 \\
\hline Convective & 208 & 1.57 & 0.036 & 374 & 114 & 8.82 & 3.48 & 21,000 & 10,500 \\
\hline Nonconvective & 154 & 1.70 & 0.043 & 335 & 64.6 & 33.2 & 1.96 & 16,700 & 3,400 \\
\hline Total & 402 & & & & & & & 41,900 & 12,600 \\
\hline
\end{tabular}

The best estimate of the total heat content in tank 101-SY is $41,900 \mathrm{BTU} / \mathrm{hr}$.

The standard deviation of the total heat generation rate was calculated from the standard deviations of the cesium content and the density measurements. A propagation-of-error-type calculation was used to give an uncertainty of the heat constant. The contribution from other radionuclides is very small in comparison to the standard deviation.

This analysis only takes into account the radioactive heat load. There is an additional heat load from the chemical reactions going on in the tank. However, the heat load from these reactions are unknown at this time. Various studies are underway to try and understand the chemical heat load.

\subsection{PLUTONIUM INVENTORY ESTIMATE}

The plutonium is listed as $\mu \mathrm{Ci} /$ gram of sample and is identified as $239 / 240 \mathrm{Pu}$. The value in grams of plutonium per gallon of waste is needed for comparison with the criticality specifications.

The isotope of $\mathrm{Pu}$ was not designated in the Herting document. This analysis will assume that all the plutonium is ${ }^{239} \mathrm{Pu}$, which is the most conservative assumption. The conversion factor of $0.062 \mathrm{Ci} / \mathrm{g}$ of ${ }^{239} \mathrm{Pu}$ will be the basis for the following analysis.

The concentrations of plutonium in Window $E$ and Window $C$ core are relatively consistent. Figure 6-2 shows the concentrations of plutonium found in the various samples. This plot is a scatter plot, and the $x$ axis represents individual samples. The solid phase from Window $E$, the composite bulk samples from Window $E$, and the composite bulk samples from Window $C$ show 
WHC-EP-0628

Figure 6-2. Plutonium Concentrations.

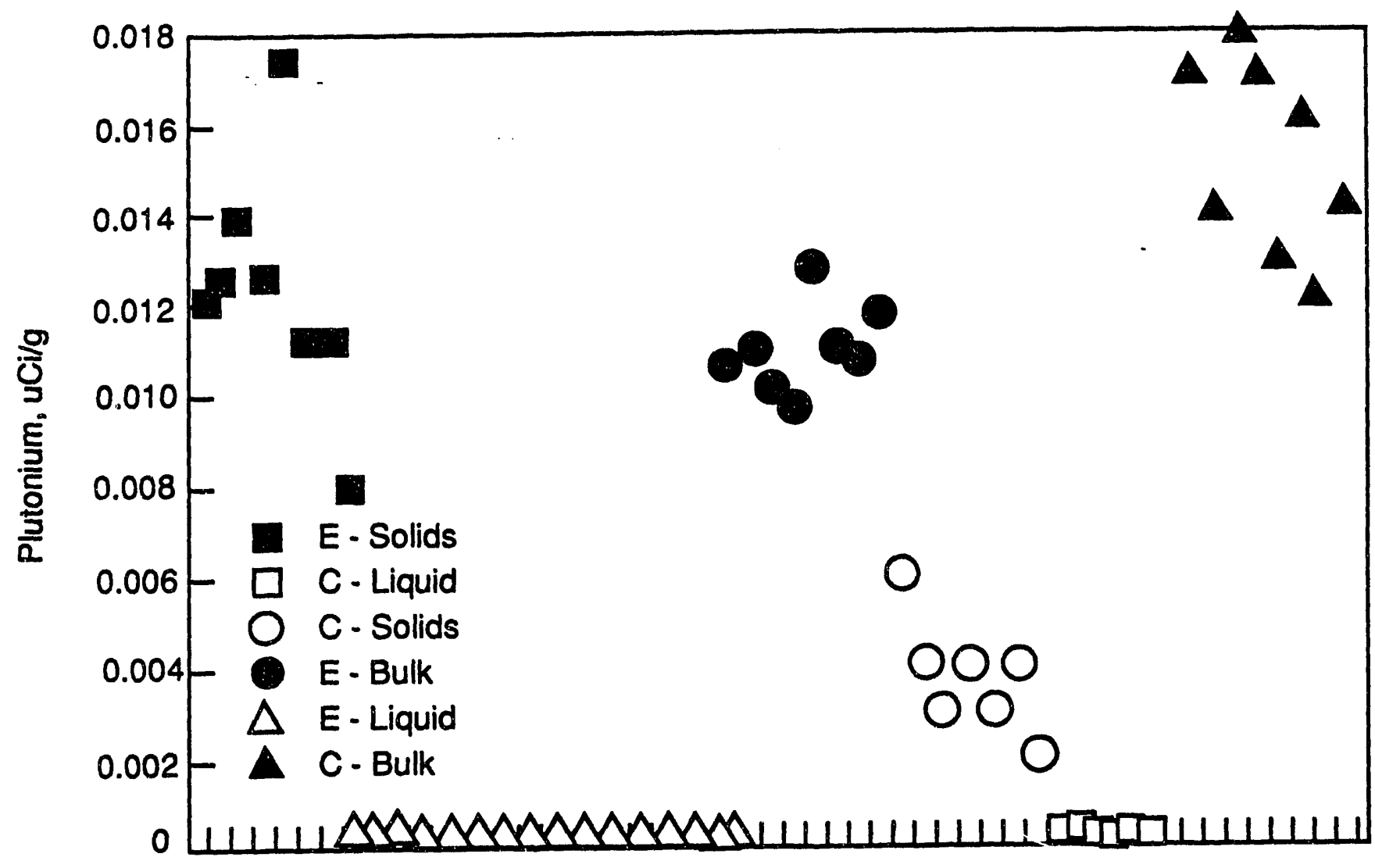

29301014.12 
similar concentrations. These samples have been averaged together, as shown in Table 6-4. The liquid samples from Window $E$ and Window $C$ cores al so were averaged together.

Table 6-4. Average Plutonium Concentrations in Tank 101-SY.

\begin{tabular}{|l|l|l|}
\hline & \multicolumn{1}{|c|}{$\begin{array}{c}\text { Solid phase and bulk } \\
\text { composite samples }\end{array}$} & \multicolumn{1}{|c|}{ Liquid samples } \\
\hline Average & $0.0128 \mu \mathrm{Ci} / \mathrm{g}$ & $9.1 \mathrm{E}-05 \mu \mathrm{Ci} / \mathrm{g}$ - \\
\hline Standard deviation & 0.00268 & $6.31 \mathrm{E}-05$ \\
\hline Maximum & $0.018 \mu \mathrm{Ci} / \mathrm{g}$ & $3.22 \mathrm{E}-04 \mu \mathrm{Ci} / \mathrm{g}$ \\
\hline Minimum & $0.00793 \mu \mathrm{Ci} / \mathrm{g}$ & $4.66 \mathrm{E}-05 \mu \mathrm{Ci} / \mathrm{g}$ \\
\hline Number of samples & 24 & 22 \\
\hline
\end{tabular}

It is important to emphasize that the plutonium is 140 times more concentrated in the solid phase than in the liquid phase. This is a clear indication that the plutonium has been precipitated out. This also shows that the complexants that have not degraded in tank 101-SY are not retaining the plutonium in the liquid phase. The implications are that the material in 101-SY could be sludge washed, with the liquid being low enough in plutonium for grout disposal. (Another consideration is americium, which is discussed in Section 6.4.) equation.

The concentration of the plutonium can be calculated by the following

$$
\frac{\mu C i}{g \text { sample }} \times \frac{C i}{10^{6} \mu \mathrm{Ci}} \times \frac{\mathrm{g} \mathrm{Pu}}{0.062 \mathrm{Ci}} \times \frac{\mathrm{g} \mathrm{sample}}{\mathrm{mL}} \times \frac{3785 \mathrm{~mL}}{\mathrm{gal}}=\frac{\mathrm{g} \mathrm{Pu}}{\mathrm{gal}}
$$

The average density for the tank is calculated from measurements on whole tank composites at $50{ }^{\circ} \mathrm{C}$ as $1.67 \mathrm{~g} / \mathrm{ml}$. Using $0.0128 \mu \mathrm{Ci} / \mathrm{g}$ leads to $0.00130 \mathrm{~g} \mathrm{Pu} / \mathrm{gal}$, which is well below the criticality prevention specification of $<0.05 \mathrm{~g} / \mathrm{gal}$. Using the surface level of 410 inches, this calculates out to $1,470 \mathrm{~g} \mathrm{Pu}$ in the entire tank. This is well below the total tank criticality limit of $50,000 \mathrm{~g} \mathrm{Pu}$.

The estimate based on Window $C$ data was $900 \mathrm{~g}$ of plutonium in the tank. The Window $C$ core data were not as complete as the Window $E$ data. The Window E data is more conservative. Both analysis lead to the same conclusions. The tank is well below tank criticality limits and the plutonium is found in the solid phase. 


\subsection{AMERICIUM INVENTORY ANALYSIS}

Figure 6-3 shows that the americium is preduininantly in the solid phase. Americium is approximately 10 times more prevalent in activity than plutonium. Therefore, the americium is the main concern for the specification of transuranic (TRU) waste. (TRU waste contains plutonium and americium in concentrations greater than $100 \mu \mathrm{Ci} / \mathrm{g}$.)

The solid-phase samples and bulk composite samples from Window $E$ were averaged with the bulk composite samples from Window $C$. The liquid samples from both cores were averaged together, as shown in Table 6-4. The average concentrations of americium are presented in Table 6-5.

The TRU limit is 100 nanoCi/g. The liquid portion of tank $101-S Y$ averages 0.751 nanoCi/g, which is definitely below TRU waste criteria. The solid phase is 180 nanoCi/g, which would classify the solid phase as TRU waste.

The implications are that waste, even though it is classified as complexed waste, may not necessarily need to have organic destruction in the pretreatment for glass. The waste in 101-sy may just need a solid-1iquid separation with no organic destruction step. 
Figure 6-3. Americium Concentrations.

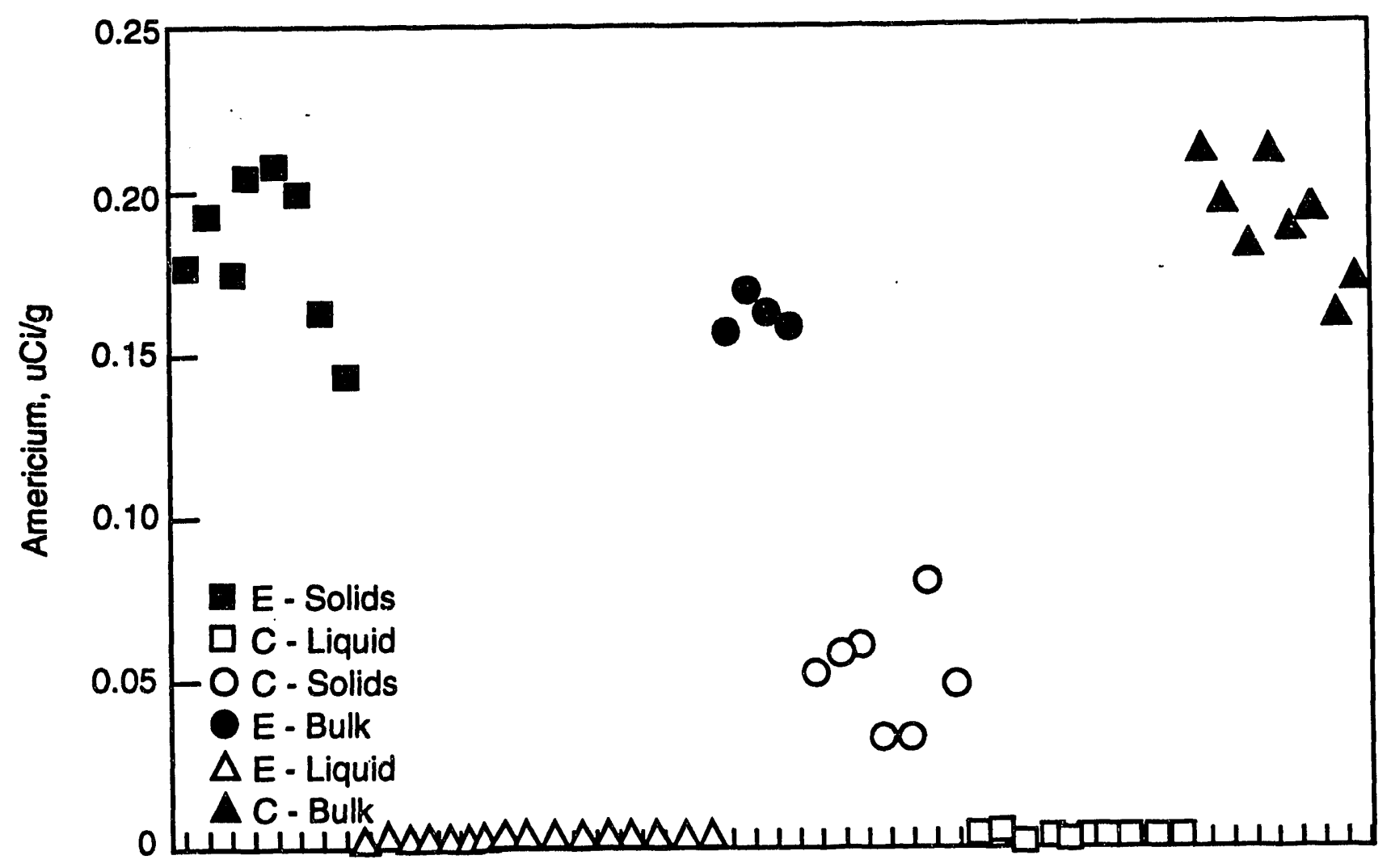

29301014.11 
Table 6-5. Average Concentrations of Americium.

\begin{tabular}{|l|l|l|}
\hline & \multicolumn{1}{|c|}{$\begin{array}{c}\text { Solid phase and bulk } \\
\text { composite samples }\end{array}$} & \multicolumn{1}{|c|}{ Liquid samples } \\
\hline Average & $0.18 \mu \mathrm{Ci} / \mathrm{g}$ & $0.000751 \mu \mathrm{Ci} / \mathrm{g}$ \\
\hline Standard deviation & 0.02016 & 0.000676 \\
\hline Maximum & $0.21 \mu \mathrm{Ci} / \mathrm{g}$ & $0.003 \mu \mathrm{Ci} / \mathrm{g}$ \\
\hline Minimum & $0.142 \mu \mathrm{Ci} / \mathrm{g}$ & $5 \mathrm{E}-05 \mu \mathrm{Ci} / \mathrm{g}$ \\
\hline Number of samples & 20 & 26 \\
\hline
\end{tabular}




\subsection{HEATING AND DILUTION TESTS}

The tank waste material from Window $E$ was used to test various mitigation concepts. To maximize the amount of information, a heating and dilution experimental matrix was established. Duplicate runs were made of the corner and central points. This section will attempt to take the information. generated and speculate on the effects for mitigation. Three levels of heating were used: $50^{\circ} \mathrm{C}, 65^{\circ} \mathrm{C}$, and $80^{\circ} \mathrm{C}$. Three levels of dilution were used: 0,15 , and 30 percent dilution by volume. Duplicate points brought the number of tests up to 14 . A weak hydroxide solution $(0.01 \mathrm{M})$ was used as a diluant to prevent precipitation of aluminum. Additional tests were made with $2 \mathrm{M} \mathrm{NaOH}$ solution as the diluant.

A composite of the various segments, representing the complete tank contents, was used for these tests. A $10-\mathrm{mL}$ aliquot of the homogenized composite was transferred to a 15-mL centrifuge cone. The weight and volume of the waste were determined. The diluent was added $(0,1.5$, or $3.0 \mathrm{~mL})$, the waste was mixed by shaking the cone with the manipulator. The cone was placed in a heated water bath at the appropriate temperature. The mixing was repeated every 30 minutes. The cone was kept in the water bath for about 3 hours to equilibrate.

The cone was then centrifuged at the selected test temperature for 7 minutes. The total weight and volume were recorded once more. Then the liquid phase, including any suspended solids, was decanted. The remaining weight and volume of centrifuged solids was measured. The weight is known more accurately than the volume. The weight and volume of the decanted liquid was calculated by difference. The centrifuged solids were sampled for percent water analysis and chemical analysis.

It should be pointed out that, in every case, a layer of foam was created on top of the sample as a result of centrifuging. The volume of the foam ranged from 0.3 to $0.8 \mathrm{~mL}$ ( 3 to $8 \%$ of the original sample volume). It is not possible to determine, from the measurements that were made, whether the entrained gas that produced the foam had always been present in the sample or became entrained during the homogenization process.

\subsection{RESULTS OF DILUTION STUDIES}

One of the proposed mitigation processes is to dilute the waste in Tank 241-SY-101. The effects of dilution only can be examined by studying the $50^{\circ} \mathrm{C}\left(122^{\circ} \mathrm{F}\right)$ runs. This is the temperature that is nearest to that found in the tank.

Dilution was tested at levels of $0 \%, 15 \%$, and $30 \%$. The maximum $30 \%$ was chosen because that is the greatest practical dilution possible in Tank 241-SY-101. To dilute tank 101-SY by $30 \%$, waste would have to be transferred to Tank 241-SY-103, which limits the amount of waste that can be moved. 
One of the chemicals in the waste is aluminum. Aluminum can form a gel-like substance at near neutral pHs. To prevent this from happening, the waste was diluted with $0.01 \mathrm{M} \mathrm{NaOH}$ solution. A smaller set was diluted with $2 \underline{M} \mathrm{NaOH}$ to see if there was any difference.

When dilution liquid is added to the waste, all of the densities decrease (see Figure 7-1). This is expected for the liquid and bulk samples. The solid layer density also decreases, but very slightly. Figure 7-1 shows that the bulk density before and after centrifuging changes because of the released foam. The after-centrifuging densities fit between the liquid layer density and the solid layer density, as they should.

Figure 7-2 shows the density of the liquid phase and the solid phase with various dilutions. Both the dilution with $0.01 \mathrm{M} \mathrm{OH}^{-}$and $2 \mathrm{M} \mathrm{OH}^{-}$are

included. The $2 \mathrm{M} \mathrm{OH}$ dilutions appear to fit well with the other values. The lines are linear regressions to fit the data. The parameters for these curves are in Table 7-1.

The low $R$ squared value for the solid phase indicates that the regression does not correlate very much variability. It would probably be correct to use the overall average value of $1.77 \mathrm{~g} / \mathrm{mL}$. However, the equation was used for the remainder of the section.

The regression equations were used to estimate the void fraction needed to bring the solid phase into neutral buoyancy with the liquid fraction. Three dilutions were compared: $0,10 \%$, and $30 \%$. The $0 \%$ will give an indication of what is now necessary for neutral buoyancy.

Table 7-2 shows the results of the calculations along with the estimated $95 \%$ confidence interval. There is a large confidence interval for the solids density, which is apparent from the data in Figure 7-2. The void fraction varies from 0.1 at $0 \%$ dilution to 0.16 at $30 \%$. This shows that more gas per solid particle needs to be trapped in the diluted waste.

Volumes are not reported in Herting (1992a). However, there is a weight $\%$ solids value that can be used to estimate volumes. Figure $7-3$ shows how the weight \% solids decrease with increasing dilution. This indicates that solids are being dissolved with the dilution. Indications also are that there are less solids but the solids need a larger void fraction of gas to be at neutral buoyancy. These are offsetting effects.

To see which phenomenon will have the greatest effect, the following analysis was performed. Assume that there are $100 \mathrm{~g}$ of sample (this includes any dilution). The weight \% solid and the liquid and solid densities can be used to estimate the volumes of each layer. To reach neutral buoyancy, the solid volume needs to expand by the void fraction found in Table 7-2. The expanded solid layer plus the liquid layer would give the estimated volume of a 100-g sample when a burp is possible.

Table 7-3 shows the result of this analysis. Note that the total volume increases with increasing dilution. 
WHC-EP-0628

Figure 7-1. Density Change With Dilution at $50{ }^{\circ} \mathrm{C}$.

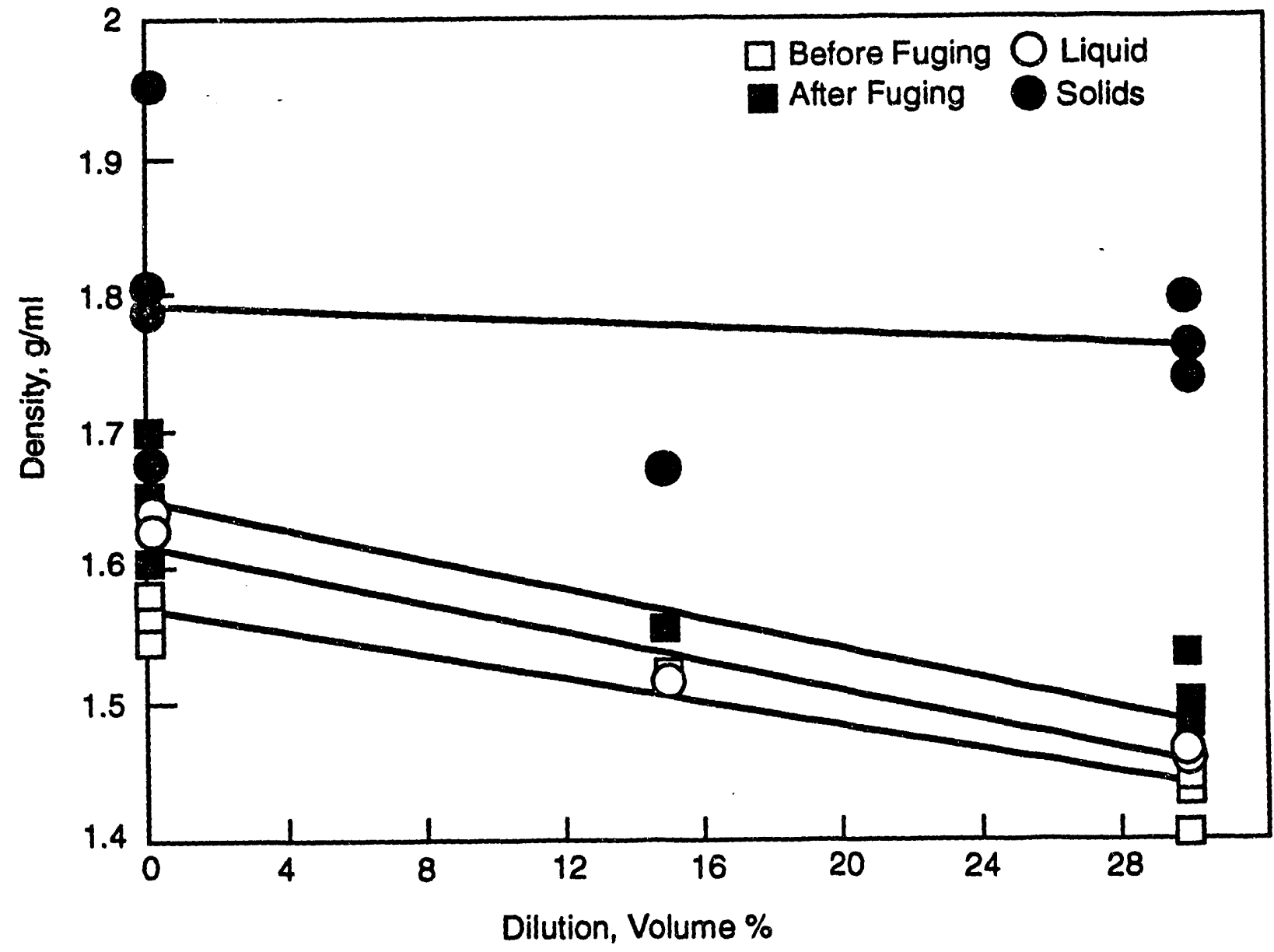

29301014.10 
WHC-EP-0628

Figure 7-2. Core "E," $50{ }^{\circ} \mathrm{C}$ Dilution Data on Density.

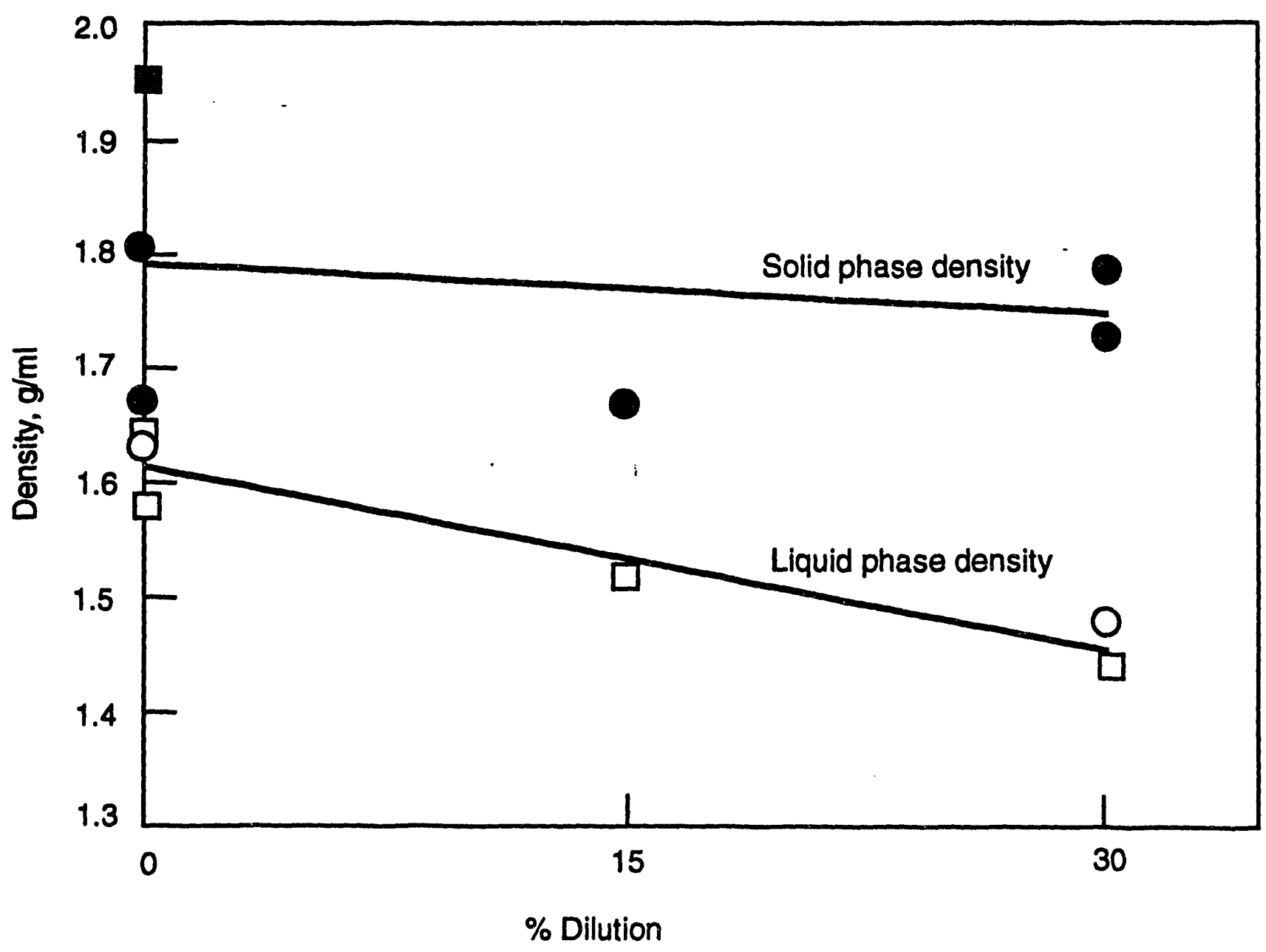

29301014.9 
WHC-EP-0628

Table 7-1. Regression Coefficients for Curves in Figure 2.

\begin{tabular}{|l|c|c|}
\hline & Liquid phase & Solid phase \\
\hline Intercept & 1.611 & 1.79 \\
\hline Slope & -.00511 & -.00122 \\
\hline R squared & 0.905 & 0.036 \\
\hline
\end{tabular}

Table 7-2. Void Fraction in Solid Phase Needed to Reach Neutral Buoyancy.

\begin{tabular}{|l|l|l|l|}
\hline \multicolumn{1}{|c|}{ Dilution } & $0 \%$ & $10 \%$ & $30 \%$ \\
\hline Liquid density & 1.61 & 1.56 & 1.46 \\
\hline $95 \%$ Confidence interval & 0.080 & 0.075 & 0.080 \\
\hline Solid density & 1.79 & 1.78 & 1.75 \\
\hline $95 \%$ Confidence interval & 0.253 & 0.238 & 0.253 \\
\hline Void Fraction & 0.096 & 0.12 & 0.16 \\
\hline $95 \%$ Confidence interval & 0.0029 & 0.0028 & 0.0028 \\
\hline
\end{tabular}

Table 7-3. Estimated Volumes of a 100-g Sample (Diluted).

\begin{tabular}{|l|c|c|c|}
\hline \multicolumn{1}{|c|}{ Dilution } & $0 \%$ & $10 \%$ & $30 \%$ \\
\hline Weight \% solids & 25.85 & 23.21 & 17.92 \\
\hline Liquid volume, mL & 46.0 & 49.2 & 56.3 \\
\hline Solid volume, mL & 14.4 & 13.1 & 10.2 \\
\hline Expanded solid volume, mL & 16.0 & 14.9 & 12.3 \\
\hline Total volume, $\mathrm{mL}$ & 62. & 64.1 & 68.6 \\
\hline Std Dev & 1.5 & 1.52 & 1.77 \\
\hline
\end{tabular}


Figure 7-3. Core "E," $50^{\circ} \mathrm{C}$ Dilution Data on Weight \% Solids.

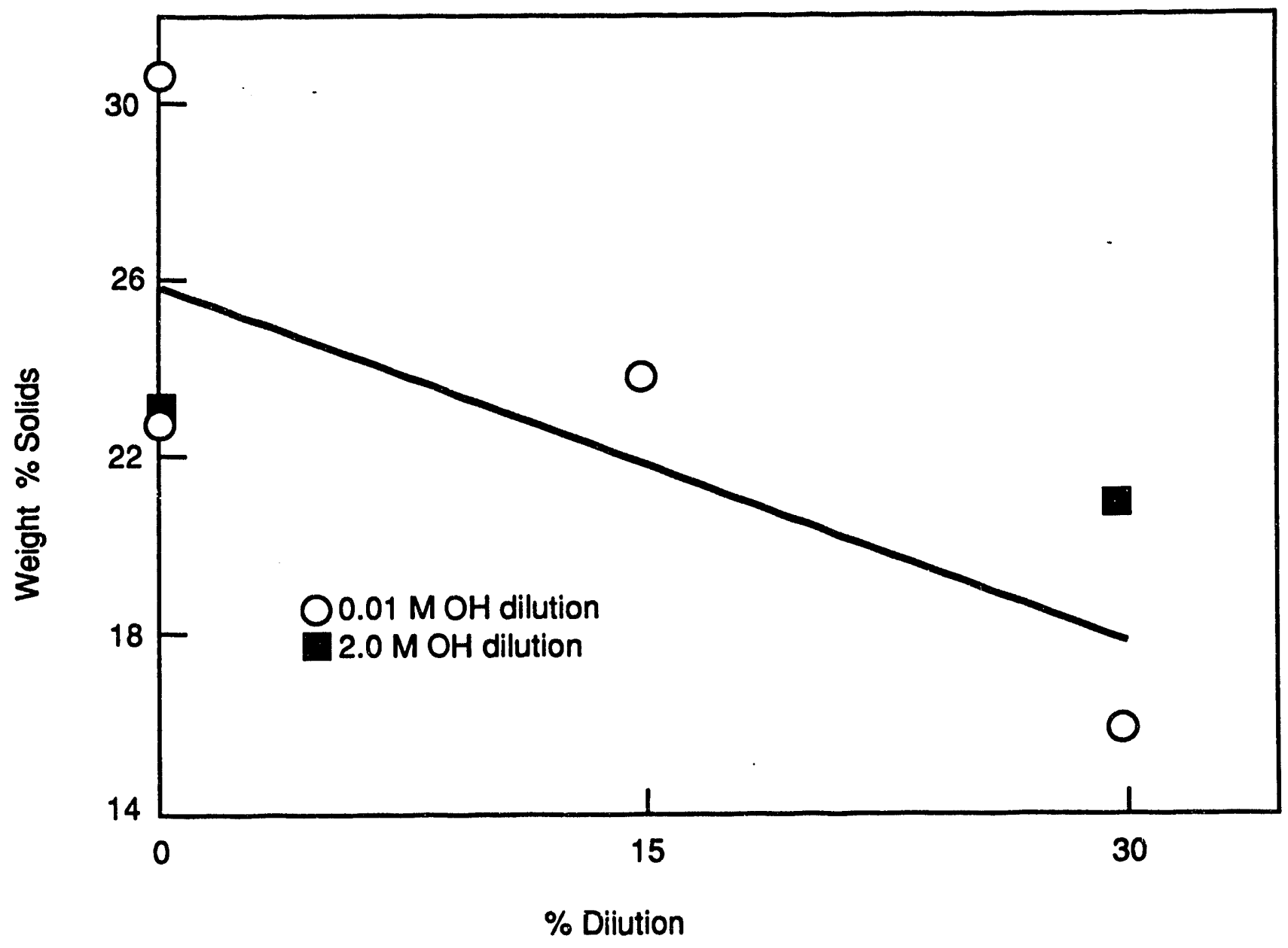

29301014.8 
To relate this back to tank 101-SY, if undiluted waste were at 400 inches after a gas release event, the surface level would reach 410.5 inches before another gas release event is possible. If the tank were diluted by $10 \%$, the tank would be at 440 inches after a gas release. The surface level would reach 452.7 inches before the next gas release event would be possible. The undiluted waste would grow 10.5 inches while the waste diluted $10 \%$ would grow 12.7 inches.

The volume decrease in the solids layers is an indication that the solids are being dissolved in the diluent. The solids layer was analyzed-for some basic chemical species. The chemical analysis indicated that dilution decreased the amount of aluminum, nitrite, and phosphate in the solid portion. Nitrite and phosphate are readily water-soluble compounds. Aluminum is most likely present in the aluminate phase. It was not expected to dissolve as readily as it did. Water increased in the solid layer. The increase in water may be an indication that the solids do not pack as tightly at higher dilutions.

The major point that is not known is how the dilution affects the physical properties. If the viscosity or shear strength were to decrease with dilution, the gas may not accumulate in these large quantities, the gas may release at approximately the rate of generation. Tanks with densities of less than 1.4 seem to not accumulate gas. Without the physical property information, it appears that there is no benefit for the modest amount of dilution that was studied.

\subsection{HEATING ONLY}

Those data that did not have any dilution allow the effect of increasing only the temperature to be seen. Those samples in the $2 \mathrm{M} O H$ dilution matrix can be freely used, as the no dilution option is the same material that is in the other matrix.

\subsubsection{Physical Properties}

Physical properties such as density, viscosity, and shear strength were measured at different temperatures. The physical properties are important to the mechanism within the tank.

The densities were measured for the bulk slurry, the liquid phase, and the solid phase after centrifuging. The results are shown in Figure 7-4. A statistical $F$ test was performed on the data, which indicated that the densities had too weak a correlation with temperature to be dependably defined. The scatter at each temperature was larger than the effect of temperature.

The weight $\%$ solid phase, shown in Figure 7-5, al so had no apparent temperature dependency. The scatter was larger than the trend.

The viscosity was measured as a function of shear rate at four temperatures. The most important of these shear rates are low shear rates, which the waste experiences during rollovers. The rates are low enough to 
WHC-EP-0628

Figure 7-4. Temperature Effects Only on Tank 101-SY Densitv.

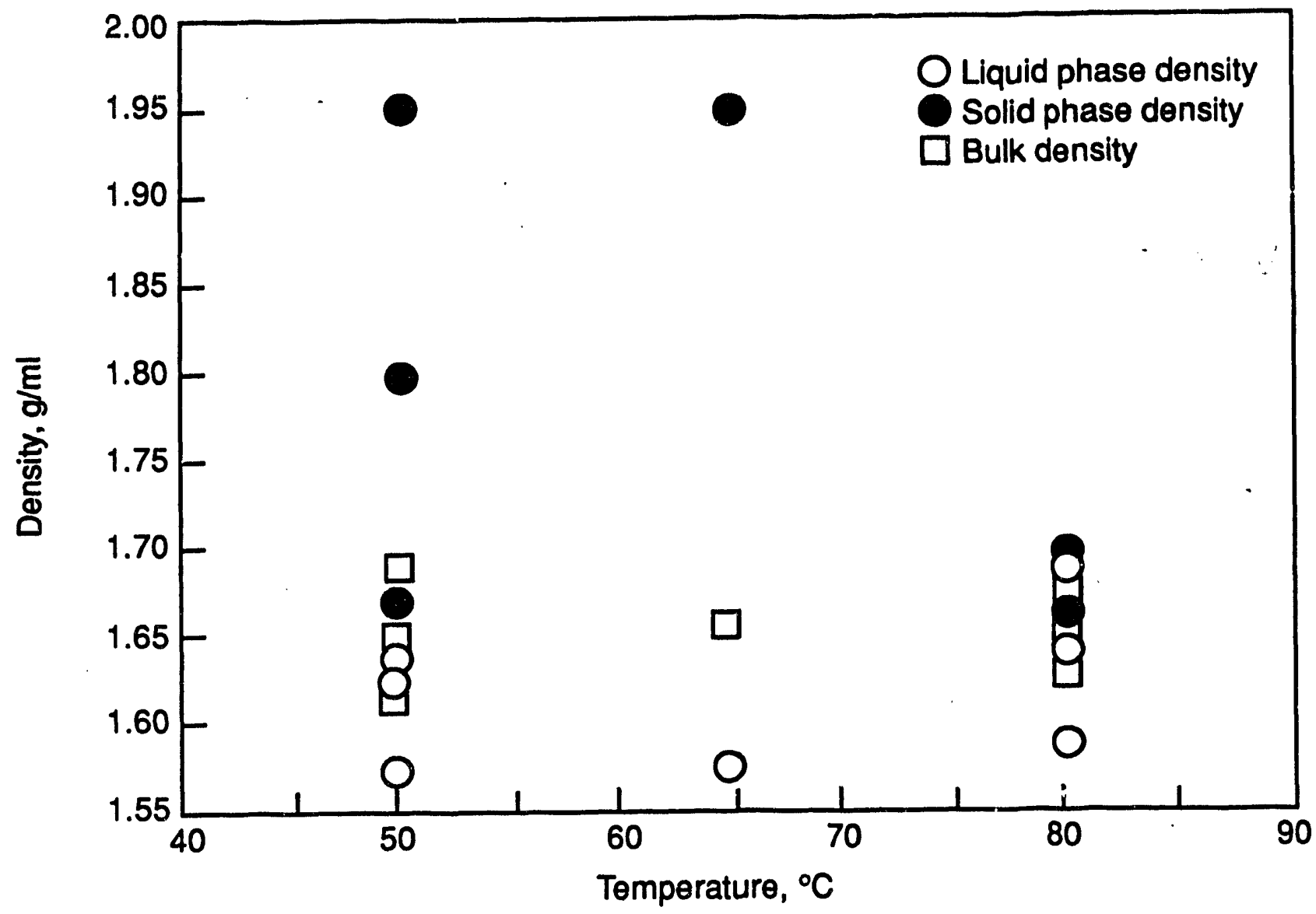

29301014.7 
Figure 7-5. Temperature Effect Only on Tank 101-SY Sarnples.

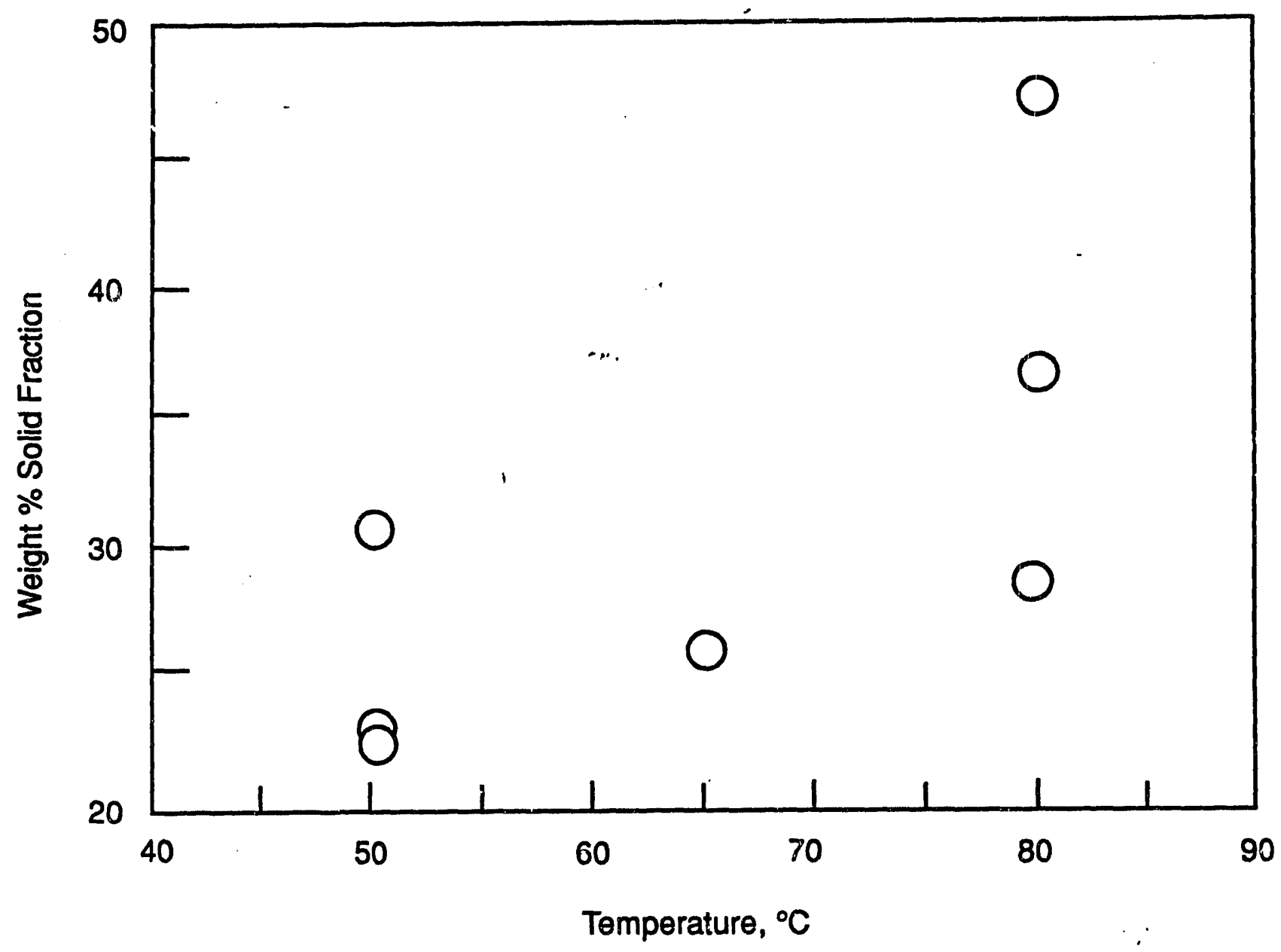

29301014.6 
remain in laminar flow. The viscosity of the nonconvective layer is also important. Results for both Window $C$ and Window $E$ cores agree that the viscosity of the nonconvective layer at low shear rates is very high; $50,000 \mathrm{cp}$ is a common value. The effect of temperature is mixed, depending on which segment is examined. Some segments show a decrease in viscosity with temperatures, but not all. The temperature effect is relatively small; a factor of 5 seems to be about the largest change in viscosity. The nonconvective layer shows that, at shear rates of less than $250 \mathrm{rpm}$, the viscosity does not drop less than 1,000 cp at any temperature.

The nonconvective layer tends to behave as a solid until a certain force is reached and then the layer behaves as a liquid. There were two measurements made of the force needed to start the layer moving. A shear vane type spindle was inserted into the waste, and the force needed to start this turning is recorded as Yield Strength. When viscosity measurements are made, the force necessary to start the cone and plate spindle moving is reported as Yield Stress. Both are measurements of the initial force needed to cause the solid to flow. The yield stress is reported in units of Pascals $(\mathrm{Pa})$, and the yield strength is in units of dynes $/ \mathrm{cm}^{2}$. Pascals may be converted to dynes $/ \mathrm{cm}^{2}$ by multiplying by 10 .

The yield strength (measured by the shear vane) is shown in Figure 7-6. The yield strength is very sensitive to temperatures between 30 and $50{ }^{\circ} \mathrm{C}$. Above $50{ }^{\circ} \mathrm{C}$ it tends to level out. There is enough scatter in the data that a clear temperature trend above $50{ }^{\circ} \mathrm{C}$ is not seen. The yield stress (as measured by the cone and plate) does not show a clear trend with temperature (Figure 7-7). The trend would imply that the scatter of data may decrease with temperature, but the yield stress does not change.

Overall, there is no indication that heating above $50{ }^{\circ} \mathrm{C}$ will decrease the force necessary to move the nonconvective layer. Indeed, there is no indication from any of the physical measurements that heating will cause enough of a change to mitigate the tank.

\subsubsection{Chemical Changes}

Increasing the temperature does change the chemical composition of the nonconvective layer. It is not fully understood what the chemical composition changes mean to mitigation.

Water in the solid phase is the largest change. Figure 7-8 shows that the weight $\%$ water increases from about $30 \%$ to about $34 \%$. This may be an indication that the solids do not pack as tight at a higher temperature and when there is more interstitial liquid.

Aluminum also changes quite dramatically. The weight $\%$ aluminum in the solid phase goes from $4.2 \%$ at $50{ }^{\circ} \mathrm{C}$ to $3.2 \%$ at $80^{\circ} \mathrm{C}$ (Figure $7-9$ ). Sodium aluminate should not be quite this temperature sensitive.

Sulfate and TOC also change with temperature. The sulfate in the solid phase decreases slightly with increasing temperature (Figure 7-10). It is al so noteworthy that the TOC increases with temperature, to over 0.5 weight $\%$ 
WHC-EP-0628

Figure 7-6. Tank 101-SY Yield Strength.

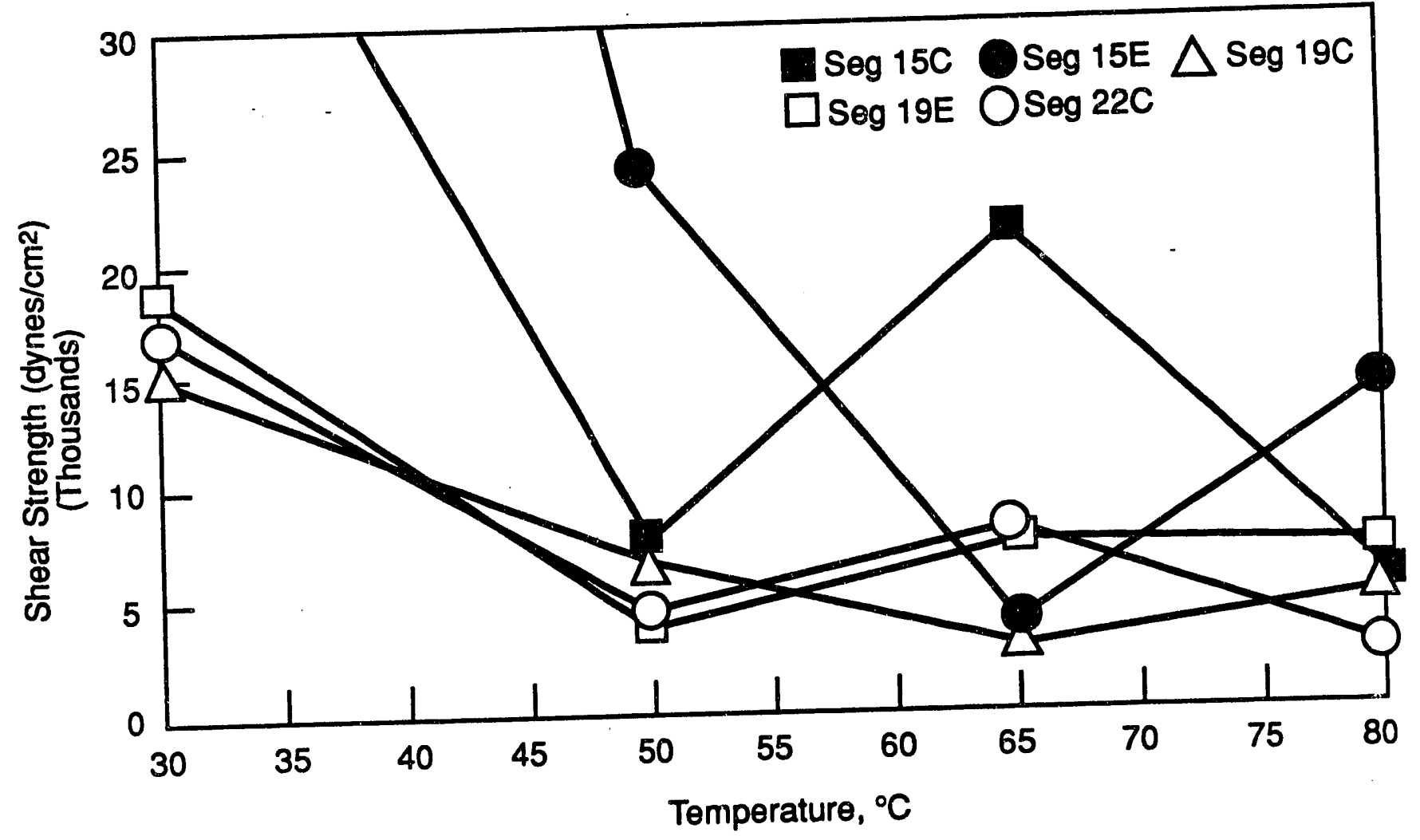

29301014.5 
WHC-EP-0628

Figure 7-7. Tank 101-SY Nonconvective Layer Yield Stress.

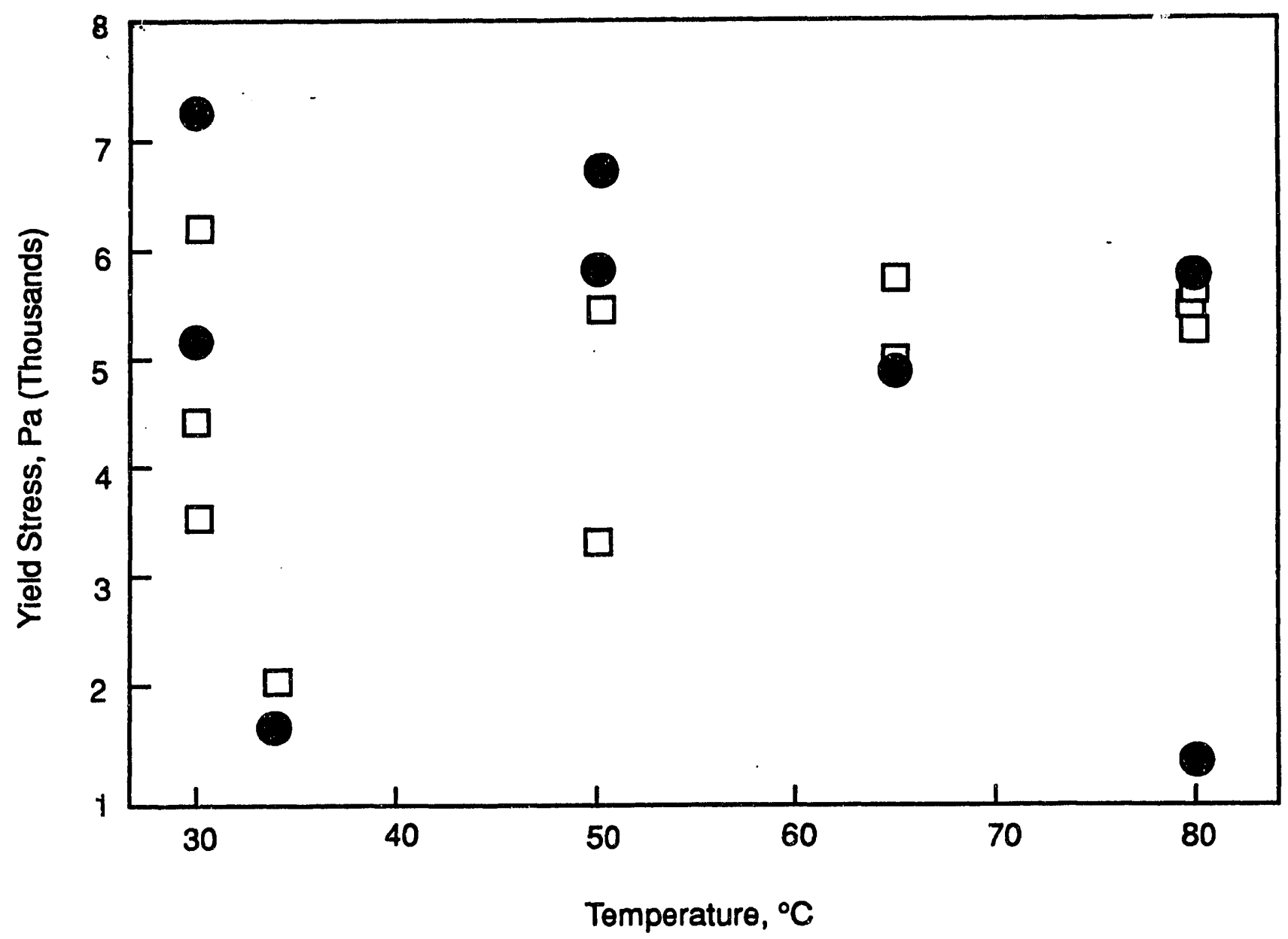

29301014.4 
WHC-EP-0628

Figure 7-8. Temperature Effect on Water in Solid Phase.

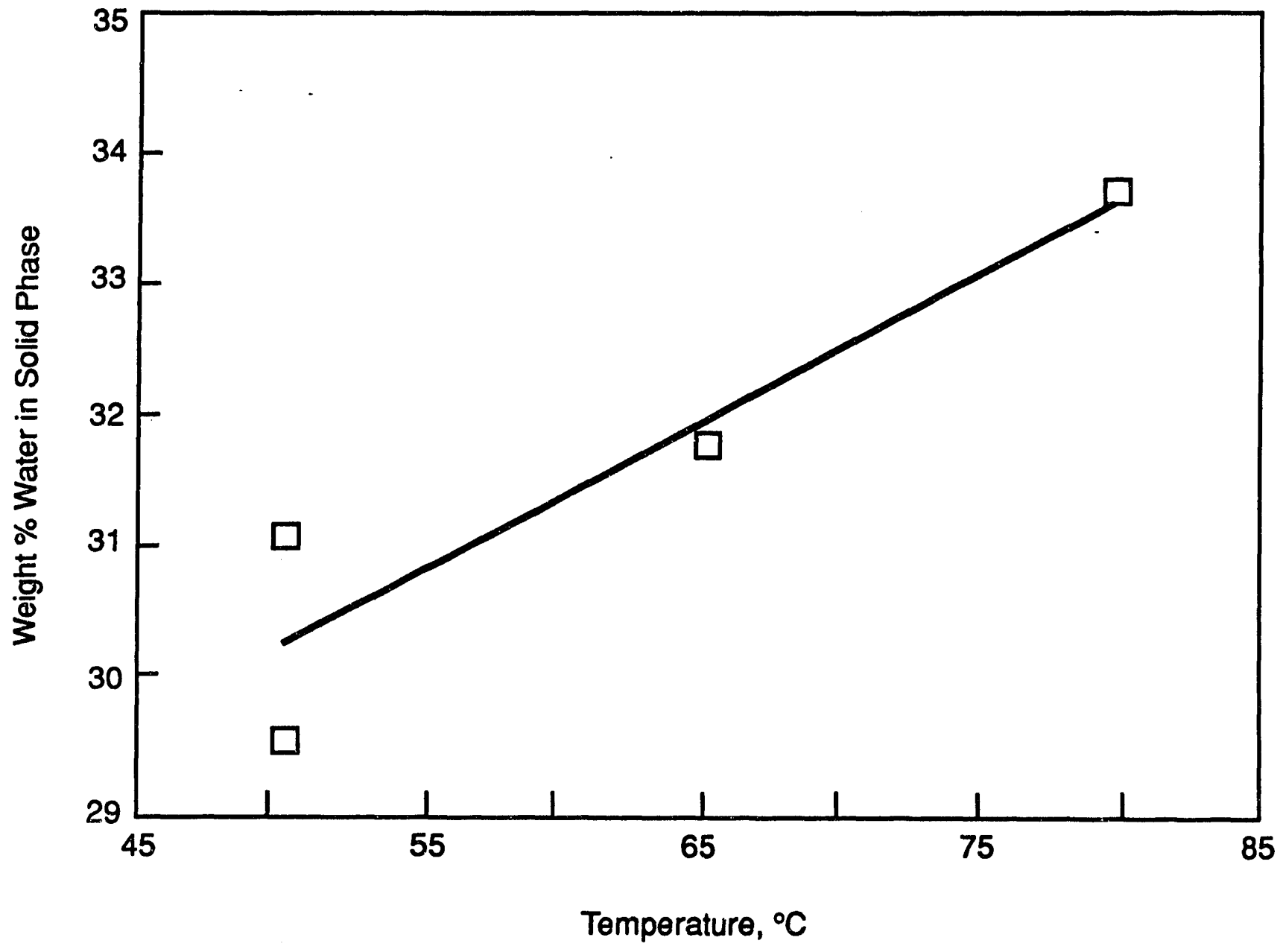

29301014.3 
WHC-EP-0628

Figure 7-9. Temperature Effect on Tank 101-SY Solid Composition.

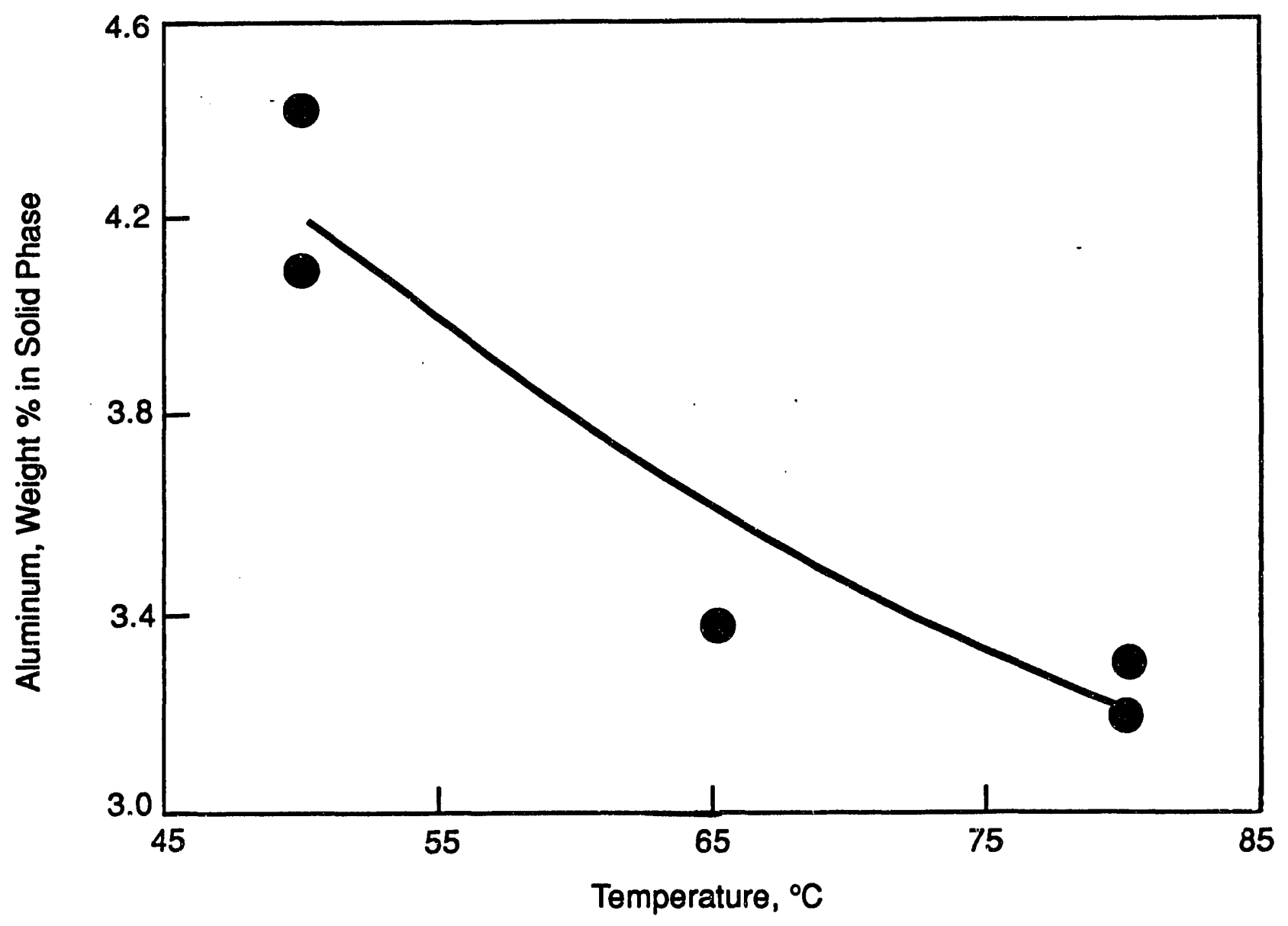

29301014.2 
WHC-EP-0628

Figure 7-10. Temperature Effect on Composition of Solid Waste.

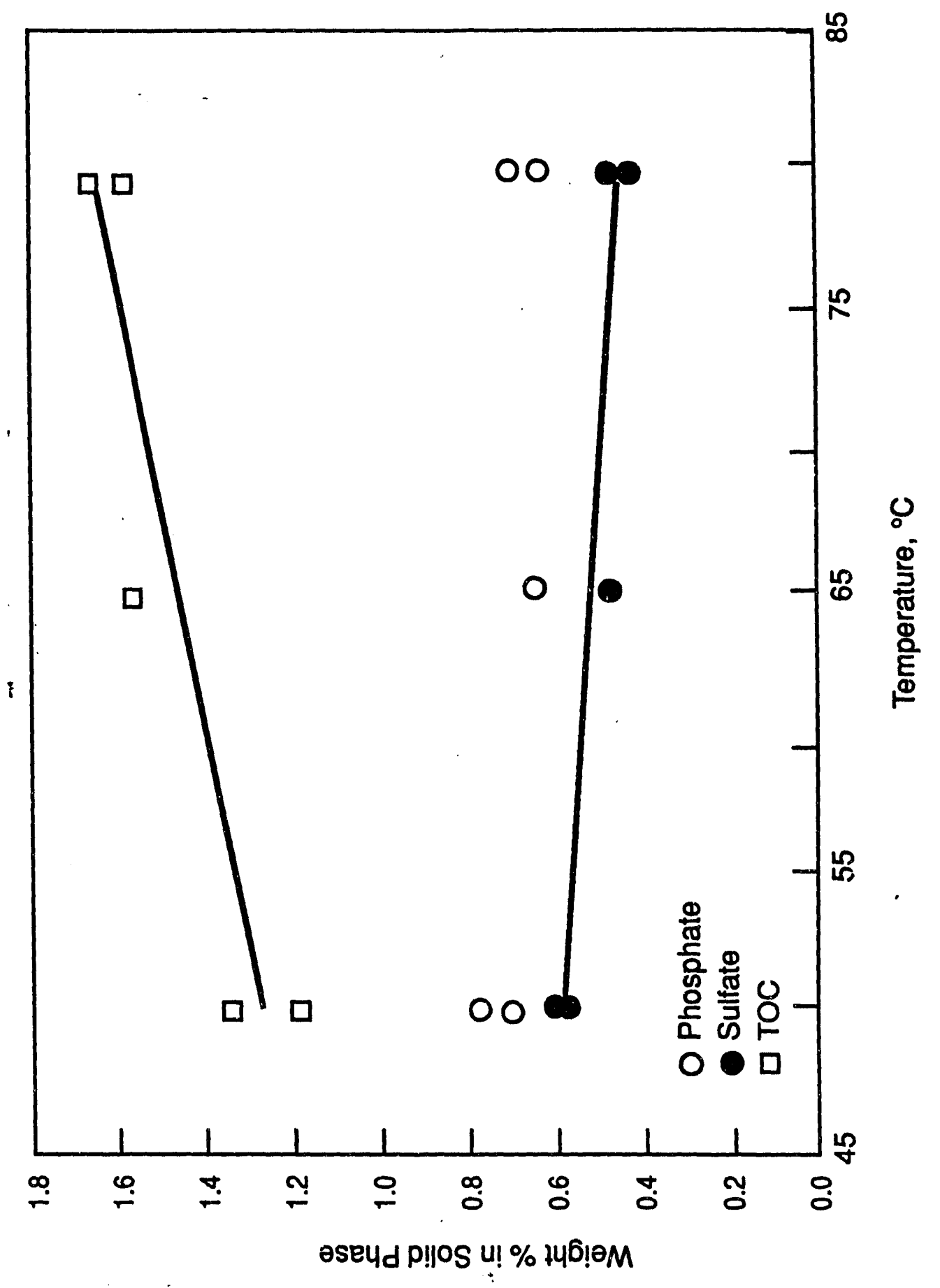

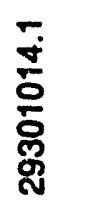

$7-15$ 
with the $30{ }^{\circ} \mathrm{C}$ change in temperature. The reason and meaning of this is unknown.

Sodium, nitrate, nitrite, and phosphate did not have a large enough change with temperature alone to be statistically important.

In general, the effects of heating alone are not great and probably are too small to be of use for mitigating the tank.

\subsection{HEATING AND DILUTION}

The effect of simultaneous heating and dilution is represented by this whole study. The figures in Herting (1992a) on the solid phases were somewhat confusing. The data were used in a Kriging method to get "fishnet" plots. Figure 7-11 shows the solid phase density plot. The weight \% solid phase is shown in Figure 7-12. These plots show relatively smooth planes, which makes clearer the trends in heating and dilution.

\subsubsection{Regression}

The density, weight \% solids, and chemical composition data were used with a multiple i inear regression technique to derive equations for the various planes. All the composite data, including the $2 \mathrm{M}$ caustic dilution data, were used in these analyses.

Both forward and backward regression techniques were used. The various effects tested were temperature, temperature squared, $\%$ dilution, \% dilution squared, and temperature times dilution. The experimental design was laid out as a factorial experiment so that all of these effects are orthoginal. To test whether or not an effect was statistically important an $F$ test was preformed. If a factor had an effect less than $F=3.1$, it was not considered important. This is approximately an $F$ test of 4 and 11 degrees of freedom at 95\% confidence. Most of the time both the forward and backward regressions gave the same result.

The following equations were derived:

$$
\begin{aligned}
& \text { Liquid density }_{\text {dig }}=1.59-0.005 * 8 \mathrm{Dil} / \mathrm{n}+7.27 \mathrm{E}-06 * \mathrm{~T}^{2} \\
& \text { Solid density }=1.92-0.000035 * \mathrm{~T}^{2}-0.000059 * \mathrm{~T} * 8 \mathrm{Dil} / \mathrm{n} \\
& W t z_{\text {Bolids }}=11.00+0.004 * \mathrm{~T}^{2} \\
& \mathrm{TOC}=-1.23+0.077 * \mathrm{~T}-0.00051 * \mathrm{~T}^{2} \\
& +.029 * 8 \mathrm{Dil} / \mathrm{n}-.00046 * \mathrm{~T} * 8 \mathrm{Dil} / \mathrm{n}
\end{aligned}
$$


WHC-EP-0628

Figure 7-11. Solid Phase Density.

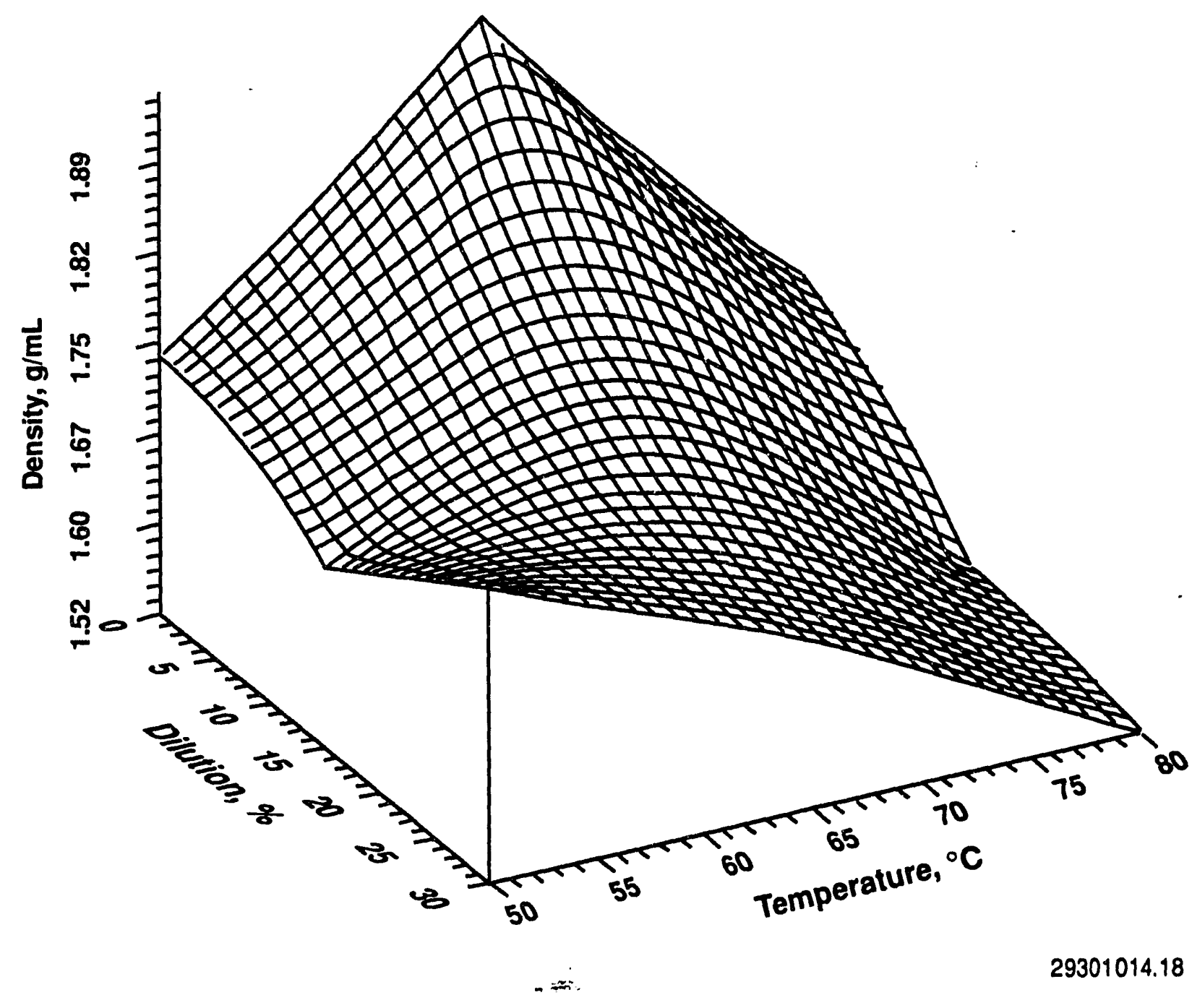


WHC-EP-0628

Figure 7-12. Weight \% of Solid Phase.

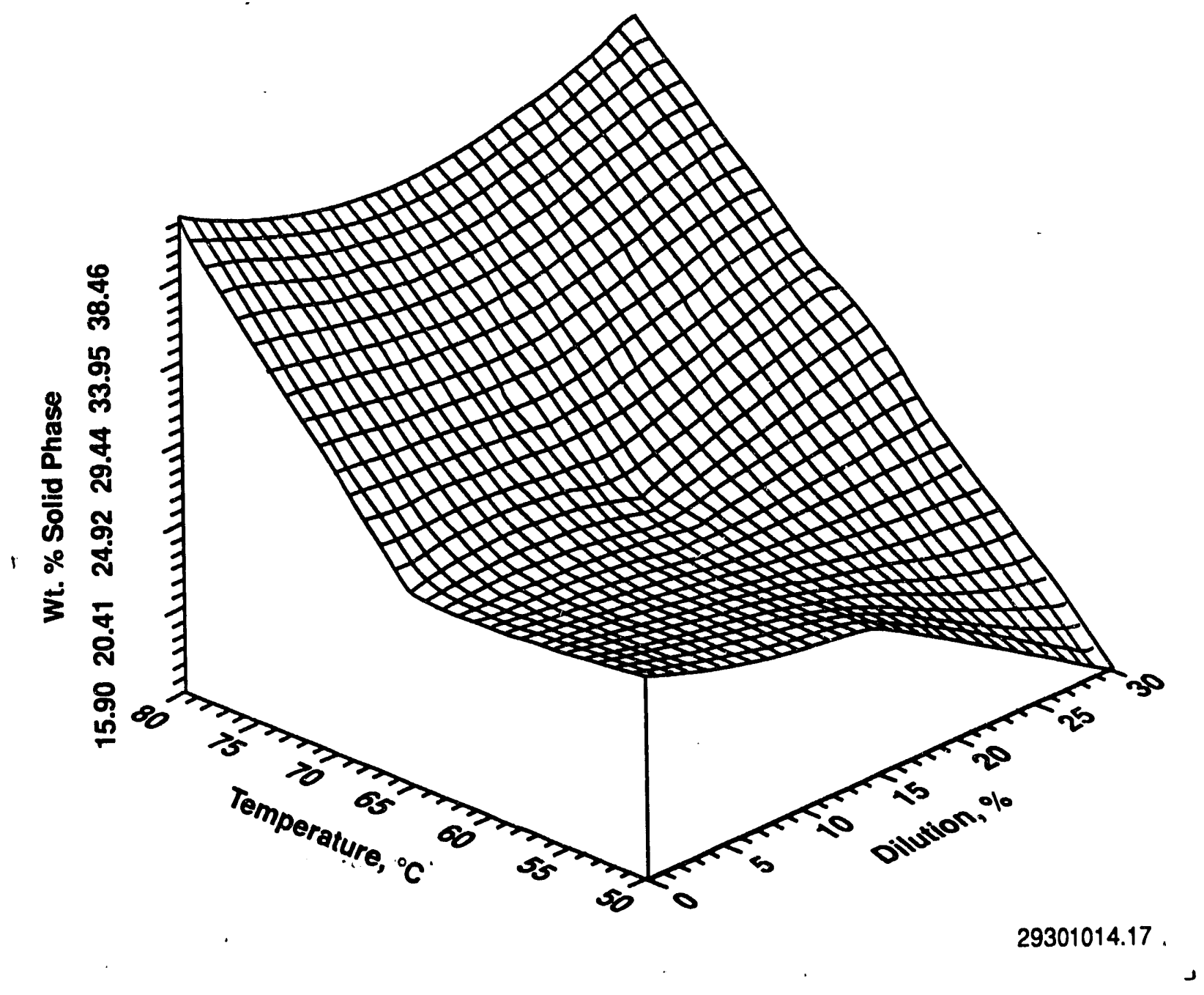




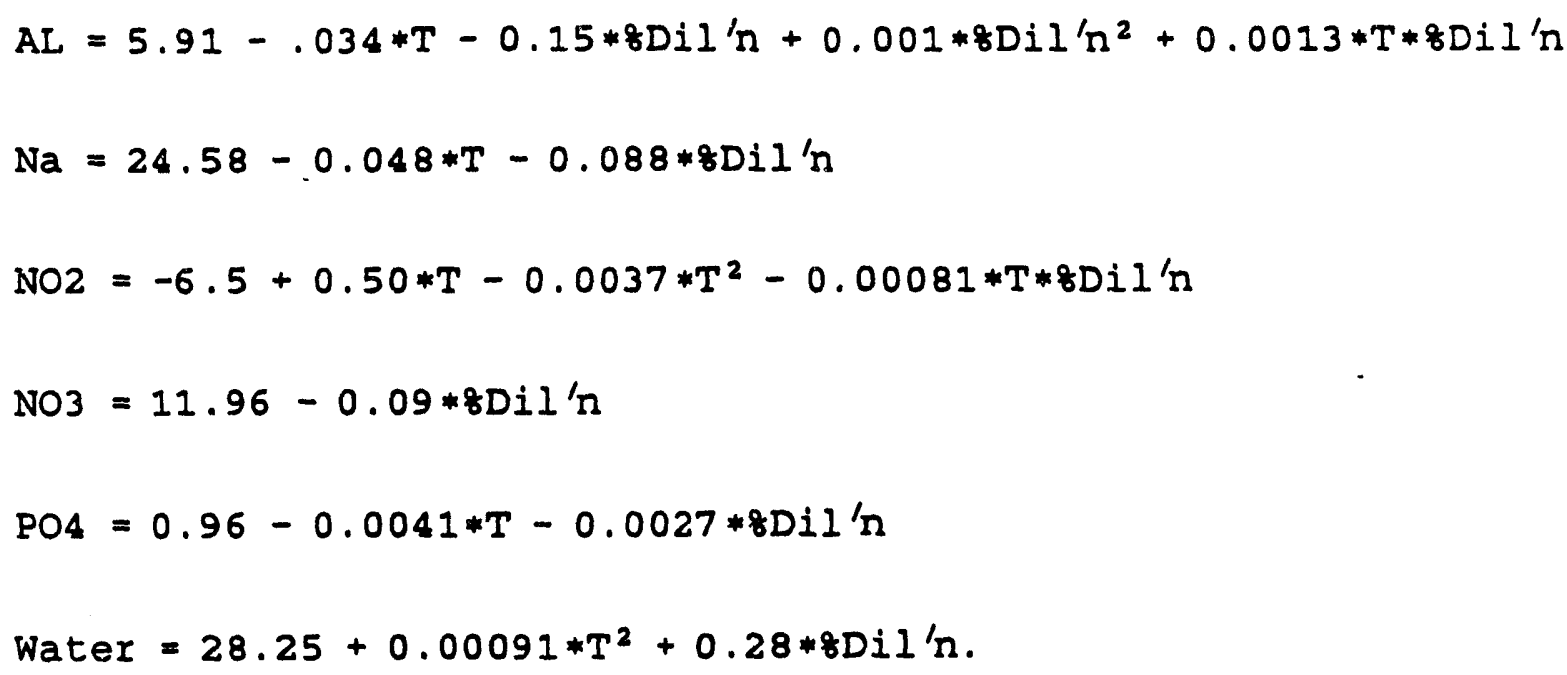

The density and weight $\%$ solids equations were used to test the effect of both heating and dilution.

The results are shown in Table 7-4, along with similar analyses using just the average data for $50^{\circ} \mathrm{C}, 0 \%$ dilution, and $80^{\circ} \mathrm{C}, 30 \%$ dilution.

Table 7-4. Heating/Dilution Effects Assuming 100-g Sample.

\begin{tabular}{|l|c|c|c|c|}
\hline & $\begin{array}{c}50^{\circ} \mathrm{C}, 0 \% \text { dil'n } \\
\text { Regression }\end{array}$ & $\begin{array}{c}50^{\circ} \mathrm{C}, 0 \% \text { dil 'n } \\
\text { Avg. Data }\end{array}$ & $\begin{array}{c}80^{\circ} \mathrm{C}, 30 \% \text { dil 'n } \\
\text { Regression }\end{array}$ & $\begin{array}{c}80^{\circ} \mathrm{C}, 30 \% \text { dil' } n \\
\text { Avg. Data }\end{array}$ \\
\hline $\begin{array}{l}\text { Liquid Phase } \\
\text { Density }\end{array}$ & 1.60 & 1.61 & 1.48 & 1.48 \\
\hline $\begin{array}{l}\text { Solid Phase } \\
\text { Density }\end{array}$ & 1.83 & 1.81 & 1.56 & 1.56 \\
\hline $\begin{array}{l}\text { Wt\% Solid } \\
\text { Phase }\end{array}$ & 21.4 & 24.9 & 37.4 & 37.9 \\
\hline $\begin{array}{l}\text { Weight Liquid } \\
\text { Phase, g }\end{array}$ & 78.6 & 75.1 & 62.6 & 62.0 \\
\hline $\begin{array}{l}\text { Weight Solid } \\
\text { Phase, g }\end{array}$ & 21.4 & 25.0 & 37.4 & 38.0 \\
\hline $\begin{array}{l}\text { At Neutral } \\
\text { Buoyancy }\end{array}$ & & & & 41.9 \\
\hline $\begin{array}{l}\text { Volume Liquid } \\
\text { Phase, mL }\end{array}$ & 49.0 & 46.5 & 42.2 & 25.7 \\
\hline $\begin{array}{l}\text { Volume Solid } \\
\text { Phase, mL }\end{array}$ & 13.3 & 15.5 & 25.3 & 67.6 \\
\hline Total Volume, mL & 62.3 & 61.9 & 67.5 & \\
\hline
\end{tabular}


WHC-EP-0628

Both the equations and the data tell essentially the same story (e.g., that heating and dilution will increase the volume of the waste when the solid phase is at neutral buoyancy ready to burp). This could mean that the tank would have larger gas release events than those that currently occur. 


\subsection{SUMMARY AND RECOMMENDATIONS}

The indications from Window $E$ are that heating and dilution, alone or together, will not remediate the gas activity in the tank. There are several factors to be considered. Dilution will ultimately remediate the gas release events. All tank farm experience shows that if the specific gravity is below about 1.4 then the gases cannot be trapped. This would require more than the $30 \%$ dilution that was studied in this test. Also unknown is the effect of dilution on the rheology of the waste. Dilution may change the viscosity and yield strength such that gases are not trapped. This was not studied.

The synthetic waste that has been used for various purposes is very much like the real waste for the major components. The two major minor components that may have an affect on the behavior is the noble metals and the correct organic molecules. However, the correct organic molecules are still mostly unknown. Further work identifying those molecules will be necessary for good synthetic waste studies.

The physical properties are important for modeling and equipment design. There are still several areas where physical properties are not known as well as would be desirable. Some of this stems from the fact that the samples are cooled, extruded, composited, etc. prior to the measurements. A number of the physical properties are sensitive to the prior history of the samples.

The heating and dilution studies did not report the physical properties. These are important as heating and dilution are expected to effect the physical properties greatly. Those physical properties should be measured.

When other tanks in the flammable gas program are core sampled, the cores should not be analyzed segment by segment. Each fascie should be composited and the composites should be analyzed. There is very little practical data from the volatile and semi-volatile organic analysis. These should not be done. The physical properties capabilities should be improved. The physical properties are necessary for equipment design and modeling. 
WHC-EP-0628

This page intentionally left blank. 


\subsection{REFERENCES}

Herting, D. L., D. B. Bechtold, B. E. Hey, B. D. Keele, L. Jensen, T. L. Welsh, 1992a, Laboratory Characterization of Samples Taken in December 1991 (Window E) from Hanford Waste Tank 241-SY-101, WHC-SD-WM-DTR-026, Westinghouse Hanford Company, Richlard, Washington.

Herting, D. L., D. B. Bechtold, B. A. Crawford, T. L. Welsh, L. Jensen, 1992b, Laboratory Characterization of Samples Taken in May 1.991 from Hanford Waste Tank 241-SY-101, WHC-SD-DTR-024, Westinghouse Haniord Company, Richland, Washington.

Reynolds, D. A., 1992, Tank 101-SY Window C Core Sample Results and Interpretation, WHC-EP-0589, Westinghouse Harford Company, Richland, Washington. 
WHC-EP-0628

This page intentionally left blank. 
WHC-EP-0628

APPENDIX A

A- $i$ 
WHC-EP-0628

This page intentionally left blank.

A- $i \mathbf{i}$ 


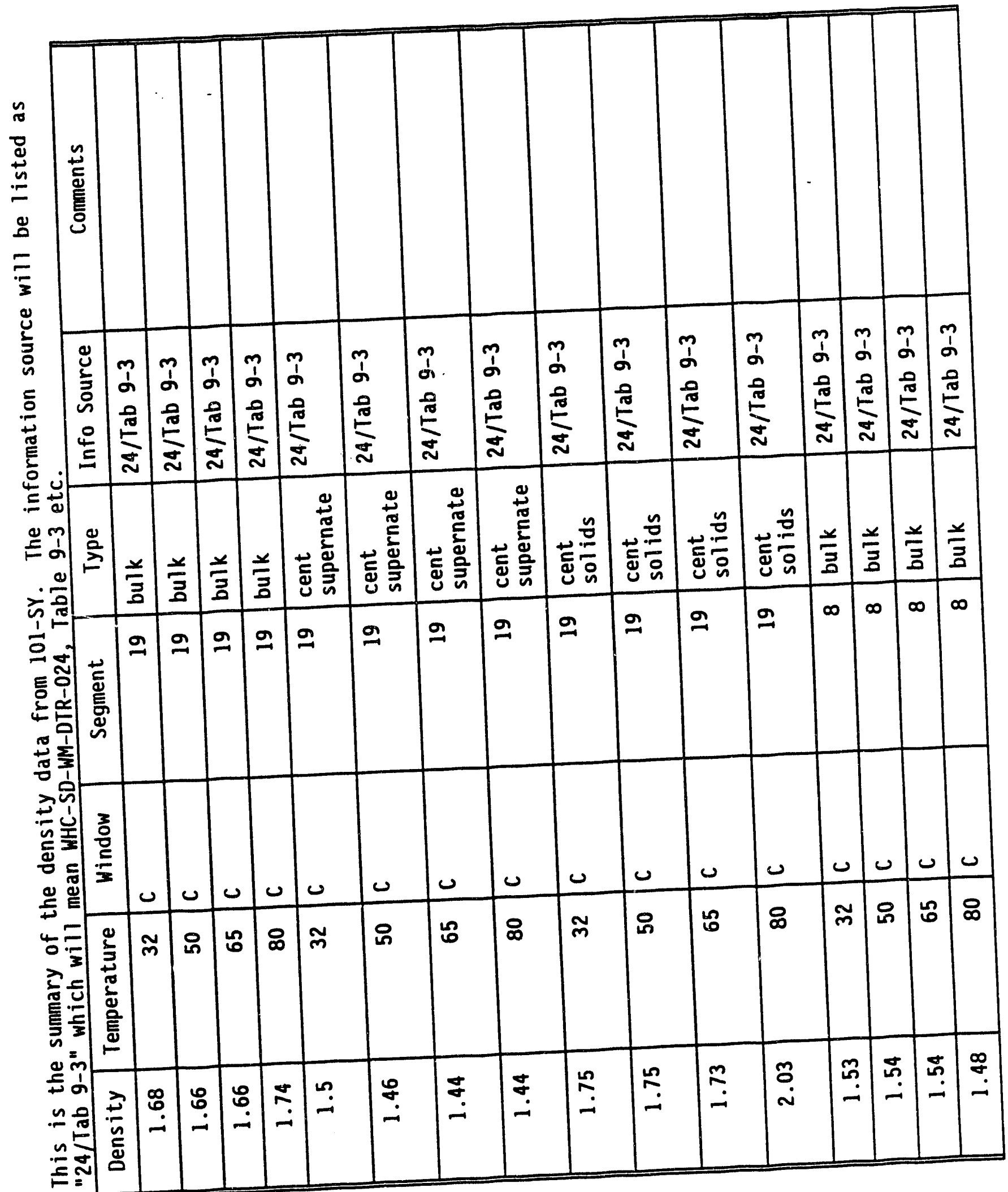




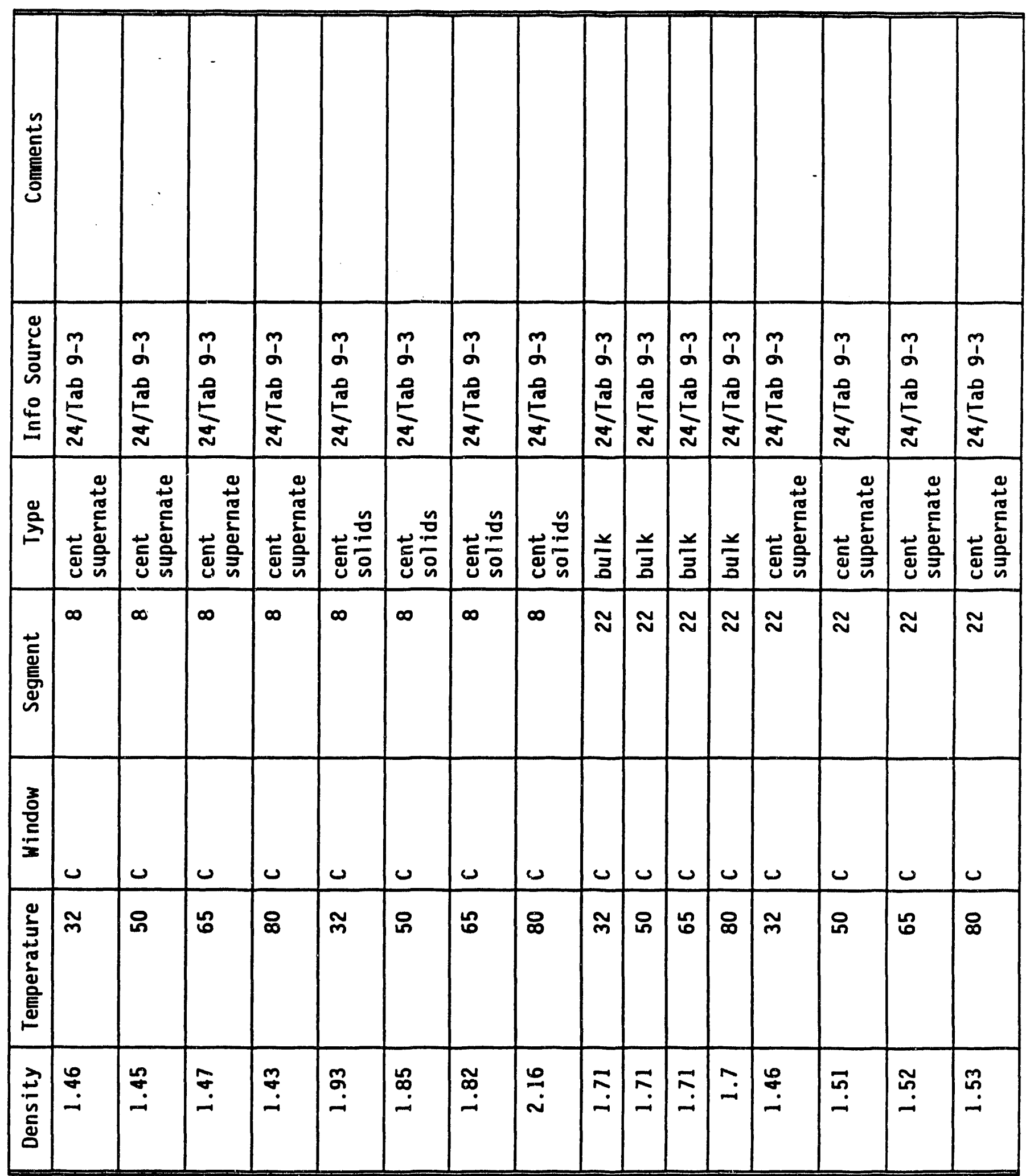




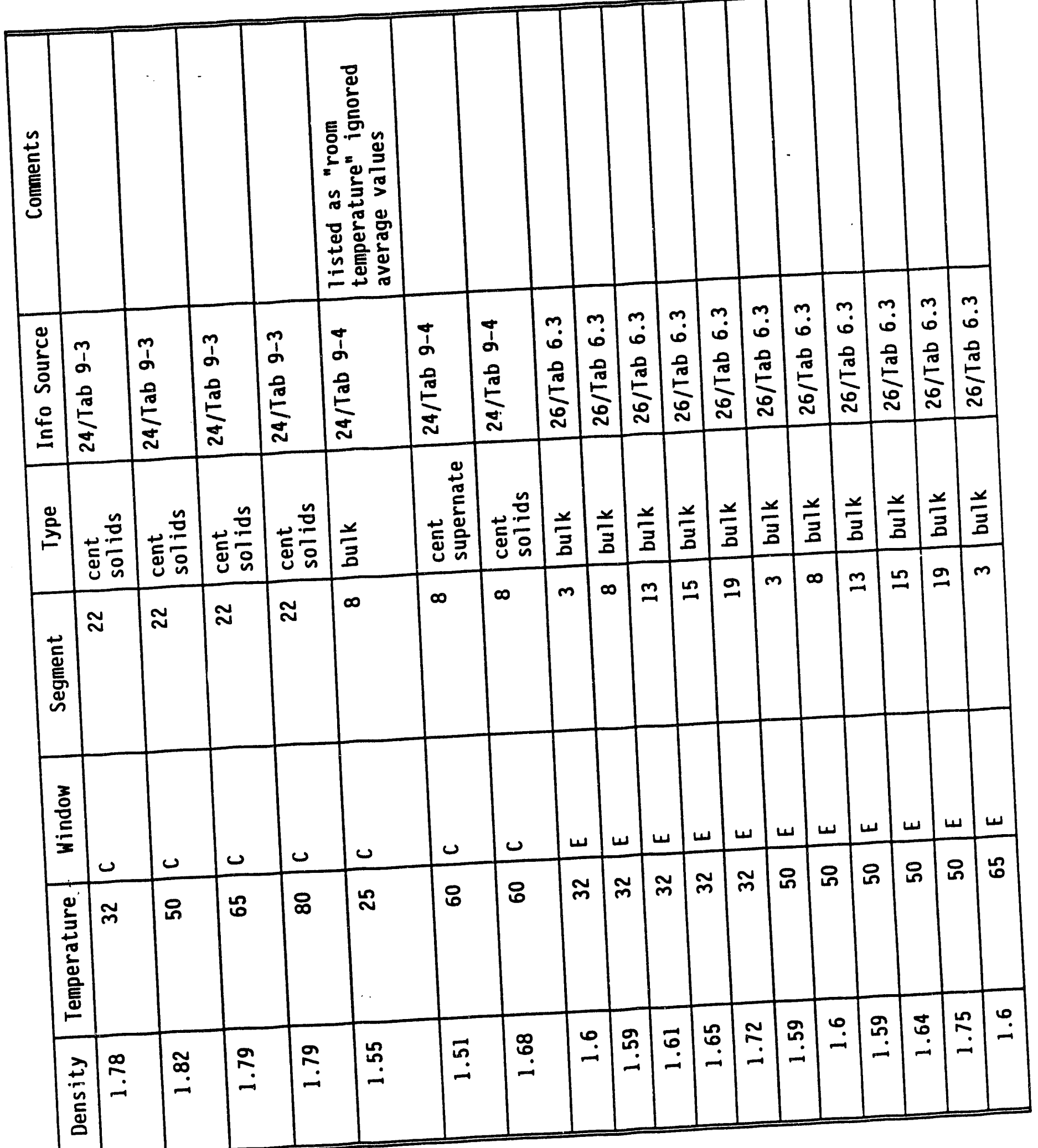




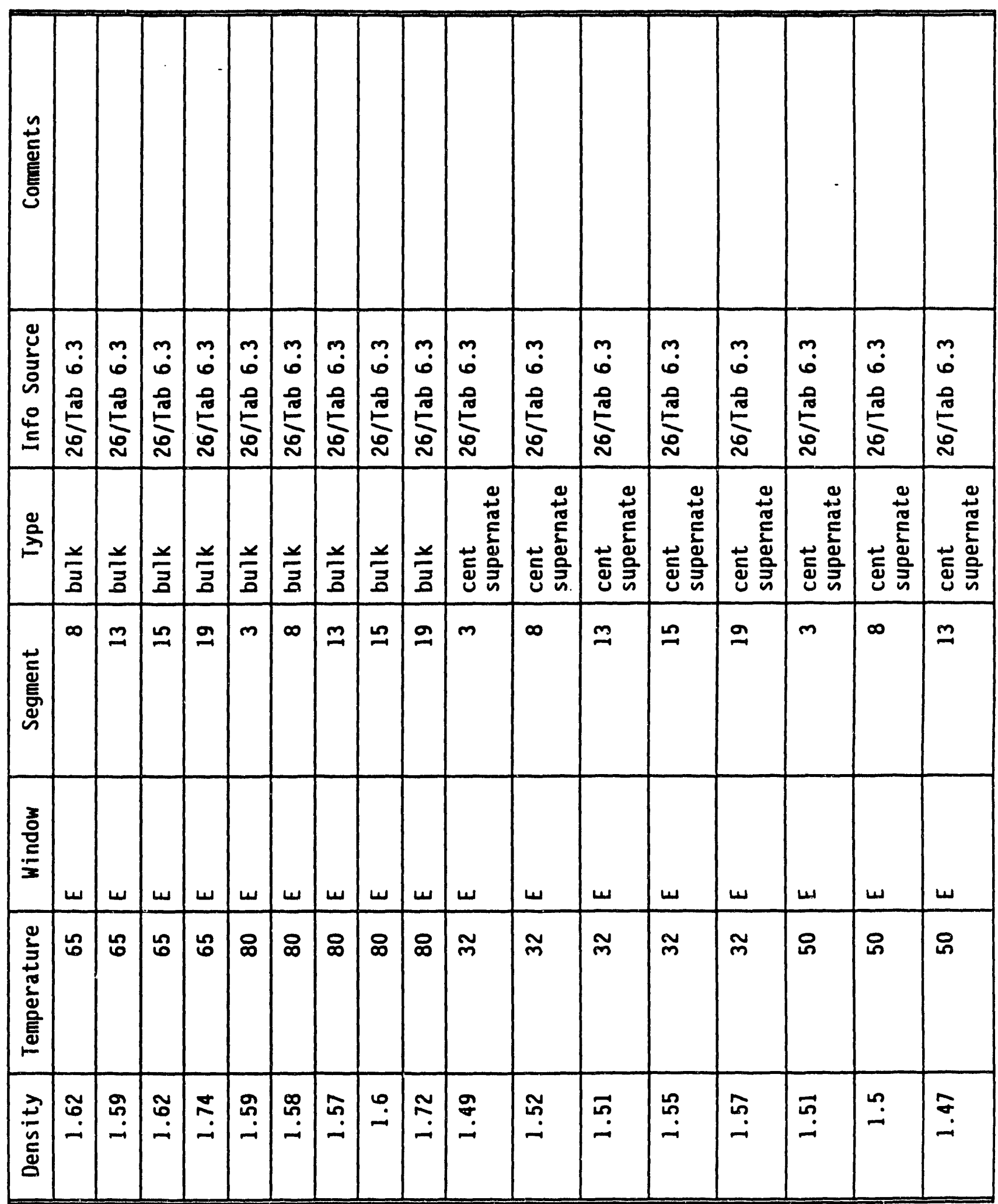




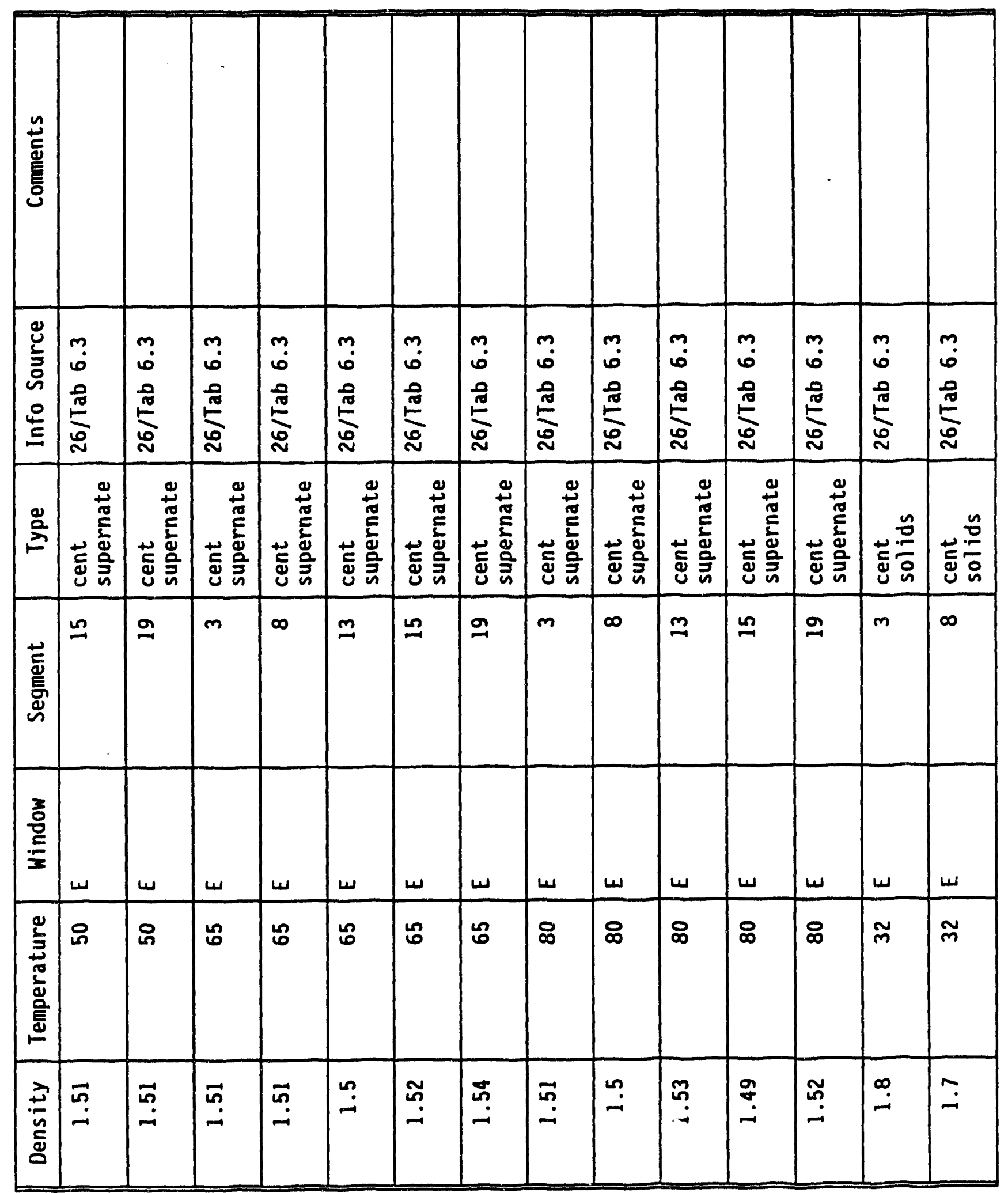




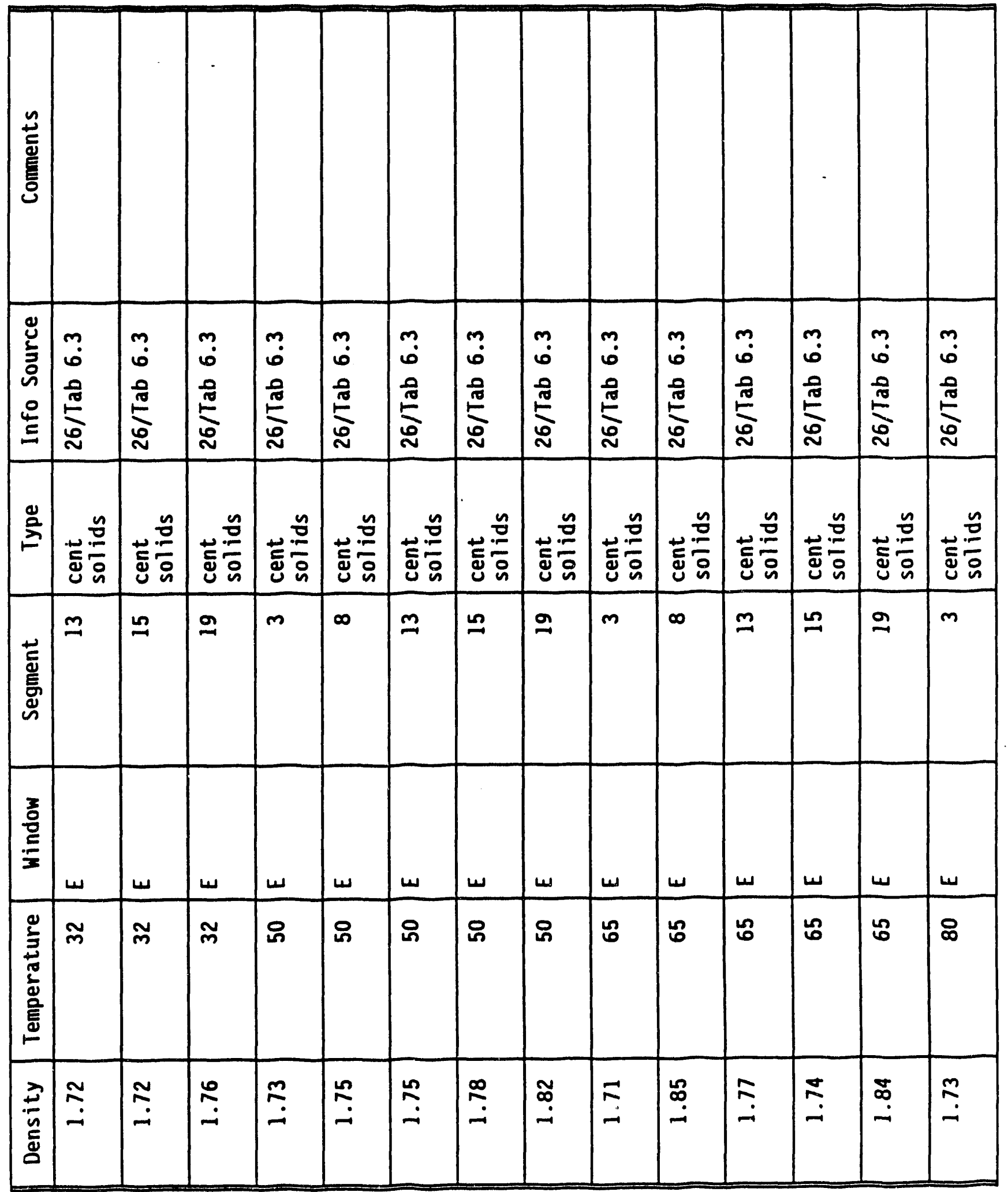




\begin{tabular}{|c|c|c|c|c|c|c|c|c|c|c|c|c|c|c|c|c|c|}
\hline 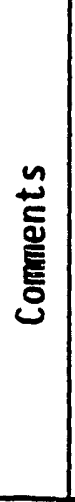 & & & - & & 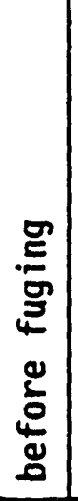 & 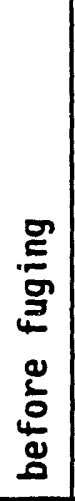 & 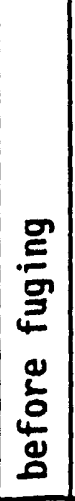 & 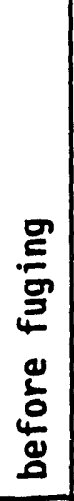 & 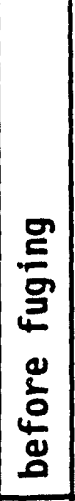 & 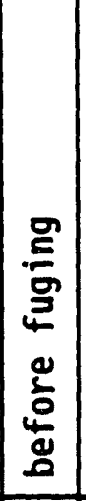 & 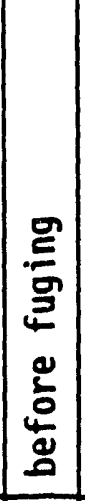 & 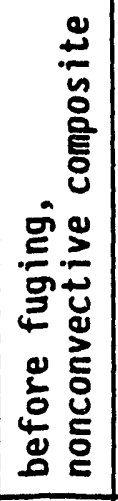 & 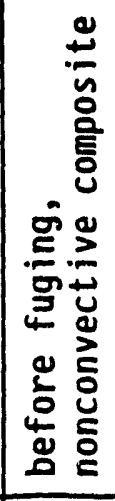 & 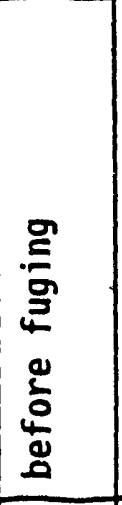 & 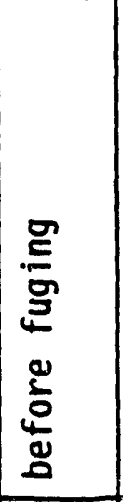 & 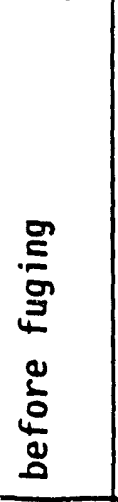 & 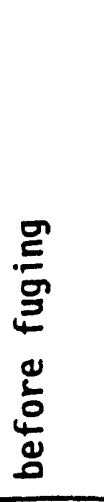 \\
\hline 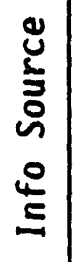 & $\begin{array}{l}m \\
0 \\
0 \\
\tilde{D} \\
\stackrel{D}{N}\end{array}$ & 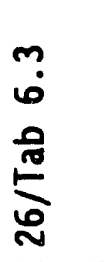 & 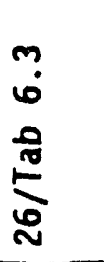 & 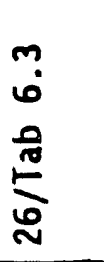 & 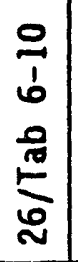 & $\begin{array}{l}0 \\
1 \\
0 \\
0 \\
\tilde{\sigma} \\
\stackrel{0}{\sim}\end{array}$ & $\begin{array}{l}0 \\
1 \\
b \\
0 \\
\tilde{0} \\
\stackrel{0}{\sim}\end{array}$ & $\begin{array}{l}0 \\
1 \\
0 \\
0 \\
\tilde{0} \\
\frac{0}{2}\end{array}$ & $\begin{array}{c}0 \\
1 \\
b \\
0 \\
\tilde{0} \\
\frac{0}{0} \\
\sim\end{array}$ & $\begin{array}{l}0 \\
b \\
b \\
\frac{0}{0} \\
\frac{\tilde{\sigma}}{2}\end{array}$ & 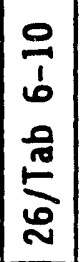 & $\begin{array}{l}0 \\
1 \\
b \\
0 \\
\frac{0}{0} \\
0\end{array}$ & 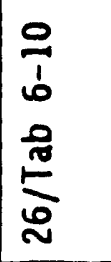 & 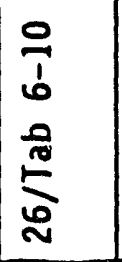 & 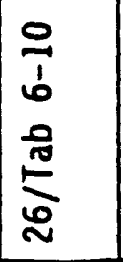 & 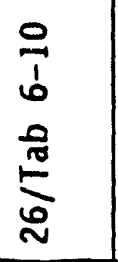 & $\begin{array}{l}0 \\
1 \\
b \\
\frac{0}{0} \\
\stackrel{0}{0}\end{array}$ \\
\hline$\stackrel{ \pm}{2}$ & 送竞 & 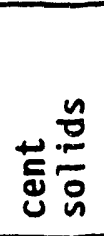 & 䓛兽 & 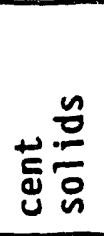 & $\underline{z}$ & $\underline{\underline{z}}$ & $\underline{\Xi}$ & $\frac{y}{z}$ & $\frac{y}{\vec{z}}$ & $\frac{\underline{z}}{\bar{z}}$ & 兰 & 竞 & $\frac{1}{3}$ & 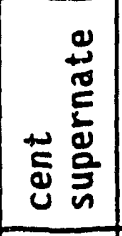 & 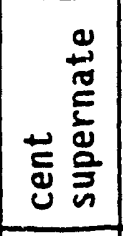 & 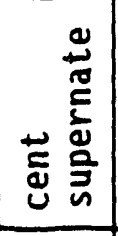 & 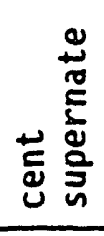 \\
\hline 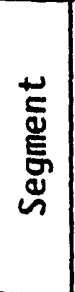 & $\infty$ & $\stackrel{m}{m}$ & 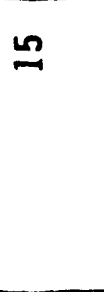 & 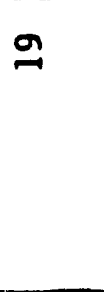 & 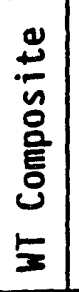 & 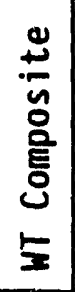 & 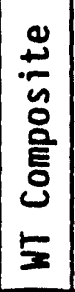 & 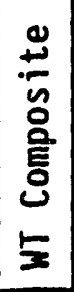 & 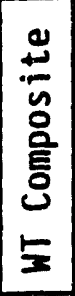 & 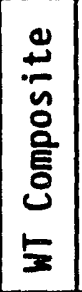 & 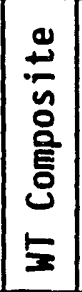 & 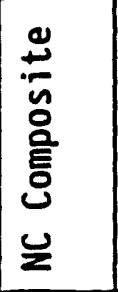 & 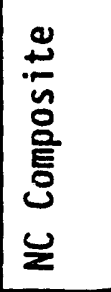 & 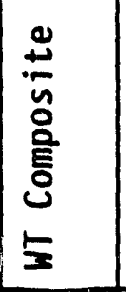 & 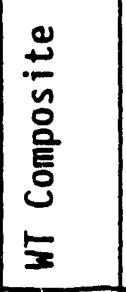 & 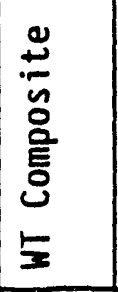 & 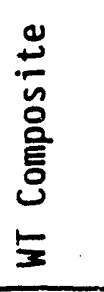 \\
\hline 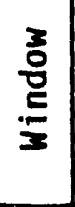 & س & w & $\omega$ & س & س & w & س & w & w & w & س & $\omega$ & س & س & س & س & $\omega$ \\
\hline 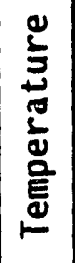 & வ & ర & ద & ర్ర & 용 & 品 & น & வ & . & 용 & ৪ & 오 & ా & 요 & 용 & صี & ం \\
\hline$\frac{2}{ \pm}$ & $\vec{\infty}$ & : & $\stackrel{\text { ֻ }}{\sim}$ & 足 & 告 & in & $\overrightarrow{0}$ & 品 & 品 & $\stackrel{\infty}{\sim}$ & 足 & $\underset{\check{\sigma}}{\tilde{\sigma}}$ & $\overrightarrow{0}$ & in & $\begin{array}{l}\dot{0} \\
\dot{\sim}\end{array}$ & $\stackrel{n}{=}$ & $\stackrel{\infty}{?}$ \\
\hline
\end{tabular}




\begin{tabular}{|c|c|c|c|c|c|c|c|c|c|c|c|c|c|c|c|}
\hline 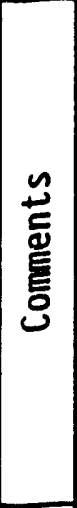 & 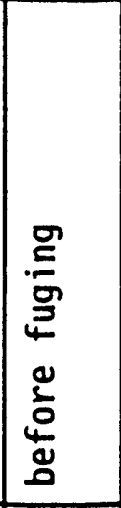 & 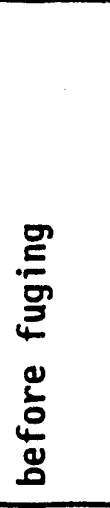 & 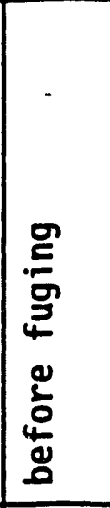 & 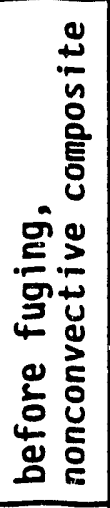 & 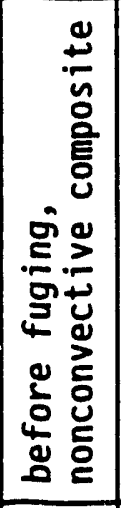 & 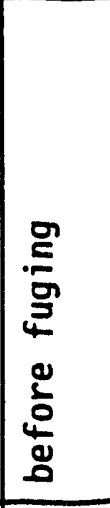 & 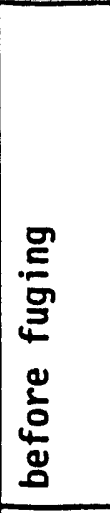 & 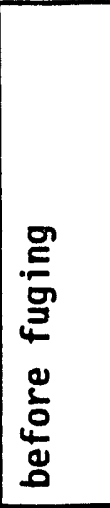 & 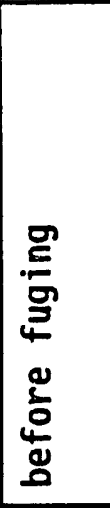 & 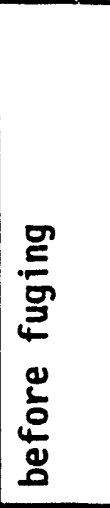 & 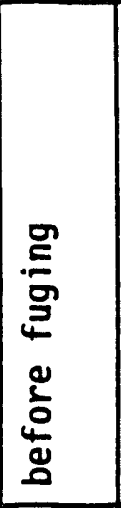 & 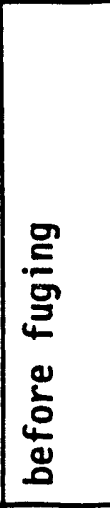 & 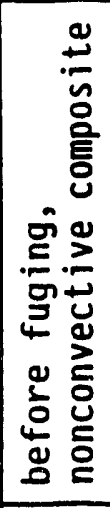 & 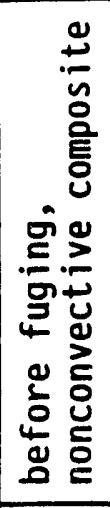 & \\
\hline 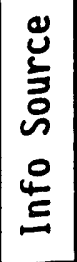 & 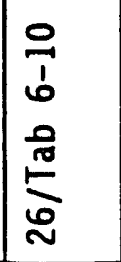 & 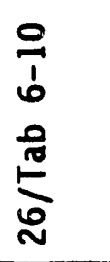 & 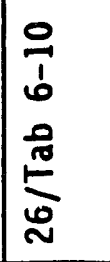 & 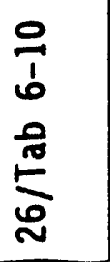 & 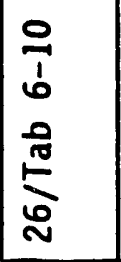 & 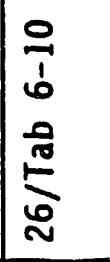 & 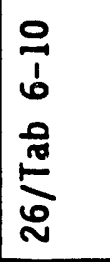 & 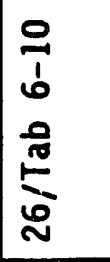 & 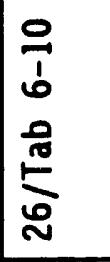 & 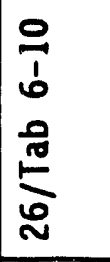 & 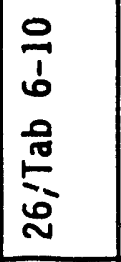 & 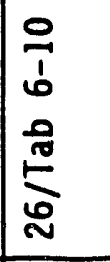 & 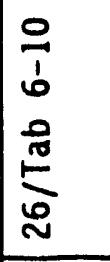 & 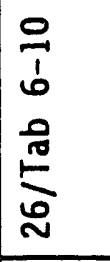 & \\
\hline 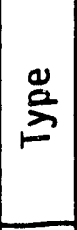 & 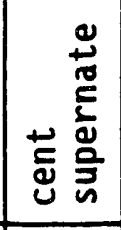 & 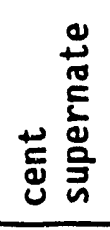 & 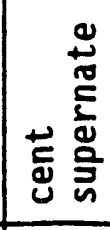 & 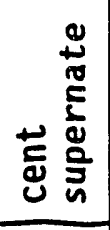 & 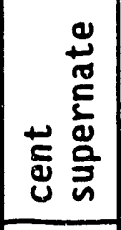 & 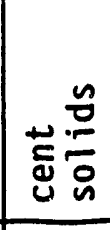 & 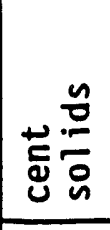 & 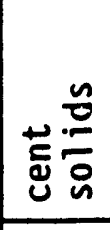 & 递 & 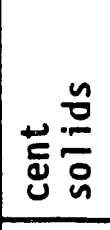 & 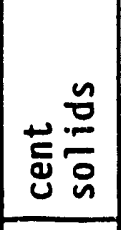 & 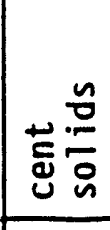 & 造送 & 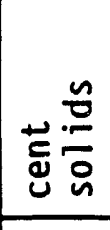 & \\
\hline 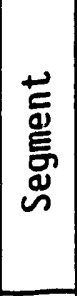 & 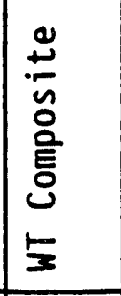 & 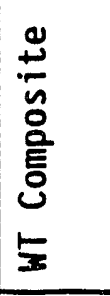 & 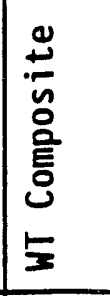 & 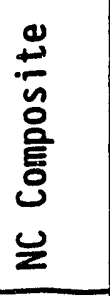 & 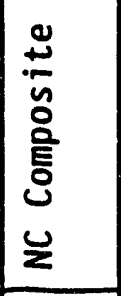 & 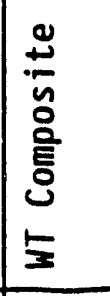 & 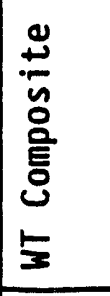 & 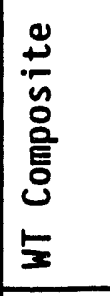 & 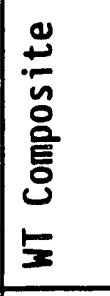 & 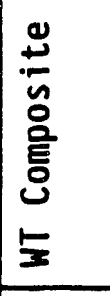 & 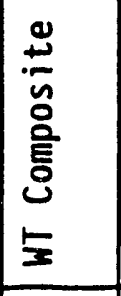 & 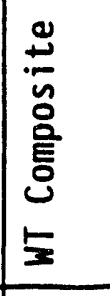 & 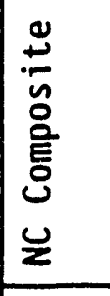 & 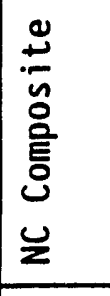 & \\
\hline 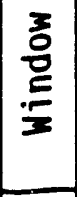 & س & س & w & س & $\omega$ & $\omega$ & w & w & $\omega$ & س & $\omega$ & س & $\omega$ & $\omega$ & \\
\hline 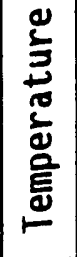 & $\infty$ & in & 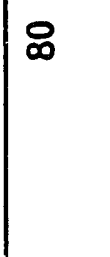 & 8 & 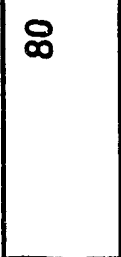 & in & in & : & ळ & 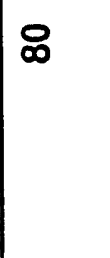 & in & 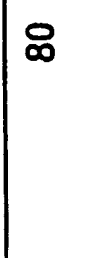 & in & ○ & $\stackrel{\mathscr{N}}{\cong}$ \\
\hline 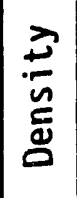 & نجِ & $\stackrel{0}{\sim}$ & 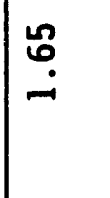 & & $\stackrel{2}{2}$ & $\stackrel{\infty}{-}$ & & $\stackrel{\text { So }}{\longrightarrow}$ & . & & $\stackrel{2}{2}$ & $\cong$ & 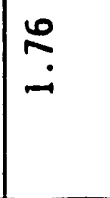 & $\stackrel{\sim}{\stackrel{I}{ت}}$ & 告 \\
\hline
\end{tabular}




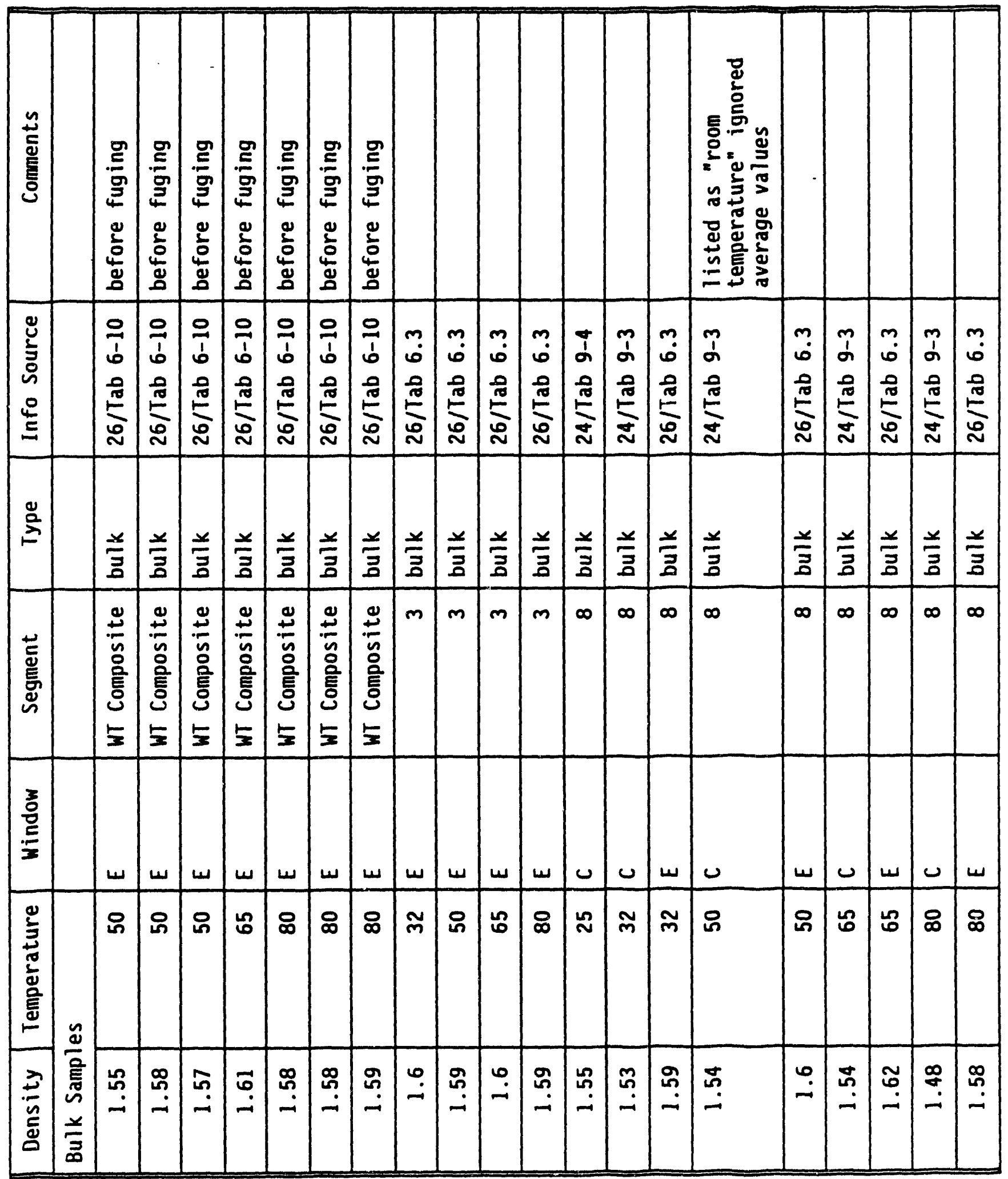




\begin{tabular}{|c|c|c|c|c|c|c|c|c|c|c|c|c|c|c|c|c|c|c|c|c|c|}
\hline 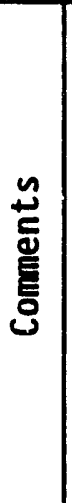 & & & & - & & & & & & & & & & & & & & & & & 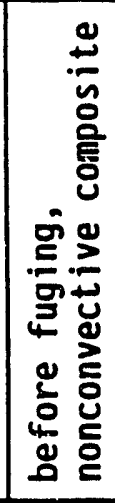 \\
\hline 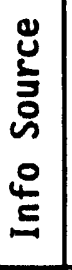 & $\begin{array}{l}m \\
0 \\
\frac{0}{0} \\
\stackrel{0}{0}\end{array}$ & $\begin{array}{l}m \\
0 \\
\stackrel{0}{0} \\
\stackrel{\sim}{\sim} \\
\stackrel{\sim}{N}\end{array}$ & $\begin{array}{l}m \\
0 \\
0 \\
\tilde{0} \\
\tilde{\sigma} \\
\sim\end{array}$ & 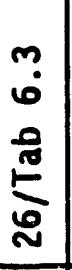 & $\begin{array}{l}m \\
0 \\
\stackrel{0}{0} \\
\stackrel{0}{0}\end{array}$ & $\begin{array}{l}m \\
0 \\
0 \\
\stackrel{0}{0} \\
\stackrel{0}{N}\end{array}$ & $\begin{array}{l}m \\
0 \\
\tilde{0} \\
\stackrel{0}{0} \\
\stackrel{0}{N}\end{array}$ & $\begin{array}{l}m \\
0 \\
\tilde{n} \\
\stackrel{0}{0} \\
\stackrel{0}{N}\end{array}$ & 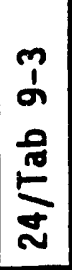 & $\begin{array}{l}m \\
0 \\
\tilde{0} \\
\stackrel{0}{0}\end{array}$ & 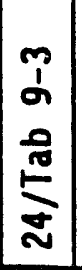 & $\begin{array}{l}m \\
0 \\
\tilde{0} \\
\stackrel{0}{\sigma} \\
\stackrel{0}{\sim}\end{array}$ & 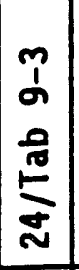 & $\begin{array}{l}m \\
0 \\
0 \\
\tilde{0} \\
\dot{0}\end{array}$ & 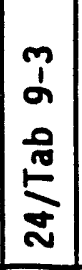 & $\begin{array}{l}m \\
0 \\
\stackrel{0}{0} \\
\frac{0}{0}\end{array}$ & $\begin{array}{l}m \\
1 \\
\sigma \\
0 \\
\tilde{0} \\
\stackrel{\sim}{\sim} \\
\tilde{N}\end{array}$ & $\begin{array}{c}m \\
1 \\
o \\
0 \\
\tilde{N} \\
\stackrel{\sim}{N}\end{array}$ & 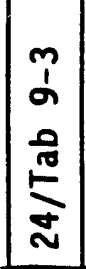 & 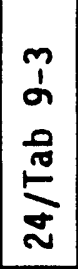 & $\begin{array}{l}0 \\
\frac{1}{b} \\
\stackrel{0}{0} \\
\frac{0}{0}\end{array}$ \\
\hline 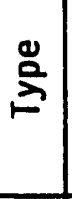 & 昙 & 兰 & $\underline{\bar{z}}$ & 竞 & 哥 & 兰 & 兰 & 兰 & $\underline{\Xi}$ & 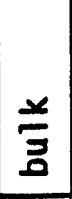 & 弮 & 兰 & 兰 & 兰 & 豆 & 兰 & 兰 & $\underset{\vec{z}}{\underline{\Xi}}$ & 兰 & $\frac{\underline{z}}{\vec{z}}$ & 兰 \\
\hline 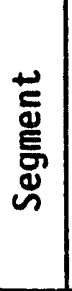 & $\stackrel{m}{=}$ & $m$ & $m$ & $\underline{m}$ & $\cong$ & $\stackrel{20}{2}$ & n & $\stackrel{n}{=}$ & $\stackrel{a}{\longrightarrow}$ & $\sigma$ & $\stackrel{a}{\longrightarrow}$ & $a$ & g & $\Omega$ & a & $\sigma$ & $\approx$ & $\approx$ & $\approx$ & $\approx$ & 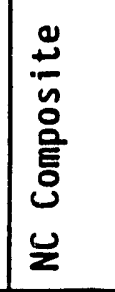 \\
\hline 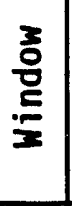 & س & س & w & س & س & س & س & س & v & س & u & س & u & س & ט & س & u & ט & ט & ט & $\omega$ \\
\hline 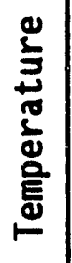 & $\tilde{m}$ & 욧 & 告 & థి & $\tilde{m}$ & 요 & ก & ర్ & $\tilde{m}$ & $\tilde{m}$ & 웃 & 요 & 告 & 15 & థ & థ & $\tilde{m}$ & in & \& & வ & 요 \\
\hline 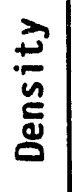 & $\overrightarrow{0}$ & 号 & مُ & $\tilde{n}$ & : & 苛 & $\tilde{\tilde{o}}$ & $\stackrel{\bullet}{-}$ & 占 & $\stackrel{\sim}{\sim}$ & $\mid$\begin{tabular}{l}
$\mathscr{8}$ \\
\hdashline \\
-
\end{tabular} & $\stackrel{n}{\sim}$ & 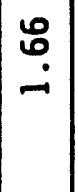 & $\underset{\sim}{\sim}$ & $\stackrel{\sim}{\sim}$ & $\underset{\sim}{\sim}$ & 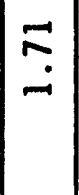 & $\vec{\sim}$ & $\vec{\sim}$ & $\check{\sim}$ & $\stackrel{\tilde{\sigma}}{\dot{\sim}}$ \\
\hline
\end{tabular}




\begin{tabular}{|c|c|c|c|c|c|c|c|c|c|c|c|c|c|c|c|}
\hline 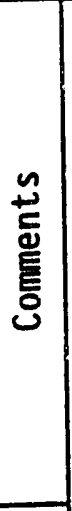 & 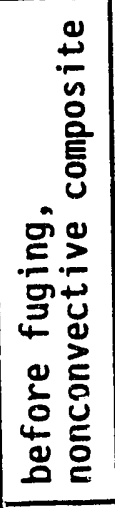 & & 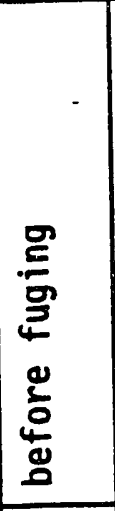 & 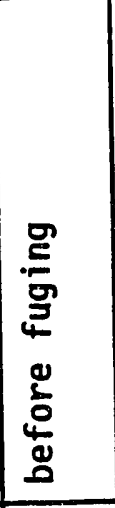 & 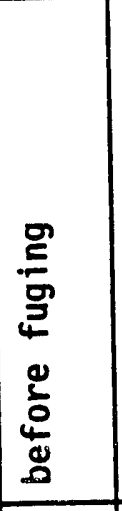 & 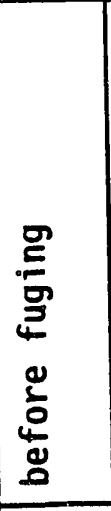 & 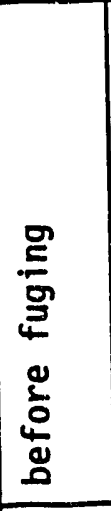 & 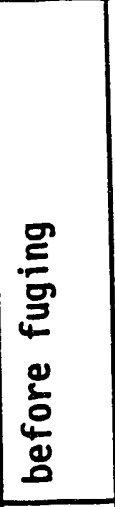 & 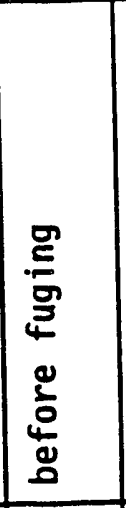 & 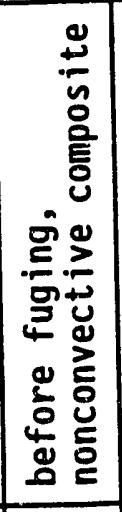 & 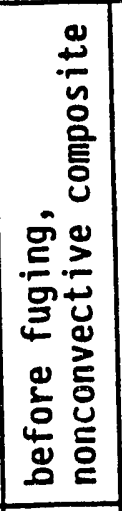 & & & & \\
\hline 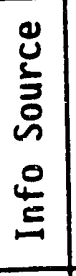 & $\begin{array}{l}0 \\
1 \\
b \\
0 \\
\tilde{0} \\
0 \\
0\end{array}$ & & $\begin{array}{l}0 \\
\dot{b} \\
0 \\
\stackrel{0}{\sigma} \\
\stackrel{0}{\sim}\end{array}$ & $\begin{array}{l}0 \\
\dot{1} \\
0 \\
0 \\
\stackrel{0}{0} \\
\stackrel{0}{\sim}\end{array}$ & $\begin{array}{l}0 \\
b \\
0 \\
0 \\
\stackrel{0}{0} \\
\stackrel{0}{\sim}\end{array}$ & $\begin{array}{l}0 \\
b \\
0 \\
0 \\
\stackrel{0}{0} \\
\stackrel{0}{N}\end{array}$ & $\begin{array}{l}0 \\
1 \\
0 \\
0 \\
\stackrel{0}{0} \\
0 \\
\sim\end{array}$ & 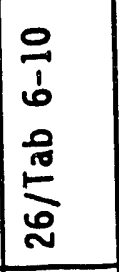 & $\begin{array}{l}0 \\
1 \\
b \\
0 \\
\stackrel{0}{0} \\
\stackrel{0}{\sim}\end{array}$ & 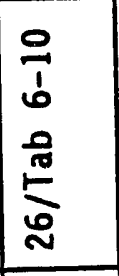 & $\begin{array}{l}0 \\
1 \\
b \\
0 \\
\stackrel{0}{0} \\
\stackrel{0}{N}\end{array}$ & $\begin{array}{l}m \\
0 \\
0 \\
\frac{0}{0} \\
\stackrel{0}{N}\end{array}$ & $\begin{array}{l}m \\
0 \\
0 \\
\stackrel{0}{0} \\
\stackrel{0}{\sim}\end{array}$ & $\begin{array}{l}m \\
0 \\
\tilde{0} \\
\stackrel{0}{0} \\
\sim\end{array}$ & $\begin{array}{l}m \\
0 \\
0 \\
\stackrel{0}{0} \\
\stackrel{0}{\sim}\end{array}$ \\
\hline$\stackrel{\Xi}{2}$ & $\frac{x}{\bar{z}}$ & & 뜸 & 뜽 & 농 & 풍 & 뜸 & 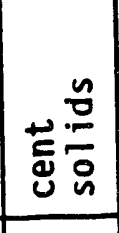 & 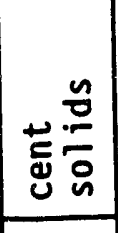 & 풍 & 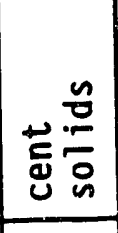 & 홍 & 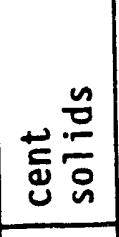 & 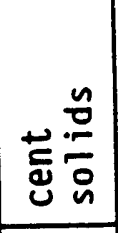 & 我点 \\
\hline 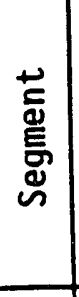 & 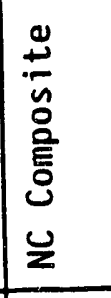 & & 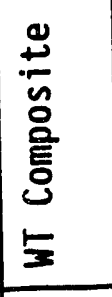 & 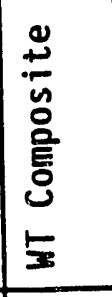 & 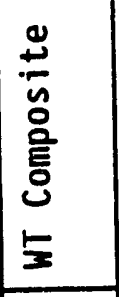 & 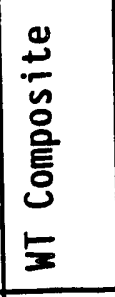 & 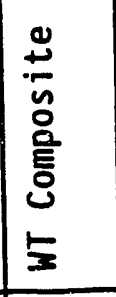 & 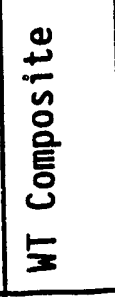 & 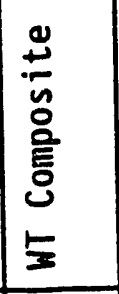 & 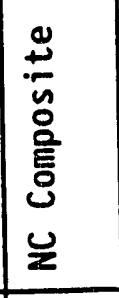 & 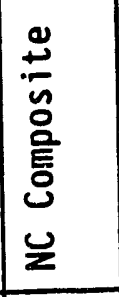 & $m$ & $m$ & $m$ & $m$ \\
\hline 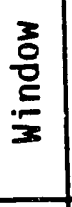 & $\omega$ & & س & $\omega$ & $\omega$ & س & $\omega$ & $\omega$ & س & $\omega$ & س & س & $\omega$ & w & س \\
\hline 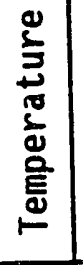 & வ & $\frac{n}{0}$ & 용 & 용 & 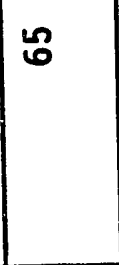 & \& & ర్ల & 옹 & \& & 용 & ৪ & $\vec{s}$ & $\tilde{m}$ & రి & ถึ \\
\hline 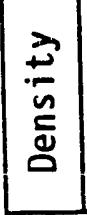 & $\overrightarrow{0}$ & 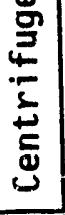 & $\stackrel{\infty}{\sim}$ & $\stackrel{\sigma}{\dot{\sigma}}$ & นٌ & 官 & $\underline{0}$ & นึ & 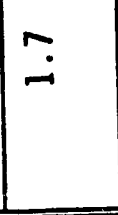 & $\stackrel{\mathscr{r}}{\stackrel{\sim}{\sim}}$ & $\stackrel{\sim}{\sim}$ & $\stackrel{m}{\sim}$ & $\stackrel{\infty}{\sim}$ & $\stackrel{n}{\sim}$ & $\ddot{\sim}$ \\
\hline
\end{tabular}




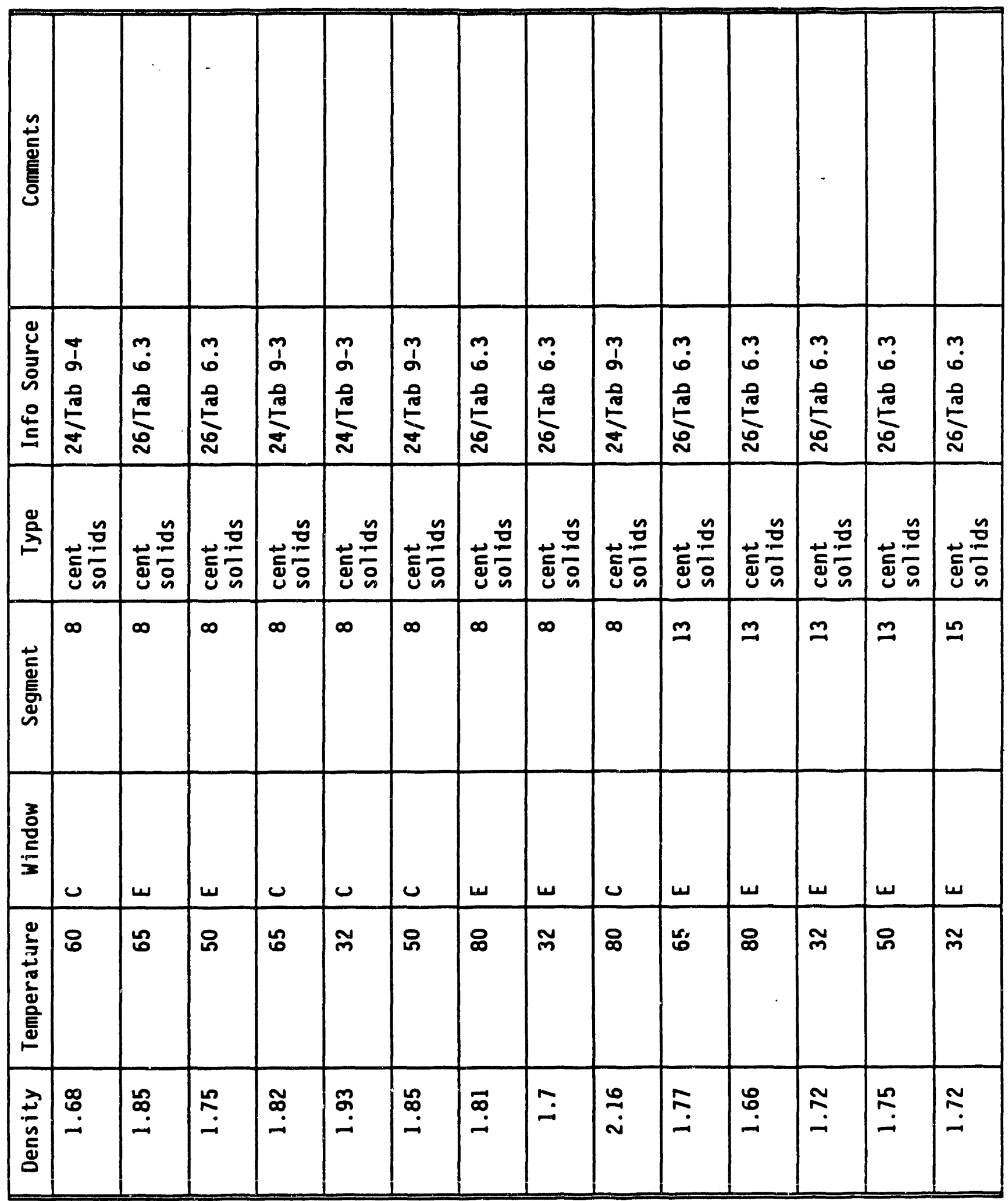




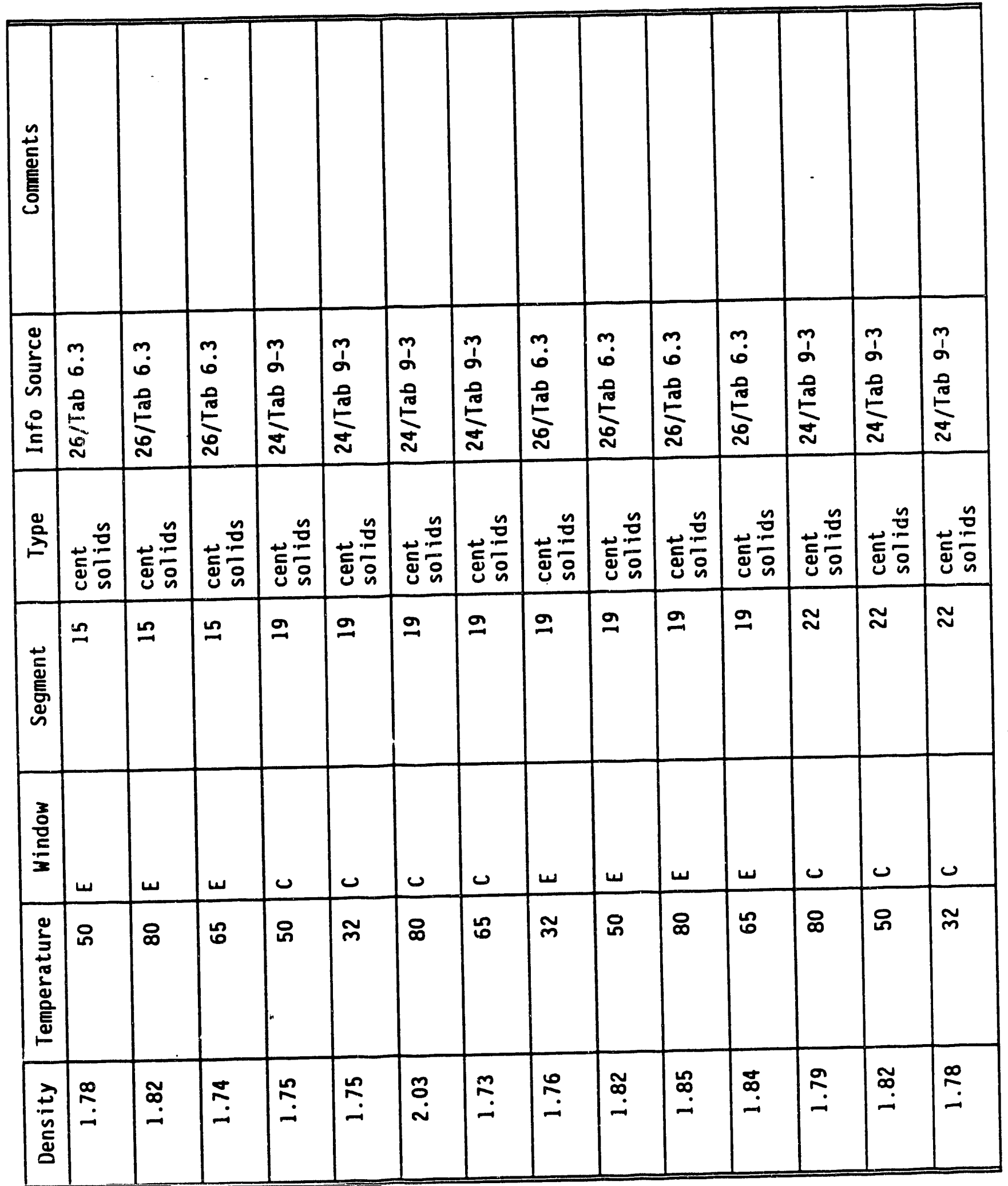




\begin{tabular}{|c|c|c|c|c|c|c|c|c|c|c|c|c|c|c|}
\hline 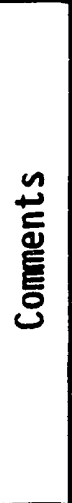 & & & & & & 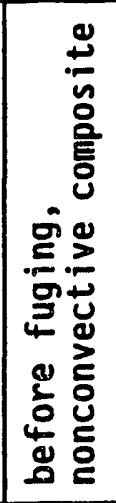 & 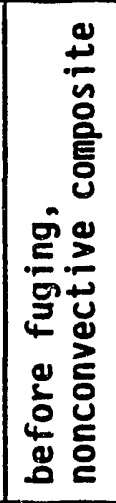 & 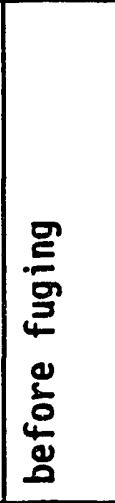 & 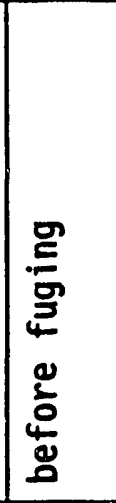 & 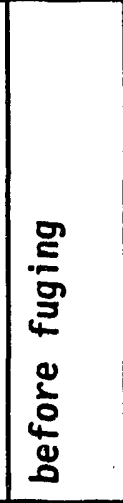 & 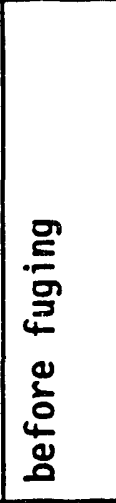 & 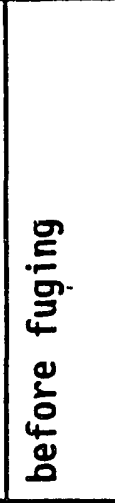 & 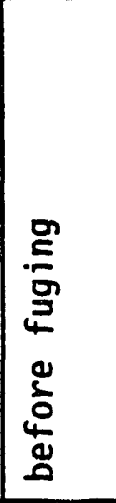 & 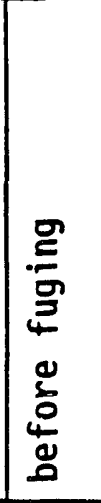 \\
\hline 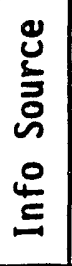 & 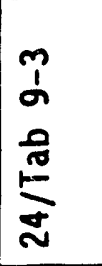 & & & & & $\begin{array}{l}0 \\
1 \\
b \\
0 \\
0 \\
\frac{0}{0} \\
\stackrel{0}{N}\end{array}$ & $\begin{array}{l}0 \\
1 \\
b \\
0 \\
0 \\
\frac{0}{0} \\
0\end{array}$ & $\begin{array}{l}0 \\
1 \\
b \\
0 \\
0 \\
\frac{0}{0}\end{array}$ & 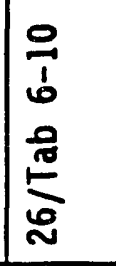 & 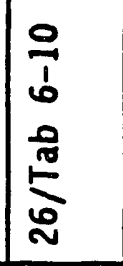 & $\begin{array}{l}0 \\
1 \\
b \\
0 \\
0 \\
0 \\
0 \\
\stackrel{0}{\sim}\end{array}$ & $\begin{array}{l}0 \\
1 \\
b \\
0 \\
0 \\
0 \\
0 \\
0\end{array}$ & 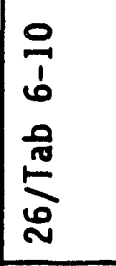 & $\begin{array}{l}0 \\
\vdots \\
b \\
0 \\
0 \\
\\
0 \\
\end{array}$ \\
\hline$\stackrel{\Delta}{\stackrel{2}{2}}$ & 递官 & & & & & 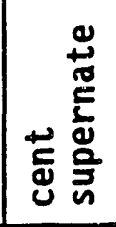 & 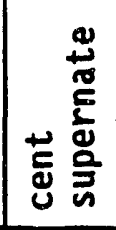 & 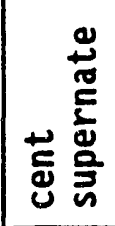 & 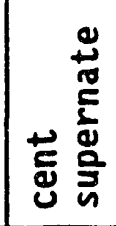 & 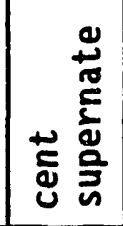 & 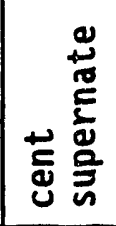 & 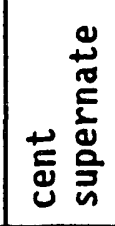 & 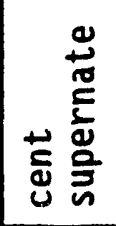 & | \\
\hline 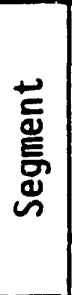 & $\approx$ & & & 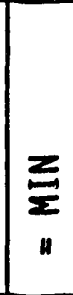 & & 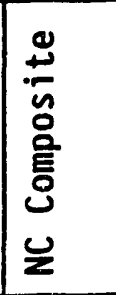 & 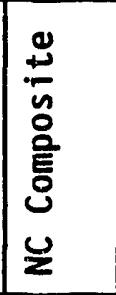 & 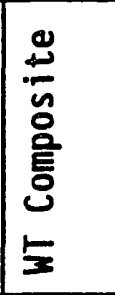 & 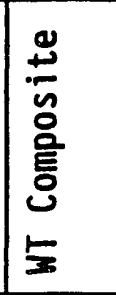 & 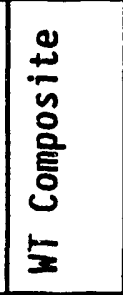 & 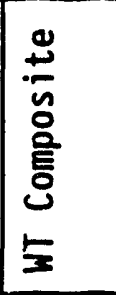 & 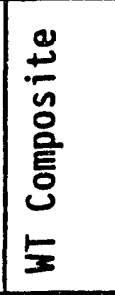 & 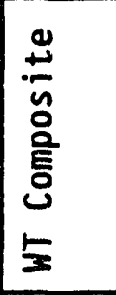 & 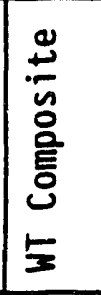 \\
\hline 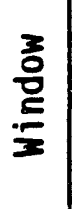 & ט & & & 追 & \multirow{3}{*}{ 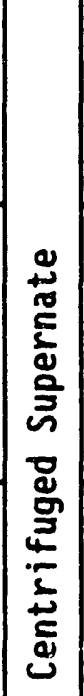 } & س & س & س & س | & س & س & س & س & س \\
\hline 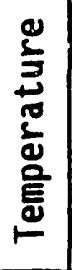 & מ & 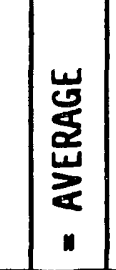 & $\begin{array}{l}\text { 㟧 } \\
\text { o } \\
\text { s } \\
\text { " }\end{array}$ & 䓂 & & in & 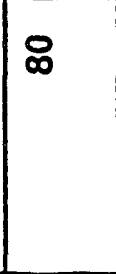 & \& & 요 & 요 & 옹 & | & வ & ৪ \\
\hline $\begin{array}{l}\frac{a}{ \pm} \\
\frac{n}{\Delta} \\
0\end{array}$ & $\stackrel{9}{\sim}$ & $\stackrel{g}{\stackrel{9}{\sim}}$ & $\frac{8}{0}$ & $\underset{\sim}{\sim}$ & & $\stackrel{0}{\sigma}$ & $\stackrel{0}{\mathscr{N}}$ & $\stackrel{\text { : }}{\sim}$ & 证 & $\begin{array}{l}\dot{0} \\
\dot{-}\end{array}$ & 年 & 馆 & 足 & 号 \\
\hline
\end{tabular}




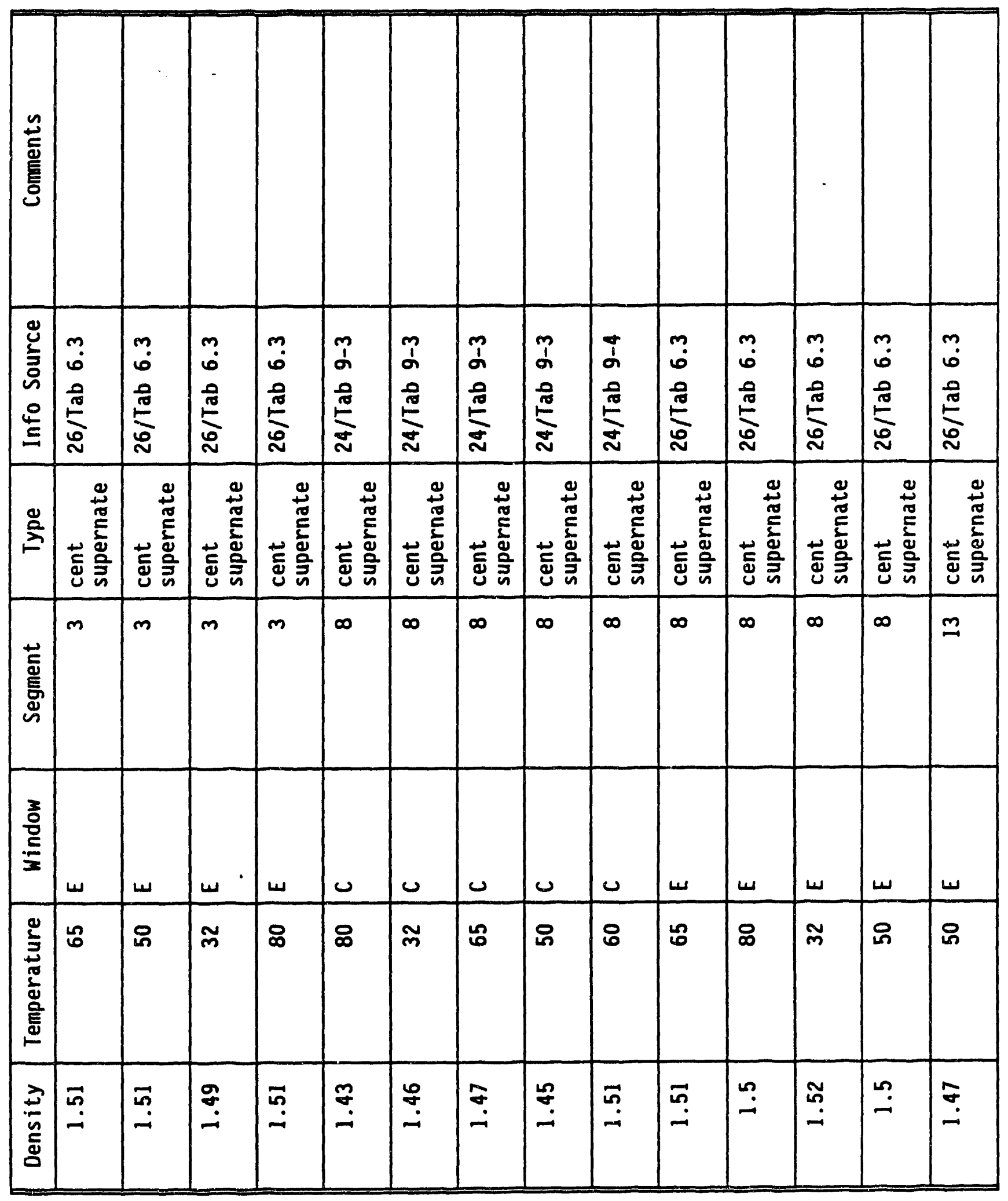




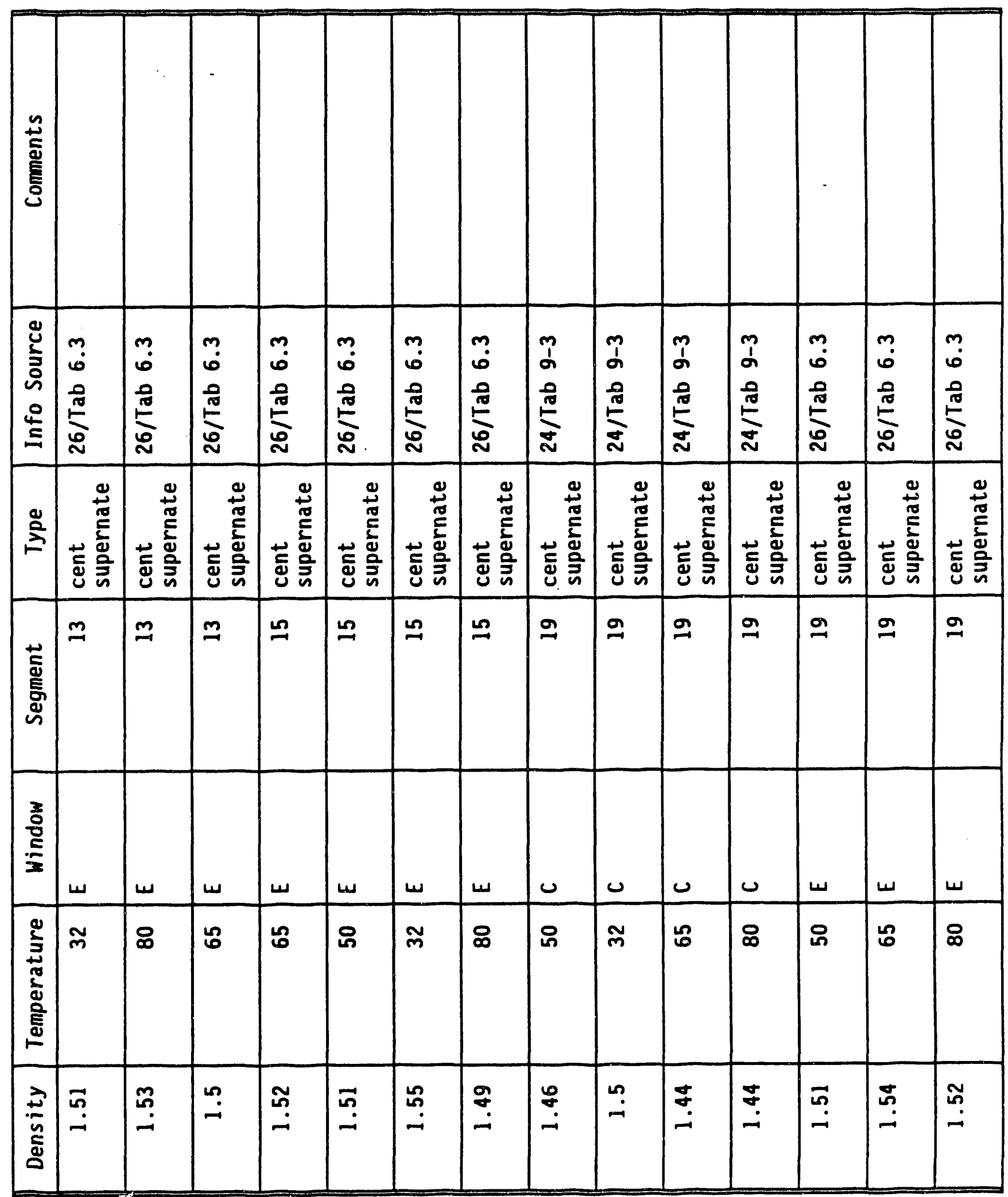




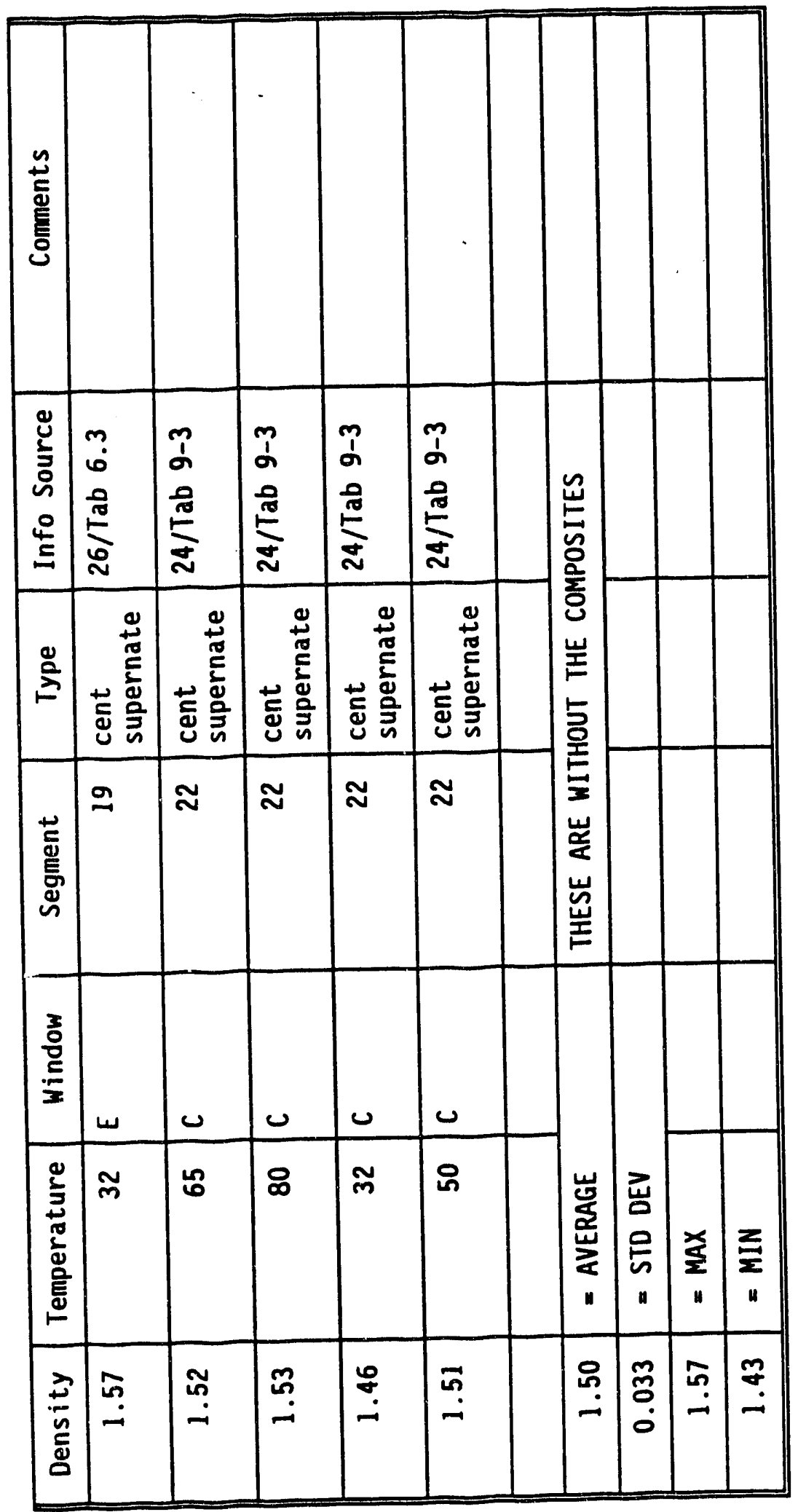


WHC-EP-0628

\section{DISTRIBUTION}

Number of Copies

ONSITE

6

U.S. Department of Energy. Richland Field office

S. 0. Branch

A4-02

R. F. Christensen

A4-02

R. E. Gerton

A4-02

J. M. Gray

G. W. Rosenwald

Public Reading Room

A4-02

A4-02

Al-65

7

\section{Pacific Northwest Laboratory}

K7-15

R. T. Allemann

S. A. Bryan

M. R. Kreiter

L. R. Pederson

D. M. Strachan

J. M. Tingey

Technical Files

P7-25

K7-90

K2-44

$\mathrm{K} 2-38$

P7-25

K1-11

51

Westinghouse Hanford Company
H. Babad
D. B. Bechtold
P. K. Bhatia
W. F. Brehm
T. M. Burke
R. J. Cash
W. L. Cowley
B. A. Crawford
D. G. Hamrick
D. L. Herting (2)
M. N. Islam
J. R. Jewett
G. D. Johnson
J. Jo
N. W. Kirch
C. A. Kuhlman
J. A. Lechelt
J. W. Lentsch
R. M. Marusich
A. F. Noonan
J. G. Propson
R. W. Reed
D. A. Reynolds (10)
L. M. Sasaki
M. H. Shannon

R2-31

T6-50

S4-58

H5-67

$\mathrm{HO}-34$

R2-31

H5-31

T6-50

R1-51

T6-50

R3-08

T6-50

R2-78

R2-11

R2-11

B3 -30

R2-11

R2-78

H5-32

R2-12

R2-18

R1-51

R2-11

R2-12

H5-30 
WHC-EP-0628

DISTRIBUTION (continued)

Westinghouse Hanford Company. (cont inued)

L. A. Tusler

R. E. VanderCook

R2-11

R. K. Welty

N. E. Wilkins

S6-07

$\mathrm{R} 1-80$

G. Wilson

R2-11

D. D. Wodrich

B3-68

Central Files (2)

$\mathrm{Bl}-59$

Document Clearanc

L8-04

TFIC

(3)

R1-08

RI-20 

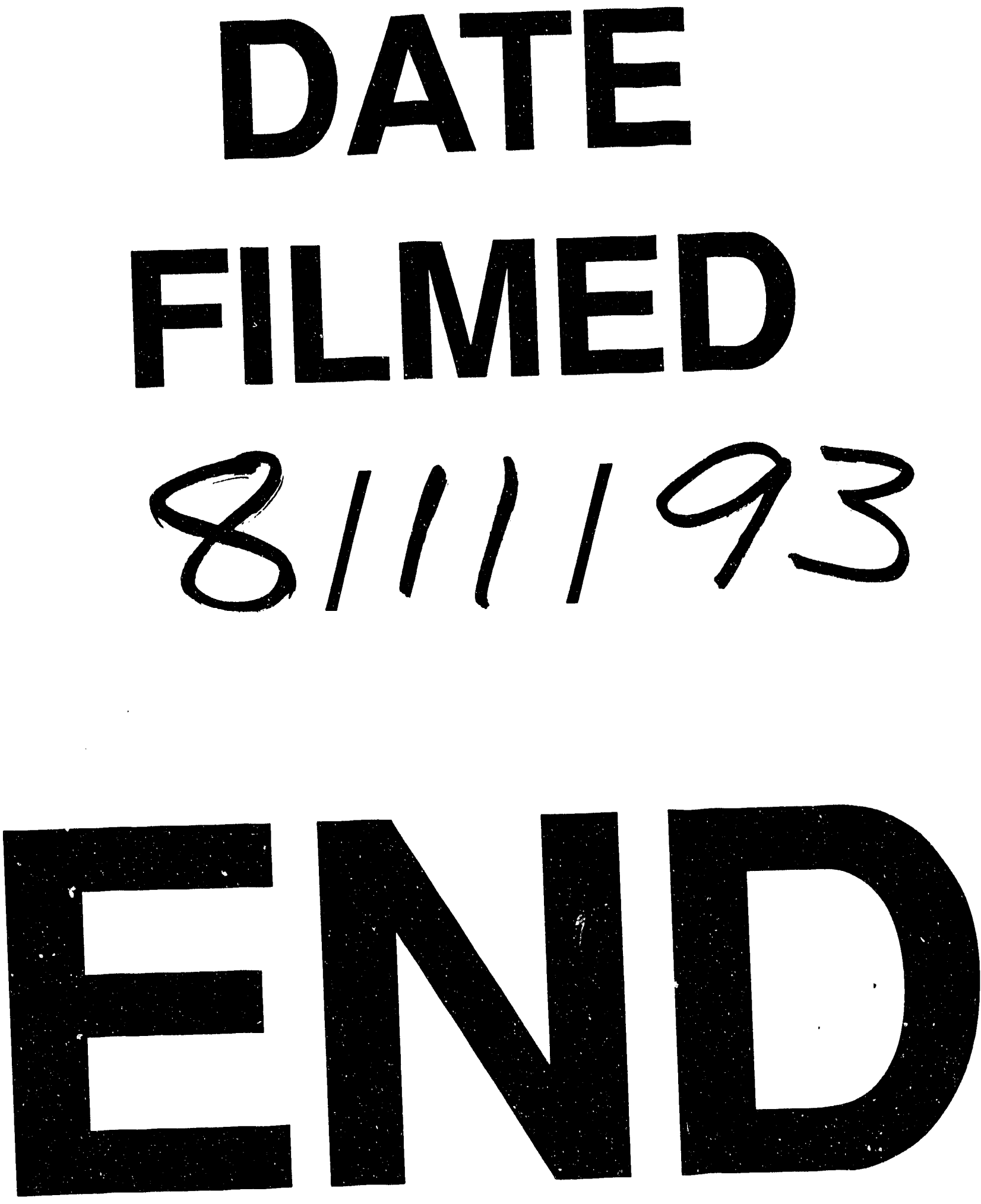
